\title{
3. Die erinnerte Zeit: Ivry und die Résistance
}

\author{
3.1. Lokale Milieubildung \\ als Prämisse für den kommunistischen Widerstand
}

Obwohl die Arbeiterschaft in der Pariser banlieue schon vorher zu den sozialistischen Parteien mit durchaus sozialrevolutionärem Impetus tendierte, bedurfte es der Erfahrung des Ersten Weltkrieges und der politisch-moralischen Krise der SFIO in der Nachkriegszeit, um in Frankreich eine kommunistische Partei entstehen zu lassen. Wie in anderen kriegsteilnehmenden Staaten auch, hatten die extremen wirtschaftlichen Bedingungen zu einer Akzelerierung des Modernisierungsprozesses geführt, von dessen krisenhaften Auswirkungen die Pariser Vorstädte besonders betroffen waren. Die Kriegswirtschaft machte nicht nur große Anstrengungen vor allem in der Metall verarbeitenden Industrie notwendig, auch die Abwesenheit der vielen arbeitsfähigen jungen Männer führte zu einer Veränderung der bisher gekannten Arbeitsordnung der Vorkriegsjahre. Dies rief nicht nur einen teilweise existenzbedrohenden Arbeitskräftemangel auf dem Land hervor, vielmehr waren gerade auch die Fabriken in der banlieue betroffen, die als eine der am stärksten industrialisierten Regionen Frankreichs einen massiven Ausstoß an kriegsrelevanten Gütern gewährleisten musste. Dieser Umstand war umso eklatanter, als die großen Industriegebiete im Norden und Nordosten Frankreichs gleich zu Beginn des Krieges deutsch besetzt worden waren, so dass sich die kriegswirtschaftlichen Anstrengungen auf die Pariser Region konzentrierten. Zwar passten sich auch einige Fabriken im Pariser Süden wie Citroën und Panhard an die besonderen Bedingungen der Kriegswirtschaft an, 80 Prozent aller kriegswichtigen Produktion fand aber in den Vororten statt ${ }^{1}$. Die Zahl der Arbeiter war beeindruckend und zeugte von der mittlerweile immensen GröBe der Betriebe: Renault in Boulogne beschäftigte 22000 Arbeiter, DelaunayBelleville in Saint-Denis 12000, die Arsenale von Puteaux 6000, die Patronenfabrik von Vincennes $5000^{2}$. Mit 5000 Arbeitern bei den CGE reihte sich Ivry in den Reigen der Vorstadt-Kriegsmaschinerie ein, ohne allerdings die ganz großen Fabriken in der Stadt zu haben. Der Industrieanteil am Wirtschaftsleben der Gemeinde blieb dennoch beträchtlich.

Angesichts der massiven Präsenz der Arbeiterschaft in den Vororten, ihrer Randstellung in der politischen Repräsentanz der Dritten Republik und ihrer sozialen und kulturellen Exklusion durch das Bürgertum verwundert die Ten-

1 Jean-Louis Robert, Rouge sang. La Grande Guerre, in: Fourcaut, Banlieue rouge, S. 146-159, hier S. 151.

2 Ibid. 
denz der banlieue zu sozialistischen Parteien nicht. Vielmehr ist erstaunlich, dass sich der PCF als führende Arbeiterpartei in den Pariser Vororten langfristig gegenüber der SFIO durchsetzen und das politisch-kulturelle Klima in einigen Kommunen maßgeblich prägen konnte.

In Ivry stellte sich der PCF 1922 zum ersten Mal bei einer Nachwahl zum Stadtrat im Hafenviertel zur Wahl, erreichte auf Anhieb 29 Prozent der abgegebenen Stimmen und konnte sechs gewählte Vertreter in den Stadtrat entsenden $^{3}$. Der lokalpolitische Durchbruch erfolgte drei Jahre später, als der PCF mit 32,3 Prozent der abgegebenen Stimmen die Mehrheit im Rathaus errang, während die Rechte 32 Prozent und die SFIO 15,3 Prozent der abgegebenen Stimmen erhielt. Bemerkenswert ist, dass es dem PCF als neuer Partei ohne große Propagandakampagne gelungen war, ein Drittel der Stimmen auf sich zu ziehen. Der Wahlerfolg war in der Tat auf die große Anzahl von Industriearbeitern in Ivry zurückzuführen, die schon in dieser Frühphase ihre Stimme dem PCF gaben. Anhand der Wahllisten lässt sich deren Konzentration in den Stadtteilen Petit-Ivry und in Ivry-Port tatsächlich in Korrelation zum Wahlsieg des PCF setzen. Außerdem verfügte Ivry mit seiner guesdistischen Tradition über ein sozialrevolutionäres Wählerpotential, das sich von dem Revolutionsversprechen der neuen Partei angezogen fühlte. Die Industriearbeiterschaft als Trägerschicht einer revolutionären Arbeiterpartei blieb die entscheidende sozioökonomische Gruppe. Denn nach Kriegsende verfügte Ivry noch über hundert Fabriken, darunter rund dreißig mit über hundert respektive vier mit über tausend Industriearbeitsplätzen ${ }^{4}$. Im Unterschied zur Vorkriegszeit wurden nun jedoch keine neuen Unternehmen mehr gegründet und es entstanden keine zusätzlichen Arbeitsplätze. Allenfalls wurden Fabriken von anderen Herstellern übernommen. So entstand etwa 1926 das Entrepôt du Bazar de l'Hôtel de Ville anstelle der Compagnie française du matériel de chemin de fer. Die Compagnie des lampes wurde 1929 vom Elektrokonzern Philips übernommen ${ }^{5}$. Schwerpunkt blieben in Ivry die Metall verarbeitende Industrie und die chemischen Werke, auch wenn die Zeit der industriellen Neugründungen vorbei war. Der Typus des Metallarbeiters war daher in Ivry überproportional präsent. Das wirkte sich favorisierend auf die kommunistische Partei aus, denn er galt als Prototyp des revolutionären Arbeiters, war allerdings im Vergleich zu Deutschland oder Belgien viel seltener in Frankreichs Industrie anzutreffen. Dass in Ivry sozioökonomische Lebenswirklichkeit und ideologische Komponenten aufeinandertrafen, erwies sich als Glücksfall für die kommunistische Partei und begünstigte die Identifikation der Einwohnerschaft mit ihren Ideen. Die industrielle Saturierung Ivrys

${ }^{3}$ Bernard Chambaz, L'implantation du Parti communiste français à Ivry, in: Jacques Girault (Hg.), Sur l'implantation du Parti communiste français dans l'entre-deux-guerres, Paris 1977, S.147-177, hier S. 158.

${ }^{4}$ Ibid., S. 148.

5 Ibid., S.148f. 
hatte auf der anderen Seite zur Folge, dass die Stadt an Attraktivität für Binnenmigranten ständig weiter verlor. Bis 1921 waren noch über 5000 Neubürger zugezogen. Danach wuchs Ivry aus niedrigem Niveau, bevor ab 1931 die Einwohnerzahl bei circa 49000 Bürgern stagnierte.

Damit setzte sich die Tendenz von vor 1914 fort: In Paris nahm die Bevölkerungszahl nicht mehr zu. Zuwanderung betraf vor allem die banlieue. Dennoch nahm der Großraum Paris im Vergleich zu anderen französischen Städten mehr und schneller Bevölkerung auf ${ }^{6}$, und das Wohnraumproblem wurde zu einer Hauptsorge für die angrenzenden Kommunen. Zudem blieben nach dem Krieg die privaten Investitionen aus, welche zu einer Entspannung auf dem Wohnungsmarkt hätten führen können. Die französische Regierung setzte 1919 ein Mietmoratorium durch, das die Mietpreise einfror und so dem Mittelstand den Anreiz nahm, in Mietimmobilien zu investieren. Gleichzeitig unterband diese gesetzliche Regelung das Interesse der Hausbesitzer, in Wohnkomfort und sanitäre Ausstattung ihrer Mietobjekte zu investieren. Dadurch befand sich ein Großteil des für die Wohnungsfrage relevanten unteren Mietsegments in einem katastrophalen Zustand. Seit dem Ende des 19. Jahrhunderts war keine Verbesserung eingetreten. Zwar hatte dies zur Folge, dass der für Miete aufzubringende Posten im Haushaltsbudget der Industriearbeiter anteilsmäßig immer geringer wurde und sich um 10 Prozent einpendelte. Ihre Wohnsituation verbesserte sich jedoch keinesfalls. In einer Stadt wie Ivry herrschten in dieser Zeit die drei-, vier- und fünfstöckigen einfachen Mietshäuser in den Arbeitervierteln vor.

Obwohl massiver Handlungsbedarf bestand, engagierten sich nur wenige in der Wohnungsfrage. Ihrer bürgerlichen Klientel verpflichtet, hatten die republikanischen Parteien kein Problembewusstsein entwickelt und trugen nichts zur Lösung des Wohnungsproblems bei. Im linken Spektrum entwickelte sich der sozialistische Bürgermeister von Suresnes, Henri Sellier (SFIO), zu einem Hauptprotagonisten in der Frage des öffentlichen Wohnungsbaus und bei der eng damit verknüpften Hygieneproblematik. Als Vorsitzender des Office public des habitations à bon marché de la Seine (OPHBM), das auf seine Initiative 1916 geschaffen wurde, trat er für eine durchgreifende Verbesserung der Lebensbedingungen der Arbeiterschaft in der banlieue ein. Er machte Suresnes mit seiner Gartenstadt (cité-jardin) zu einer Vorzeigekommune für zeitgenössisches, gesundes Wohnen. Ähnliche Wohnanlagen wurden dann auch in den Vorstädten Stains, Drancy, Arcueil, Suresnes, Champigny-surMarne, Le Plessis-Robinson und Châtenay-Malabry errichtet ${ }^{7}$. Als konzeptionelle Idee stand dahinter, durch die komfortablen Wohnungen mit Garten

${ }^{6}$ Das jährliche Wachstum in anderen französischen Städten betrug 0,8 Prozent. Hier lag die Zuwachsrate bei 1,65 Prozent. Die Bevölkerung von Paris wuchs von 1861 bis 1931 um 69 Prozent, in der banlieue im gleichen Zeitraum um 684 Prozent (Sowa, Wohnungsfrage, S.188).

7 Pennetier, Viet-Depaule, Biographies croisées, S. 189. 
den familiären Zusammenhalt und die Bindung an das Haus zu fördern. Damit sollten insbesondere die Familienväter von Ausschweifungen ferngehalten und vor kommunistischen Umtrieben geschützt werden. Günter Sowa wertet in seiner Studie zur Pariser Wohnungsfrage die Realisierungen in Suresnes als »Symbol für die Integration der reformistischen Linken in die bürgerliche Republik « ${ }^{8}$.

Die kommunistische Antwort auf die Wohnungsfrage wich erheblich von Selliers Modell ab und lag im Bau von Sozialwohnungen durch die öffentliche Hand. Ein Grund hierfür lag darin, dass sich die Wähler des PCF Wohnungsbesitz in den auch die Mittelklasse ansprechenden Gartenstädten nicht leisten konnten. Sie waren auf die finanzielle Unterstützung durch die Kommunen angewiesen. Die Errichtung von Sozialwohnungen in der banlieue war der Schlüssel für die Entstehung eines kommunistischen Milieus und seine enge politische Bindung an die lokale Herrschaftsstruktur. In Ivry ist diese Verbindung geradezu idealtypisch nachzuvollziehen. Drei Jahre nach dem Wahlsieg des PCF erging 1928 das Gesetz Loucheur, welches erstmalig den öffentlichen Wohnungsbau durch den französischen Staat vorsah. Daraufhin entstanden im folgenden Jahrzehnt 40000 habitations à bon marché (HBM) im Département de la Seine ${ }^{9}$. Während in Paris vor allem die freien Flächen um die geschliffenen Festungsanlagen mit den neuen öffentlichen Wohnungen bebaut wurden - Henri Sellier hatte sie als Verantwortlicher des Wohnungsamtes für die Pariser Region extra zu diesem Zweck erworben - und somit den Haussmannschen Gesamtcharakter der Stadt nicht in Frage stellten, wurden die $\mathrm{HBM}$ in der banlieue zum architektonischen Kennzeichen der Arbeiterstädte.

Der junge kommunistische Stadtrat begann 1929, den ersten öffentlichen Wohnblock in Ivry zu errichten. Der große, moderne Komplex mit mehreren hundert Wohnungen wurde in der Rue Parmentier unweit des Rathauses errichtet, die 1935 in Anlehnung an den Protagonisten der Französischen Revolution in Rue Marat umbenannt werden sollte. Zum gleichen Zeitpunkt wurde nordöstlich des Rathauses ein weiterer Wohnkomplex an der Place Philibert-Pompée errichtet. Bis 1937 waren so rund achthundert Wohnungen entstanden, in denen ein Zehntel der Ivryer Bevölkerung untergebracht war ${ }^{10}$. Die Wohnkomplexe waren als Ensemble geplant und bestanden aus mehreren fünfstöckigen Gebäuden, die zwar aneinandergebaut waren, jedoch alle über ihren eigenen Aufgang, die sogenannten »escaliers« verfügten. Beide Ensembles, sowohl jenes in der Rue Marat als auch dieses an der Place Philibert-Pompée, waren um einen Hof gruppiert, so dass möglichst viel Sonnenlicht und frische Luft in die unteren Wohnungen gelangen konnten. Alle

8 SowA, Wohnungsfrage, S. 214.

9 Dominique Borne, Henri Dubief, La crise des années 30, 1929-1938, Paris 21989, S.231.

10 Chambaz, L'implantation, S. 151. 
Wohnungen wurden zentral beheizt und hatten Elektrizität, was den modernen und fortschrittlichen Charakter der Wohnanlagen unterstrich, hatten doch Arbeiterunterkünfte in der Regel nicht diesen Komfort ${ }^{11}$. Mit diesem modernen Wohnungsbau suchte man nicht nur für bessere hygienische Verhältnisse zu sorgen, um Infektionskrankheiten und der viel gefürchteten Tuberkulose Herr zu werden, sondern realisierte jene Form von Massenunterkünften, wie sie auch in Deutschland und speziell in Berlin auf der Suche nach neuen, hygienischen Wohnformen unter Architekten diskutiert wurde ${ }^{12}$.

Andreas Wirsching hat in seiner vergleichenden Studie über den politischen Extremismus in Deutschland und Frankreich die Bedeutung des Scheiterns der Metallarbeiterstreiks 1919/20 für die Konstituierung der französischen kommunistischen Partei herausgestellt ${ }^{13}$. Sie schien als Partei neuen, leninistischen Typs am besten die Forderung zur revolutionären Tat zu bedienen, die unter den französischen Arbeitern insbesondere nach dem enttäuschenden Streikausgang weit verbreitet war ${ }^{14}$. Zwar lässt sich argumentieren, dass auch Ivry über eine gewisse revolutionäre Tradition verfügte, für die dauerhafte Durchsetzung des PCF spielte hier aber gerade die Wohnungsfrage eine entscheidende Rolle. Denn mit ihr waren zwei wegweisende Entwicklungen verbunden, die sich als konstituierend für das kommunistische Milieu erweisen sollten. Zum einen favorisierte die neue Bauweise die Einfügung der HBM-Bewohner in einen quasifamiliären, nachbarschaftlichen Zusammenhang, der für die solidarischen Binnenbeziehungen in der kommunistischen Arbeiterschaft von großer Bedeutung war. Denn im Gegensatz zum Bürgertum leitete sich die Identität französischer Arbeiter im Großraum Paris wesentlich stärker aus ihrem Wohnviertel ab und war territorial an dieses gebunden ${ }^{15}$. Soziale Kontakte bestanden in erster Linie zu den Nachbarn und zu Familienangehörigen im gleichen Wohnviertel. Für die mittelfristige leninistische Organisation von Ivrys Arbeiterschaft war daher das räumlich nahe Beieinanderwohnen eine wichtige Voraussetzung. Der zweite mit der Wohnungsfrage verbundene Pfeiler für die Etablierung und Herrschaftssicherung des PCF in Ivry war die zügige Schaffung des Wohnungsamtes und seine personelle Besetzung mit dem orthodoxen Kommunisten Venise Gosnat. Diese Institution gewährleistete nicht nur den professionellen Bau neuer Sozial-

11 Downs, Municipal communism, S. 210.

12 Marianne RodensteIn, »Mehr Licht, mehr Luft«. Gesundheitskonzepte im Städtebau seit 1750, Frankfurt a. M. 1988, S. 173; Werner Durth, Jörn DüwEL, Niels Gutschow, Architektur und Städtebau der DDR, Bd.1: Ostkreuz, Personen, Pläne, Perspektiven, Frankfurt a. M., New York 1998, S. 16-31.

13 Andreas Wirsching, Vom Weltkrieg zum Bürgerkrieg? Politischer Extremismus in Deutschland und Frankreich 1918-1933/39, Berlin und Paris im Vergleich, München 1999.

14 Ibid., Kapitel »Revolutionärer Generalstreik oder Lohnbewegung?« und »Die Wendung zum Kommunismus«, S. 88-111, hier S. 108.

15 Henri Mendras, La Seconde Révolution française 1965-1984, Paris 1986, S. 367. 
wohnungen, für den seit 1928 öffentliche Kredite zur Verfügung standen, sondern sicherte darüber hinaus die Vergabe der begehrten Wohnungen an tatsächliche oder potentielle Genossen. Sie waren dadurch noch stärker in den Milieuzusammenhang eingebunden und zeigten sich dankbar gegenüber der Partei, die das essentielle Wohnungsproblem für die betroffene Familie gelöst hatte. Außerdem war sie so in ein soziales Netz eingebunden, das sie möglicherweise durch die eigene Migration in der Provinz zurückgelassen hatte. Für die Entwicklung von dauerhaften Loyalitätsbeziehungen war das Beherrschen des öffentlichen Wohnungsmarktes, der in Ivry in den folgenden Jahrzehnten bis zu 75 Prozent des Gesamtwohnungsmarktes ausmachen sollte, von wesentlicher Bedeutung ${ }^{16}$.

Die kommunistische Partei begann also in den Vorstädten ein Politikfeld auszufüllen, das von den bürgerlichen und sozialistischen Kräften eindeutig vernachlässigt wurde. Zu groß war auch in der Krisenzeit der 1930er Jahre die Konzentration auf die klassischen Themen der Republik, das Problem von Schule und laizistischem Staat und die Sorge der classes moyennes um ihre kleinteilige Wirtschaftsform. Obwohl sich die im europäischen Vergleich frühe Demokratisierung Frankreichs als modernes Politikmodell erwiesen hatte, lehnten weite Teile der französischen Gesellschaft die Industrialisierung als weiteres wesentliches Element der Moderne ab. Dominique Borne und Henri Dubief machen in ihrer Studie über die Krise der Zwischenkriegszeit diese »résistance à l'industrialisation « 17 als weit verbreitete Grundhaltung und Epochenkennzeichen aus, das sich auch in der sozialen Exklusion des neu aufkommenden Typs des Industriearbeiters ausdrückte. Mitunter führte dies zu einer großen Rekrutierungswelle von Arbeitern im Ausland, vor allem Italien und Polen, wo die Menschen weniger Berührungsängste mit der Fabrikarbeit hatten ${ }^{18}$. Für die Industriearbeiter in der Vorstadt führte die soziale Ausgrenzung auch praktisch dazu, dass sich niemand für ihre Belange einsetzte, obwohl sie trotz gewerkschaftlicher Organisation gerade in den paternalistisch geführten Betrieben gesellschaftliche Unterstützung gebraucht hätten ${ }^{19}$.

Dieses soziale und affektive Vakuum in der banlieue suchte der PCF in seiner Frühphase gezielt zu füllen und in politische Herrschaft umzusetzen. So hatte die nationale Parteiführung in der ersten Hälfte der 1920er Jahre den Uhrmechaniker und Mitglied des Politbüros, Georges Marrane, nach Ivry

\footnotetext{
16 Im Februar 1990, als die Frage der Mieterhöhungen zur Kostendeckung in Ivrys Sozialwohnungen diskutiert wurde, hielt der kommunistische Stadtrat weiter an seinem traditionellem Politikelement fest und proklamierte: »Nous poursuivons une politique totalement tournée vers le logement social« (Ivry, ma ville 173 [1990], S. 20f.).

17 Borne, Dubief, La crise, S. 16.

18 Chambaz, L'implantation, S. 158.

19 So waren von 1930 bis 1935 lediglich 37 Prozent der Streiks im Pariser Großraum erfolgreich. Oft wurden auch Entlassungen und Aussperrungen der Arbeiter seitens der Arbeitgeber praktiziert, zumal die seit 1930 ansteigende Arbeitslosenzahl die Arbeiterschaft in ihrer Durchsetzungskraft erheblich schwächte.
} 
entsandt, um die kommunistische Liste bei den Stadtratswahlen 1925 anzuführen und das durch die Industriearbeiterschaft vorhandene Wählerpotential auszuschöpfen. Marrane, Jahrgang 1889, hatte am Ersten Weltkrieg teilgenommen und war während der Kriegshandlungen verletzt worden. Als Sozialist setzte er sich nach Kriegsende für die Wiederaufnahme der Beziehungen zu den anderen sozialistischen Parteien in Europa ein ${ }^{20}$. In der ersten Hälfte der 1920er Jahre etablierte er in Paris mehrere Arbeiterkooperativen. Seit Januar 1923 mit exponierten Sozialisten wie Marcel Cachin eines der fünf Mitglieder des Politbüros des PCF, behielt Marrane diese Position über mehrere Jahre inne und verblieb in den 1930er Jahren weiterhin im Zentralkomitee ${ }^{21}$. Marcel Cachin war eine Symbolfigur des französischen Sozialismus aus der Vorkriegszeit und zunächst von den Ideen der traditionellen Führungspersönlichkeiten, namentlich Jules Guesdes, geprägt. Er war mit Ivrys Kommunisten eng verbunden und nicht nur auf den offiziellen Parteiveranstaltungen zugegen, die in der Zwischenkriegszeit oft auf "parteieigenem Terrain « in Ivry stattfanden ${ }^{22}$, sondern ging auch im fortgeschrittenen Alter bis zu seinem Tod 1958 in der Nachbargemeinde Choisy-le-Roi in Ivry ein und aus.

In seiner Funktion als Führungsmitglied war Marrane eng in den Kampf des PCF gegen eine Ruhrbesetzung mit französischen Truppen involviert, welche als politisches Mittel und Folge des Versailler Vertrages von kommunistischer Seite vehement abgelehnt wurde. Denn der Einsatz des Militärs stand im Gegensatz zur offiziellen pazifistischen Haltung der Partei ${ }^{23}$. Die Komintern organisierte daher vom 6. bis 9. Januar 1923 in Essen eine internationale Konferenz, an der fast das gesamte französische Politbüro teilnahm ${ }^{24}$. So sollte gegen die zu erwartende französische Besetzung des Ruhrgebiets protestiert werden. Zwei Tage nach diesem Treffen marschierten französische Truppen im Ruhrgebiet ein, um ein Druckmittel für die Einforderung deutscher Reparationszahlungen zu haben. Am gleichen Tag wurden die in Paris verweilenden Gaston Monmousseau, Albert Treint, Marcel Cachin und Georges Marrane wegen Komplotts gegen die innere und äußere Staatssicherheit verhaftet und im Pariser Gefängnis La Santé inhaftiert. Bürgermeister Georges Marrane hatte also in dieser Aufbauphase der Partei den kommunistischen Internationalismus nicht nur theoretisch rezipiert, sondern auch lebensweltlich erfahren.

Tatsächlich konnten die jungen kommunistischen Arbeiter um Georges Marrane bei ihrer ersten gesamtstädtischen Wahlaufstellung ein Drittel der abgegebenen Stimmen auf sich vereinen und so den ersten kommunistischen

20 Stadtarchiv Ivry, 386 W 3, autobiographische Skizze von Georges Marrane, 1969, S.1.

21 Courtois, Lazar, Histoire, S. 76, 95.

22 So der Parteitag zum Übergang zur Volksfronttaktik 1934, vgl. auch KRIEgEL, Les communistes français, S.260.

23 Stadtarchiv Ivry, 386 W 3, autobiographische Skizze von Georges Marrane, 1969, S.2.

24 Courtols, Lazar, Histoire, S. 76. 
Stadtrat von Ivry stellen. Es war dem PCF bei dieser wichtigen Kommunalwahl von 1925 gelungen, neben Ivry eine ganze Handvoll Schlüsselgemeinden der banlieue zu erringen und sich erstmals als politisch relevanter Faktor in den Vorstädten zu behaupten. So wurden nun auch Bobigny, Clichy, SaintDenis und Ivrys Nachbargemeinden im Pariser Südosten Malakoff, Villejuif und Vitry kommunistisch verwaltet ${ }^{25}$. Es war Ziel der Parteileitung, durch die kommunale Verwaltung der frisch eroberten Vorstädte an politischer Legitimation und Kompetenz zu gewinnen und sie »besser« als bürgerliche Stadtverwaltungen $\mathrm{zu}$ administrieren:

Il nous faut montrer par des réalisations concrètes mais bien étudiées et non bouclées, mais mieux organisées que celles de la bourgeoisie, que nous ne sommes pas des démagogues mais de véritables réalisateurs capables d'être, après la révolution, ceux qui construiront des œuvres sociales intéressant la santé publique ${ }^{26}$.

Außerdem, so hieß es in einem parteiinternen Strategiepapier von 1927, sollte mit den kommunistischen municipalités eine strategische Basis für die Partei geschaffen werden:

Au début, pour briser l'esprit localiste et social-démocrate, on avait coupé à tort et à travers. Ensuite, il y a eu une transformation avec comme base fondamentale l'intérêt d'avoir pour chaque rayon une base industrielle et la possibilité de s'appuyer sur une municipalité communiste ou une coopérative ${ }^{27}$.

Damit waren zwei Leitmotive anstehender Lokalpolitik genannt: die »bessere « Stadtverwaltung durch sozialpolitische Maßnahmen und der Ausbau der 1925 gewonnenen Vorstädte zu Parteibastionen.

Tatsächlich entwickelte sich Ivry bis 1932/33 zu einer kommunistischen Hochburg, die auf der sozialpolitischen Umklammerung der Einwohnerschaft, der politischen Expansion der kommunistischen Partei und ihrer Organisation nach leninistischen Prinzipien basierte. Diese in allen europäischen kommunistischen Parteien zu beobachtende Bolschewisierung bedeutete vor allem die Etablierung eines hierarchischen Parteiapparats und die Unterwerfung unter Moskauer Vorgaben ${ }^{28}$. Dazu zählten außerdem die einheitliche Bezeichnung der Parteien und ihre vertikale Organisation. Diese begann in den einzelnen Parteizellen und wurde in der französischen Variante in den Organisationsstufen »section«, »rayon « und »fédération« fortgesetzt. Wie in allen anderen kommunistischen Parteien erfolgte die nationale Führung durch das Politbüro, welches aus dem Zentralkomitee hervorging.

25 WirSCHING, Weltkrieg, S. 410.

26 AIRM 119, Memorandum o.D. [1925], zitiert nach WIRSCHING, Weltkrieg, S. 411.

27 Parti communiste - Région parisienne. Un an après Lille. Rapport moral et politique, 1927, S. 8, zitiert nach GIRAULT, L'implantation, S. 61-117, hier S. 72.

${ }^{28}$ Wir folgen hier dem zeitgenössischen Bolschewisierungsbegriff. Die von Andreas Wirsching implizierte moralische Abhängigkeit vom Willen Moskaus scheint uns im lokalen Zusammenhang erst einzutreten, als er von den lokalpolitischen Akteuren erfahrungsgeschichtlich und biographisch nachvollziehbar wird. Vgl. WirSchING, Weltkrieg, S.284f.; Courtois, LaZAR, Histoire, S. 83-98. 
Um den Einfluss der Partei auf lokaler Ebene sicherzustellen, bemühten sich die Kommunisten in Ivry darum, die Zahl der Parteizellen als unterste Organisationseinheit auszuweiten. Obwohl sich die parteipolitische Expansion in den Fabriken Ivrys vermuten ließe, war es erklärtes Ziel des Stadtrats - so in einer Erklärung vom April 1926 - alle lohnabhängig Beschäftigten einzubinden:

Dans le programme soumis aux électeurs lors des élections municipales de 1925 par les candidats du BOP [Bloc ouvrier et paysan], nous avons déclaré qu'un des points les plus importants consistait dans la liaison, aussi étroite que possible, avec tous les travailleurs d'Ivry ${ }^{29}$.

Es gehörte zu den Besonderheiten des städtischen Kommunismus, die gesamte Lebenswelt seiner Einwohnerschaft durchdringen zu wollen. Eine zu enge Definition des »Arbeiters« wäre daher kontraproduktiv gewesen und hätte Teile der Einwohnerschaft ausgeschlossen. Stattdessen versuchte der kommunistische Stadtrat, möglichst breite, in Ivry vertretene und oft dem Kleinbürgertum angehörige Berufsgruppen anzusprechen: »Il n'est pas superflu de rappeler, encore une fois, que nous entendons par travailleurs tous ceux qui, à l'usine, dans les bureaux, dans les boutiques et dans les transports font œuvre utile de production ou de répartition pour la collectivité « ${ }^{30}$.

Diese weite Definition korrespondierte mit der Form der Parteizellengründung: Die erste kommunistische Zelle entstand 1925 bei dem amerikanischen Schuhhersteller United Shoes. Es folgte einige Monate später eine Zellengründung im Straßenbahndepot an der nordöstlichen Stadtgrenze zu Paris, 1926 gab es gleich drei neue Zellen von Arbeitern der Bauwirtschaft, der Metall verarbeitenden Industrie und der kommunalen Materialwirtschaft, bevor die Zahl bis 1930 auf dreizehn Zellen anwuchs ${ }^{31}$. Dabei ist es für Ivry charakteristisch, dass sowohl der klassische Wirtschaftszweig der Metallverarbeitung stark vertreten war - die Nachbarkommunen hatten in diesem Bereich bestenfalls eine kommunistische Betriebszelle - als auch der kommunale öffentliche Dienst mit zwei Parteizellen. 1930 gab es ebenfalls vier Gebietszellen, die an das jeweilige Wohngebiet gebunden waren ${ }^{32}$. Nach dem Munizipalgesetz von 1884 war es zudem dem Bürgermeister erlaubt, kommunales Personal in dem Maße einzustellen, wie es die Verwaltung seiner Kommune erforderte, ohne dass dies gegenüber einer Institution gerechtfertigt werden musste $^{33}$. In den Vorstadtgemeinden hatte der PCF damit ein ideales Instrument in der Hand, um eine eigene Klientel im Rathaus heranzuziehen und fest zu etablieren. So wurden in Ivry neue Stellen in der Kommunalverwal-

${ }^{29}$ Bulletin municipal officiel, April 1926, Nr.1, zitiert nach Chambaz, L'implantation,

S.167.

30 Chambaz, L'implantation, S. 167.

31 Ibid., S.163.

32 Ibid.

33 Froment-Meurice, Mairie, S. 50. 
tung geschaffen und mit kommoden Kandidaten besetzt. 1933 war bereits das gesamte Personal im Rathaus ersetzt worden ${ }^{34}$.

Diese Vervielfachung der Parteizellen bedeutete gleichzeitig eine Vervielfachung der Mitgliederzahl und aktualisierte die Frage nach einer lokalen Neuorganisation der Partei. Bis Ende 1931 war Ivry dem vierten Rayon von Paris untergeordnet, der Ivry, Vitry und das ebenfalls kommunistisch regierte 13. Arrondissement umfasste. Parteiintern galt dieser Mitgliederbezirk als der bei weitem wichtigste in der Pariser Region ${ }^{35}$. Aufgrund der bis 1931 erreichten Mitgliederstärke und ihres relativ großen Einflusses erhielt Ivrys Unterorganisation schließlich selbst den Status eines Rayons, dessen Sekretär Émile Zellner wurde. Die lokale Parteisektion bewegte sich damit klar gegen den nationalen und Pariser Trend, der den PCF in diesem Zeitraum rund zwei Drittel seiner Mitglieder verlieren ließ ${ }^{36}$. Dies erhöhte gleichzeitig ihr Ansehen innerhalb der Partei. Vielleicht ist darauf die Entscheidung zurückzuführen, Maurice Thorez als Kandidaten für die Wahl zur Deputiertenkammer 1932 im sicheren Wahlkreis Ivry-Vitry aufzustellen. Der französische Kommunistenführer war stark in Ivrys Milieu verankert. Zudem fanden regelmäßig Sitzungen des Politbüros und schließlich auch Parteitage in Ivry statt. Auch Thorez' Familienangehörige, wie seine zweite Frau Jeannette Vermeersch und deren Schwester, hatten sich in einem der neuen Sozialwohnungsbauten in Ivry niedergelassen.

Ein weiterer Standortvorteil der proche banlieue gegenüber Paris war für die kommunistische Partei zudem die Übereinstimmung der von der Moskauer Parteizentrale zwischen 1928 und 1932 propagierten Verelendungstheorie mit der Lebenswirklichkeit ihrer Bewohner. Denn diese waren täglich mit schlechten Arbeitsbedingungen, miserablen Wohnungen und steigender Arbeitslosigkeit konfrontiert ${ }^{37}$. Der lokale PCF propagierte mit dieser Theorie einen für seine Klientel plausiblen Welterklärungsansatz. Seine selbst gestellte Aufgabe war es, Ivrys Einwohnerschaft durch soziale Fürsorge und mit praktischen Lebenshilfen sicher um die Klippen des Kapitalismus zu geleiten. Diese sozialpolitischen Maßnahmen des kommunistischen Stadtrates prägten den Alltag in der banlieue in den 1930er Jahren und verliehen seiner Herrschaft kulturelle Kohärenz.

\footnotetext{
${ }^{34}$ La Banlieue de Paris, 28.4.1933.

35 WirSCHING, Weltkrieg, S. 411.

36 Chambaz, L'implantation, S.164, Wirsching, Weltkrieg, S. 559.

37 Damit ist für den Ivryer Fall der Annahme von Wirsching zu widersprechen, nach der die Frage der Arbeitslosigkeit für die Mitgliedschaft des PCF, die sich zumeist aus qualifizierten Facharbeitern zusammensetzte, wenig relevant gewesen sei. Gerade im konkreten lokalen Zusammenhang erwies sie sich als ideale Plattform für den Ausbau der kommunistischen Machtbasis und für die Bildung von Loyalitätsbeziehungen zwischen der municipalité und Ivrys Einwohnerschaft.
} 


\subsubsection{Sozialpolitik als Fundament lokalkommunistischer Herrschaft}

$\mathrm{Zu}$ der wichtigsten lokalpolitischen Innovation neben dem forcierten sozialen Wohnungsbau gehörte die Einbindung der Familienpolitik in den Kompetenzbereich der Kommunalverwaltung. Dies umfasste auch die Kinderbetreuung im Alltag und in den Ferien. Die Politik der petite enfance sah die Eröffnung einer Kinderkrippe in jedem Stadtviertel vor. Seit 1905 gab es zwar bereits ein städtisches dispensaire, eine medizinische Tageseinrichtung, wo Kinder und Säuglinge Gesundheitspflege und Betreuung erhielten. Erklärtes und realisiertes Ziel war es nun jedoch, möglichst viele Kinder in diesen Einrichtungen unterbringen zu können, um den Müttern bei wirtschaftlicher Not die Erwerbstätigkeit zu ermöglichen. Außerdem sah das städtische Angebot eine bessere und kostenlose gesundheitliche Versorgung der Kleinkinder vor. 1928 gab es so bereits achttausend registrierte Pflegeakte an Kleinkindern ${ }^{38}$. Dies war angesichts einer geringen Geburtenrate nach dem Krieg und der immer noch hohen Säuglingssterblichkeit in Frankreich eine wichtige Verbesserung und minderte die erhebliche gesundheitliche Benachteiligung der Kinder von Arbeitern und kleinen Angestellten. Im Kampf gegen die Tuberkulose wurden neue Geräte angeschafft, die der Volkskrankheit mit UV-Strahlen vorbeugen sollten. Im gleichen Sinn ließ der Stadtrat in den besonders schlecht ausgestatteten Vierteln wie Ivry-Port Badehäuser errichten, die den neueren Standards entsprachen. Da es in Frankreich in der Zwischenkriegszeit noch keine staatliche, für alle offene Krankenversicherung gab und man ohnehin zu berufsständischen Lösungen neigte ${ }^{39}$, war die städtische Gesundheitspolitik eine wichtige Vorwegnahme späterer sozialstaatlicher Angebote.

Dies galt in gleichem Maße für die Einführung der Arbeitslosenunterstützung durch Ivrys kommunistische municipalité, für die es in Frankreich zu diesem Zeitpunkt ebenfalls keine gesetzliche Regelung gab. Da es in den 1930er Jahren noch keine offizielle Arbeitslosenstatistik gab, lässt sich das im Vergleich zu anderen Industrieländern in Frankreich zeitverzögert aufgetretene Phänomen der Arbeitslosigkeit methodisch nur anhand von städtischen Fürsorgeleistungen nachweisen. Ivry erscheint als Vorstadt mit besonders hoher Arbeitslosigkeit, was sich angesichts der wirtschaftlichen Schwierigkeiten eines Industriestandortes durchaus nachvollziehen lässt. Andererseits trugen die finanziellen und materiellen Zuwendungen der Stadt erst zur Visualisierung der Erwerbslosigkeit bei, die in anderen Orten versteckt geblieben wäre. Und spiegelte das verzögerte Auftreten der Arbeitslosigkeit vor allem in den 1930er Jahren nicht grundsätzlich eine Schwäche, zumindest aber eine Rückständigkeit des französischen Wirtschaftssystems wider? Saisonale Erwerbslosigkeit kannte man bereits als soziale Erscheinung des 19. Jahrhunderts ${ }^{40}$.

38 Chambaz, L'implantation, S. 158.

39 RitTer, Sozialstaat, S.188f.

40 WeBer, La fin, S. 311. 
Denn später waren konjunkturelle Anreize durch Rationalisierung der Produktionsweise bei gleichzeitiger Erhöhung der Massennachfrage nicht vorgesehen $^{41}$, so dass die französische Industrie weiterhin in herkömmlicher Weise produzierte, ohne arbeitsorganisatorische Innovationen ausreichend aufgenommen zu haben. Es ist in jedem Fall bemerkenswert, dass die ersten Angaben zur Arbeitslosenzahl in Ivry eineinhalb Jahre nach Amtseinführung des kommunistischen Stadtrats im Dezember 1926 erschienen und für Februar 1927 mit dreihundert angegeben wurden ${ }^{42}$. Bis Ende 1932 steigerte sich ihre Zahl erheblich auf 2019, 1935 hatte sie den Höchststand von fast dreitausend erreichtet. Auf diesem Niveau hielt sich die Statistik bis $1936^{43}$.

Einige Indikatoren lassen vermuten, dass im Großraum Paris die Praxis der allocations au chômage wesentlich verbreiteter war als in anderen Teilen Frankreichs. So lebten dort rund 20 Prozent der arbeitsaktiven Bevölkerung, aber 50 Prozent der registrierten unterstützten Arbeitslosen. Dominique Borne und Henri Dubief gehen in ihrer Schätzung für das Jahr 1935 von ca. 1 Million Arbeitslosen aus, darunter vor allem Industriearbeiter, eine Gruppe, die ohnehin zur Hälfte unterbeschäftigt war. Auf der anderen Seite bot das Phänomen der Arbeitslosigkeit der kommunistischen Partei ideologische Anknüpfungspunkte für die Diskreditierung des kapitalistischen Wirtschaftssystems $^{44}$. Es ist anzunehmen, dass Beschäftigungslosigkeit tatsächlich als soziales Problem zumal in der städtischen Gesellschaft auftrat und für die Betroffenen individuell dramatisch war. Das Herausstreichen ihrer Bedeutsamkeit für die Unmenschlichkeit der westlich-kapitalistischen Gesellschaft, der die französischen Kommunisten seit 1917 ein alternatives Wirtschaftssystem entgegenhalten konnten, stand jedoch insgesamt als Argument für den Wunsch nach einer sozialrevolutionären Zukunft Pate.

Neben der finanziellen und materiellen Hilfe gehörte es zu den Innovationen des städtischen Kommunismus, die Beschäftigungslosen in Komitees zu organisieren ${ }^{45}$. In Ivry entstand im Januar 1932 das erste comité des chômeurs. Gleichzeitig bemühte sich Bürgermeister Georges Marrane um die Erhöhung des Anteils des Département de la Seine am finanziellen Aufwand für die Arbeitslosen. Der Stadtrat von Ivry nahm zudem selbst Kredite auf, um die rund 8500 betroffenen Personen, die Arbeitslosen und ihre Familien in Ivry

\footnotetext{
41 Borne, Dubief, La crise, S. 31f.

42 Chambaz, L'implantation, S. 168.

43 Vgl. hierzu die Angaben in: Ivry, fidèle à la classe ouvrière et à la France, supplément au Travailleur d'Ivry, Nr.1319, S.114-116.

44 Andreas WIRSChING, KPD und PCF zwischen »Bolschewisierung « und »Stalinisierung«. Sowjet-Russland, die Kommunistische Internationale und die Entwicklung des deutschen und französischen Kommunismus zwischen den Weltkriegen, in: Ilja МiecK, Pierre Guillen (Hg.), Deutschland - Frankreich - Russland. Begegnungen und Konfrontationen, München 2000, S. 277-292, hier S.288f.

45 Zur Erwerbslosenpolitik der kommunistischen municipalités vgl. WIRSCHING, Weltkrieg, S. 411 .
} 
finanziell zu unterstützen ${ }^{46}$. Dies führte einerseits zu Solidarität und gegenseitiger Unterstützung der Betroffenen, andererseits förderte es die Loyalitätsbeziehungen und - kritisch formuliert - das Abhängigkeitsverhältnis zur kommunistischen Partei, die diese Loyalität einforderte. So berichtete eine oppositionelle Quelle, dass Georges Marrane es sich persönlich vorbehielt, die Arbeitslosenunterstützung um die Hälfte zu kürzen, wenn sich die Betroffenen nicht konform verhielten oder versuchten, den PCF durch Gegenpropaganda in Verruf zu bringen ${ }^{47}$. Insbesondere die Arbeitslosenkomitees wurden von der Partei genutzt, um namentlich die betroffenen jungen Männer in diese Organisation einzubinden, so zu erfassen und im Falle eines politischen Einsatzes - sei es bei einer Demonstration oder bei einem Straßenkampf wie am 6. Februar 1934 - schneller mobil machen zu können. Durch die Arbeitslosenkomitees erhöhte sich so nicht nur die organisatorische Schlagkraft der Partei und der mit ihr verschränkten lokalen Organisationen; auch durch die physische Präsenz und Besetzung des öffentlichen Raumes war die horizontale organisationelle Durchdringung der Vorstadtbewohner gewährleistet und stellte eine politische Innovation des PCF dar ${ }^{48}$. Auch von Seiten der Polizei wurde diese enge Verbindung von sozialer Fürsorge und politischer Mobilisierung wahrgenommen und kritisiert:

Une résistance de plus en plus marquée se manifeste dans les comités locaux contre les dirigeants de l'Union régionale des comités de chômeurs, à qui l'on reproche de prendre exclusivement leurs mots d'ordre au parti communiste. De nombreux adhérents se plaignent que leur action ait été jusqu'à présent orientée uniquement vers des buts politiques. Ils constatent que sous le prétexte de poursuivre l'aboutissement de leurs revendications immédiates, ils ont été surtout invités à participer à des démonstrations communistes préparées et dirigées en dehors de tout contrôle de la part des chômeurs ${ }^{49}$.

Ähnlich verhielt es sich mit der Wohnungspolitik. So kamen die ab 1929 neu errichteten Wohnungen zwar durchaus den Ivryer Fabrikarbeitern zugute. Dort wohnten aber auch die Angestellten der mairie und treue Mitglieder der Partei $^{50}$. Zweitausend Anfragen von Ivryer Familien nach einer Wohnung in den neuen $\mathrm{HBM}^{51}$ machten deutlich, welche Machtstellung der PCF aufgrund seiner Position im Verwaltungsrat der Wohnungsbehörde ${ }^{52}$ in diesem $\mathrm{Zu}$ -

\footnotetext{
46 Ivry, fidèle à la classe ouvrière, S.113.

${ }^{47}$ La Banlieue de Paris, 17.6.1932.

48 Vgl. Girault, L'implantation, S. 108: »La grande nouveauté introduite par le parti communiste dans la vie politique de la banlieue est l'engagement physique des militants sur tous les terrains, y compris à l'entreprise «.

49 AN F7 13557, zitiert nach WIRSCHING, Weltkrieg, S. 415.

50 Girault, L'implantation, S. 73.

51 AN F7 13127 PCF de la Seine, Ivry Mandat Marrane.

52 Der conseil d'administration setzte sich aus Abgesandten des Präfekten, des Stadtrats und der lokalen Vereine zusammen. Entscheidend war die Stelle des Geschäftsführers, der die letztendliche Entscheidungsgewalt über den Verein innehatte. In kommunistisch regierten Gemeinden war das meistenteils ein Parteimitglied, wodurch sich die Wichtigkeit dieser Stelle für den Zugriff auf das per se öffentliche Wohnungseigentum erklärt.
} 
sammenhang innehatte. Durch das Monopol bei der Vergabe von Sozialwohnungen konnte sie einen harten Kern von Getreuen in Nachbarschaftsverhältnissen zusammenordnen, die zwar insgesamt nur 10 Prozent der Ivryer Bevölkerung ausmachten, in ihrer Loyalität gegenüber der Partei aber überdurchschnittlich engagiert waren. So verfügte der PCF in den 1930er Jahren aufgrund seiner vergleichbaren Position in anderen roten Vorstädten über einen festen Wohnungsbestand, in dem er seine Kader kostenlos unterbringen oder vor der Polizei verstecken konnte. Im Fall von Ivry war Venise Gosnats Frau Alice als concierge im HBM-Komplex an der Place Philibert-Pompée angestellt und konnte von ihrem Pförtnerhäuschen in der Mitte des Platzes aus die Treppenzugänge kontrollieren. Dies gewährleistete einen absoluten Zugriff der Partei auf die Bewohner und demonstrierte die tatsächliche Macht des PCF im Alltag der Regierten. Die engen Loyalitätsbeziehungen sorgten ebenso für emotionalen Zusammenhalt wie für materielle Besserstellung der betroffenen Mieter. So versorgte der Stadtrat sie nicht nur prioritär mit Kohle, Kleidung und Essen, sondern engagierte auch Arbeitslose für die Stadtverwaltung, um sie dann in den Dienst der Partei zu stellen. So erhielt der Kommunist André Faux, als er 1933 mit seiner Frau nach Ivry zog, eine Wohnung in den HBM an der Place Philibert-Pompée, wo er in der Theatergruppe und im Chor des Mietervereins mitwirkte. Von Georges Gosnat, dem Sohn von Alice und Venise Gosnat in die Partei gebracht, leitete er von 1935 bis 1938 die Parteizelle Jean-Jaurès in Ivry-Port. Außerdem arbeitete er als Leibwache bei Maurice Thorez, der ebenfalls zeitweilig in diesem Gebäudekomplex wohnte ${ }^{53}$. Ab 1933 gab Ivrys PCF die Lokalzeitung »Le Travailleur « heraus, die nicht nur in propagandistischer Manier über die Aktivitäten der Genossen berichtete, sondern auch die publizistische Deutungshoheit im kommunistischen Milieu übernahm. Dass die Zeitung in den HBM-Ensembles gelesen wurde, rundete die soziale Kontrolle und Indoktrination ihrer Bewohner ab.

Auch die Politik der petite enfance trug zur Beständigkeit und Dauer des lokalen kommunistischen Milieus wesentlich bei. Sie förderte die Gesundheit der Kinder durch regelmäßige und kostenfreie Behandlung, was ja Ziel sowohl der kommunistischen wie der sozialistischen Stadtverwaltungen in Paris' rotem Gürtel war. Zudem hatten Ivrys Kommunisten mit der sechs- bis achtwöchigen Ferienkinderverschickung ein Mittel erster Ordnung in der Hand, die Eltern in Dankbarkeit an sich zu binden ${ }^{54} .1929$ hatte die Stadt Ivry ein Grundstück an der Atlantikküste in der Nähe von Royan gekauft, auf dem sie die Ferienkolonie Les Mathes gründete, in der Ivrys Kinder bald ihre Ferien verbringen sollten. Im ersten Sommer waren es lediglich zweihundert, dann steigerte sich die Zahl bis 1934 auf rund fünfhundert Ferienkinder ${ }^{55}$. Diese

53 Michèle Rault (Bearb.), Stadtarchiv Ivry, LN 1936, Témoignage 1983.

54 Vgl. Downs, Municipal Communism, S.212.

55 Chambaz, L'implantation, S. 167. 
alljährliche Kinderverschickung wurde offiziell durch das Euvre des vacances populaires enfantines (OVPE) organisiert. Die Gründung des OVPE fand gleich zwei Monate nach der Einsetzung des kommunistischen Stadtrats statt und zeugte von dessen Intention, die Kinderferien auch im Falle eines kommunalen Machtwechsels weiter durchführen zu können ${ }^{56}$. Vereine zu gründen, in denen der Bürgermeister selbst oder andere Stadtratsmitglieder den Vorsitz übernahmen, um sie dann großzügig aus der Stadtkasse zu subventionieren und so ein Politikfeld zu besetzen, das nicht originär zu den Aufgaben von Stadtrat und -verwaltung gehörte, war ein juristisches Konstrukt, das die Munizipalgesetzgebung und das französische Vereinsgesetz zuließen. So entzogen sich die Subventionierung der Vereine und deren eigene Ausgaben jeglicher offizieller Finanzkontrolle und erlaubten den Stadträten eine Politik vor allem in den Bereichen Kultur, Sport und Erziehung nach ihrem Gusto ${ }^{57}$. Diese Art von Vereinsgründungen war in Städten und Gemeinden üblich, die ihre Parteiklientel mit Posten zu versorgen hatten. Andererseits konnten so eigene Politikvorstellungen auf einer anderen Ebene als über die Entscheidungen des Stadtrats umgesetzt werden. In Ivry war diese Konstellation besonders ausgeprägt. Während das OVPE ein Herzstück lokaler Sozialpolitik darstellte, erfuhren auch die kommunistischen Vorfeldorganisationen wie die 1919 von dem kommunistischen Intellektuellen Henri Barbusse gegründete Vereinigung ehemaliger Frontkämpfer, die Association républicaine des anciens combattants (ARAC) oder die Frauen- und Jugendorganisationen Association des femmes françaises und Jeunesses communistes intensive ideologische und materielle Unterstützung durch den kommunistischen Stadtrat.

Bereits im ersten Sommer nach den Kommunalwahlen von 1925 brach eine erste Expedition aus Ivry mit mehreren hundert Kindern an die Atlantikküste auf. Es bestand ein absoluter Wille bei den kommunistischen Arbeitern aus der banlieue, die sich für diese Aktion zur Verfügung gestellt und dazu unbezahlten Urlaub genommen hatten, den Kindern das Meer zu zeigen. Laura Lee Downs unterstreicht in ihrer Analyse der kommunistischen »Kindheitspolitik « in Ivry die fürsorgende, fast mütterliche Art, mit der der kommunistische Stadtrat von »seinen« Ivryer Kindern sprach, denen man einen richtigen Sommerurlaub jenseits der tristen Industrievorstadt ermöglichen wollte. Es war Ziel der städtischen Politik, alle in Ivry lebenden Kinder einzubinden und gleichzeitig die Kinderferienverschickung zu monopolisieren. So wurde das Sozialwerk der Ivryer Katholiken, das sich ohnehin seit Jahrzehnten mit einer antiklerikalen Mehrheitsgesellschaft konfrontiert sah, systematisch an den Rand gedrängt. Schon vor Entstehung der kommunistischen Bewegung in Frankreich hatten sich die Ferienkolonien der katholischen Pfarrgemeinden - drei insgesamt - in Ivry kaum gegen die republikanisch-säkularen Bewegungen durchsetzen können. Nach der Machtübernahme des lokalen PCF erlebte

56 Downs, Municipal Communism, S. 223.

57 Froment-Meurice, Mairie, S. 53. 
die Auseinandersetzung einen Höhepunkt, in dessen Folge die katholischen Gläubigen in Ivry marginalisiert wurden. Auf dem Gebiet der Kinderverschickung geschah dies zunächst über die Subventionskürzung für die katholische Kolonie La Belle Étoile in Savoyen, bevor diese bescheidene finanzielle Hilfe 1929 endgültig wegfiel ${ }^{58}$. Die kostenlose kommunistische Ferienkolonie konkurrierte nun direkt mit der beitragspflichtigen katholischen Kolonie um die katholischen Arbeiterfamilien. Drei Jahre später verlor die katholische Gemeinde ihr Ferienhaus in den Alpen, während das kommunistische Les Mathes mit Hilfe von Ivrys Arbeitern für achthundert Kinder mit fünf Schlafbaracken ausgebaut wurde.

Die Kinderferienverschickung war zwar Teil des sozialpolitischen Maßnahmenkatalogs des kommunistischen Stadtrats, nahm aber in verschiedener Hinsicht eine Sonderstellung ein, die mit der Vorstellung von Kindheit und ihrer biologischen Funktion als wesentlicher Sozialisationszeitspanne zusammenhing. Danach waren Kinder die Avantgarde der besseren, revolutionären Zukunft und ihre frühzeitige kommunistische Sozialisation deshalb wünschenswert. Kanonisiert wurde diese Vorstellung in dem Maurice Thorez zugeordneten Satz: »L'enfance, c'est notre plus grand espoir«. Während für Ivrys katholische Gemeinde die Verinnerlichung des Glaubens, seine Einbindung in den Ferienalltag und ein Rechristianisierungseffekt bei den Kindern im Mittelpunkt stand, versuchte sich die kommunistische Ferienkolonie in Les Mathes in der Einübung einer idealen kommunistischen Gemeinschaft, die dem Leben in Ivry nachempfunden war ${ }^{59}$. Der Ferienaufenthalt stellte dabei einen Höhepunkt im Alltagsleben dar, an den sich nicht nur viele zurückerinnerten, sondern der auch die Funktion hatte, kommunistische Werte früh an die Jungen weiterzugeben. Für die Herausbildung einer kohärenten kommunistischen Kultur war die Ferienverschickung daher ein wichtiger Stützpfeiler und Les Mathes ein bedeutender Ort der Erinnerung für Ivrys nachwachsende Generationen.

Dennoch wurde der Aufenthalt von den Kindern dort sehr unterschiedlich erlebt. Für die meisten war es die erste Gelegenheit, von zu Hause wegzukommen und das Meer zu sehen. Insofern war es für viele eine positive Kindheitserfahrung, die nicht nur den grauen Alltag des année scolaire durchbrach, sondern die Idee einer Kindheit mit Recht auf Ferien vor dem Eintritt in das Erwerbsleben mit dreizehn Jahren realisierte. Ideologisch wollte der lokale PCF das bürgerliche Urlaubsmonopol durchbrechen und den unterprivilegierten Arbeiterkindern einen ähnlichen Standard bieten, wenn auch als kollektive Erfahrung und nicht als individuelle Reise mit der Familie in die Sommerfrische. Obwohl die mairie besonders mit dem Gesundheitsaspekt und der guten Verpflegung für ihre Ferienkolonie warb, waren die ersten Aufenthalte sehr chaotisch, was an der mangelnden Erfahrung des Begleitpersonals, der

58 Downs, Municipal Communism, S.214.

59 Stadtarchiv Ivry, Br 451, Venise Gosnat, Villanous, 1948. 
materiell zunächst unzureichenden Ausstattung der Gebäude und schließlich am mangelnden pädagogischen Konzept lag. Während in den späten 1930er Jahren und insbesondere nach dem Zweiten Weltkrieg sehr klare Vorstellungen über die kommunistische Stadt der »petits Ivryens « vorherrschten ${ }^{60}$, bestand die Hauptherausforderung in der Frühphase der Kolonie darin, den Alltag in den Griff zu bekommen. Für einige Kinder war dies eine willkommene Abwechslung, konnten sie doch unbeaufsichtigt durch die Pinienwälder streifen und kleine Bandenkriege austragen. Andere litten unter dem Mangel an Zuwendung und empfanden das plötzlich aufgezwungene Leben in der Gemeinschaft, in der alle im gleichen Saal schliefen oder gemeinsam nackt duschen mussten, als sehr unangenehm ${ }^{61}$. Laura Lee Downs betont, dass die Trennung auch von sehr jungen Kindern von ihren Eltern über den Zeitraum von mehreren Wochen in den kommunistischen Quellen überhaupt nicht thematisiert wurde. Während es in der zeitgenössischen Literatur in England für die Londoner Arbeiterkinder als psychisch schädigend angesehen wurde, von den Eltern, insbesondere der Mutter, über einen längeren Zeitraum hin getrennt zu werden, schien in der französischen Arbeiterbewegung die Idee vorzuherrschen, dass affektive Bindungen nicht so wichtig waren, in jedem Fall aber durch die Fürsorge anderer ersetzt werden konnten.

Bis 1932/33 kann somit von einem relativen Abschluss der unmittelbaren Durchsetzungsphase des PCF in Ivry gesprochen werden. Politisch war der kommunistische Stadtrat als führende Kraft etabliert und hatte die SFIO der großen politischen Tendenz in der banlieue folgend - fast vollständig zurückgedrängt, so dass die traditionell sozialistische Partei bei der Kommunalwahl von 1935 nur noch 5,5 Prozent erreichte ${ }^{62}$. In ihrer chronischen Schwäche spiegelten sich die Lebensferne der SFIO-Führung und die Heterogenität ihrer politischen Vorstellungswelt wider, die sich nicht in so klare Strukturen wie die kommunistische pressen ließ. Die SFIO, welche lange Zeit für die reformerischen Kräfte der Dritten Republik stand und sich am Ideal der Republik der freien Bürger orientierte, konnte dem realen Bedürfnis der Arbeiterschaft nach materieller Etablierung und sozialpolitischer Unterstützung nicht im gleichen Maße nachkommen wie die Kommunisten, die mit dem neuen Konzept der Parteidisziplin einen Großteil der Industriearbeiter auch ideell an sich binden konnten. Dass sich die politische Stimmenverteilung innerhalb eines Jahrzehnts so grundlegend wandeln konnte, lag an der bewussten Anstrengung des PCF, eine besonders gute lokale Verwaltung mit starkem sozialpolitischem Engagement zu gewährleisten und dadurch intensive Bindungen und Abhängigkeitsverhältnisse innerhalb der Einwohnerschaft zu schaffen. Dieser Durchsetzungswille leitete sich zum Teil aus der Konkurrenz zu bürgerlichen Gemeinden ab, entstand aber auch aus dem Gedanken heraus,

60 Ibid.

${ }^{61}$ Downs, Municipal Communism, S. 215.

62 Chambaz, L'implantation, S. 160. 
durch die allumfassende organisatorische Einbindung von Ivrys Bevölkerung über die Partei und ihr nahestehende Organisationen und Vereine einen direkten Zugriff für ihre politische Mobilisierung zu haben. Auch wenn nur 2,5 Prozent der Lohnarbeiterschaft und 3 Prozent der kommunistischen Wählerschaft tatsächlich Mitglied des PCF waren ${ }^{63}$, so sympathisierte doch ein Großteil der Ivryer Einwohnerschaft mit den Kommunisten, die sich verbal und faktisch mit ihr verbündeten. Der Preis für die relativ starke Vergemeinschaftung in dieser Phase war die politische Unterwerfung unter den Willen der lokalpolitischen Elite. Es gibt allerdings einige Hinweise darauf, dass dieser Prozess in relativ großem Konsens erfolgte. Die sozioökonomische Zusammensetzung vieler Vorstadtgemeinden zeichnete sich im Vergleich zu Paris durch hohe Homogenität aus ${ }^{64}$. Insbesondere Ivry war von der Präsenz gering qualifizierter Arbeiter geprägt. Die sozialen Schranken zur Lebenswelt der kleinen Angestellten und Beschäftigten des aufstrebenden kommunalen öffentlichen Dienstes wurden zudem durch das verbale Versprechen der kommunistischen municipalité aufgehoben, sich in den Dienst aller lohnabhängig Beschäftigten zu stellen. Tatsächlich berührten sich die Lebenswelten ohnehin, die Problematik der zuziehenden Landbevölkerung und ihre ökonomische und soziale Integration in die lange gewachsenen Strukturen der französischen Hauptstadt waren für viele gleich und kulminierten in der Sorge um Arbeitsplatz, Wohnraum und Gesundheit der Kinder.

\subsubsection{Das Verhältnis zur bürgerlich-katholischen Rechten in Ivry}

Es gehörte zu den Kennzeichen des französischen Parteiensystems der Dritten Republik und insbesondere seines Mitte-Rechts-Spektrums, sich weniger in festen Strukturen als in relativ losen Verbänden und Parteiungen zu organisieren. In kleineren und mittleren Städten und auf dem Land setzten sich diese zumeist aus den örtlichen Honoratioren zusammen. Parteiorganisationen mit einer Basis und institutionellen Zwischenstufen fanden sich eher in stärker urbanisierten Räumen und bei der politischen Linken, zum Teil bei den Sozialisten und selbstverständlich bei den Kommunisten als Partei neuen Typs, in der der »Masse« eine klare Funktion zugewiesen war. Das Bekenntnis zum katholischen Glauben war ein konstituierendes Element des nationalkonservativen Milieus und seine Konfessionsschule die Spitze gegen die laizistische Republik, deren Lossagung von der katholischen Tradition Frankreichs ihr nicht verziehen wurde. In enger Verbindung mit dem örtlichen Klerus stehend, grenzte es sich kulturell gegen die aufstrebende Arbeiterschaft ab und formierte sich politisch in der konservativen Rechten.

Auch in Ivry bestand die Spitze der droite aus Notabeln wie Ärzten und Kaufleuten. Als Reaktion auf den Bedeutungsgewinn des PCF, den man hier

63 Ibid., S.164.

64 Wirsching, Weltkrieg, S. 149. 
zunächst als vorübergehendes Phänomen einschätzte, hatte Ivrys Bürgertum unter Federführung von Charles M. Guerder 1929 einen Freundeskreis gegründet ${ }^{65}$, der sich zwar um politische Belange kümmerte, in erster Linie aber auf gesellschaftlichen Überzeugungen fußte. Die Amis d'Ivry veranstalteten regelmäßig Konzerte, Bälle und Wahlen zur »Miss Ivry«, trafen sich aber auch zur Unterstützung der Spitzenkandidaten ihrer Wahlliste, des Arztes Perreau für den Stadtrat und Jean Jardels für die Deputiertenkammer. In der bürgerlichen Wochenzeitung »La Banlieue de Paris« bauten sie zudem ein oppositionelles Forum zur kommunistischen Leitlinie aus Georges Marranes Rathaus auf. Hier polemisierten die Amis d'Ivry - teils in offenen Briefen - gegen Georges Marrane und lokale PCF-Spitzen wie Hippolyte Marquès, Venise Gosnat oder Édouard Quincey ${ }^{66}$ und kritisierten ihre Methoden der lokalen Machterhaltung wie die Monopolisierung kommunaler Einrichtungen wie Sportstätten oder Versammlungssäle durch kommunale Angestellte und PCFMitglieder ${ }^{67}$.

Dennoch scheiterten verschiedene Versuche, erfolgreich ein politisches Gegengewicht aufzubauen und sich als konservative Sammlungspartei zu Ungunsten des PCF zu formieren. So organisierte das Comité des républicains nationaux d'Ivry im Juni 1933 eine Zusammenkunft, an der teilzunehmen alle Bürger Ivrys aufgerufen waren:

Le Comité des républicains nationaux d'Ivry qui regroupe en son sein des adhérents des tous les partis modérés, fait un pressant appel à tous les nationaux d'Ivry et leur demande de venir renforcer la section, qui mène, seule, la bataille pour les idées d'ordre et de bon sens ${ }^{68}$.

Bereits Monate vorher hatte Henri Guilhamon, der Meinungsführer der républicains nationaux in der »Banlieue de Paris«, die lokalpolitische Situation dahingehend analysiert, dass nur ein starker Zusammenhalt der nationalen Parteien einen Gegenpol zum kommunistischen Rathaus entwickeln könnte:

Certes, nous pensons aussi que chaque parti doit rester parfaitement autonome; mais nous pensons également qu'il ne serait pas inutile, en vue des batailles futures, de mettre dès maintenant en commun quelques-unes des idées maîtresses des partis d'ordre. Il ne faut pas se dissimuler, en effet, que si, au moment des élections, nous voulons bouter hors de chez nous le communisme, il faudra nécessairement opposer à l'adversaire une seule force, fournie par l'union des tous ceux qui ne se sentent pas murs pour la dictature bolcheviste. S'unir à la dernière heure est impossible; il n'est pas trop de plusieurs mois de discussions courtoises et franches pour arriver à une entente absolue entre tous les modérés, seul moyen de vaincre ${ }^{69}$.

Tatsächlich war der Zeitpunkt für eine effektive gemäßigt-rechte politische Gegenbewegung 1933 bereits verpasst, zu sehr hatte sich der PCF in der Stadt

65 La Banlieue de Paris, 17.3.1929.

66 Vgl. etwa den Artikel »Diable boiteux« in: La Banlieue de Paris, 30.6.1933.

${ }^{67}$ Ibid., 10.4.1936.

68 Ibid., 30.6.1933.

${ }^{69}$ Ibid., 6.1.1933. 
etabliert und seine Herrschaft auf solide Füße gestellt. Zwar gelang eine Kooperation zwischen den verschiedenen nationalen Gruppierungen, so dass bei den Stadtratswahlen von 1935 die unspezifisch benannte »rechte Liste « mit Jean Jardel als Gegenkandidat zu Georges Marrane an der Spitze aufgestellt werden konnte. Diese Wahlen im Mai 1935 mit 26 gewonnenen Rathäusern bedeuteten jedoch den endgültigen politischen Durchbruch des PCF als führende Partei in der roten banlieue, in der Ivry nach einem Jahrzehnt kommunistischer Herrschaft bereits eine Vorbildfunktion einnahm. Außerdem zeigte das Beispiel von Jacques Doriot in Saint-Denis, dass die persönliche Loyalitätsbindung an den Bürgermeister in den kommunistischen Vororten eine sehr wichtige Rolle spielte, hinter der die politische Bindung an die Partei gegebenenfalls zurücktrat ${ }^{70}$, so dass Jardel gegen den etablierten Marrane keine Chance hatte.

Das konservativ-katholische Milieu radikalisierte sich in den 1930er Jahren zunehmend in Abwehr der kommunistischen Hegemonie. Dabei war der Konflikt nicht auf die klassischen Arenen politischer Auseinandersetzung wie den Stadtrat begrenzt, sondern zog sich durch die sozialen Institutionen. Es ging letztendlich auch um die physische Vorherrschaft in Ivry und die Besetzung des Stadtgebietes mit den Ausdrucksformen kommunistischer kultureller Formation. Die kommunistische municipalité hatte sich seit der Gründung der Amis d'Ivry und der starken Polarisierung im Zuge der Februarereignisse von 1934 klar auf den politischen Gegner als Vorhut des Faschismus eingeschossen. Sie nahm die konservativen Einwohner Ivrys daher auch nicht als zu regierende Bürger wahr, sondern ging teilweise dazu über, sie aus dem öffentlichen Raum zu verdrängen. So wurden sie von den städtischen Sportstätten ohne Mitgliedschaft in den kommunistischen Sportorganisationen ausgeschlossen ${ }^{71}$, politische Veranstaltungen wurden von städtischen Abgesandten gestört, städtische Einrichtungen standen für Versammlungen oder Veranstaltungen der Amis d'Ivry nicht zur Verfügung72. Das Bürgertum außen vorlassend, richtete sich stattdessen das Interesse des kommunistischen Stadtrates ausschließlich auf Arbeiter, Arbeitslose und bedingt auf das Kleinbürgertum als Basis ihrer Herrschaft ${ }^{73}$. Die Ivryer Sektion der SFIO, welche

\footnotetext{
70 Jean-Paul Brunet, Jacques Doriot. Du communisme au fascisme, Paris 1986.

71 La Banlieue de Paris, 16.6.1933.

72 Die Veranstaltungen der Amis d'Ivry fanden in der Regel im Chaperon-Saal in Ivrys Hafenviertel statt.

${ }^{73}$ Insbesondere die Unterstützung der Arbeitslosen dominierte die städtischen Ausgaben. Rund ein Drittel bis die Hälfte des Budgets war für die unmittelbare finanzielle und materielle Hilfe vorgesehen. Der Stadtrat organisierte Kohle- und Nahrungsmittellieferungen, Volkssuppen, Verteilung von Kleidung, besonders an die Kinder, und kostenlose Arztbehandlung (Z. VAJDA, L'évolution contemporaine d'Ivry-sur-Seine, 1935). Die städtischen Subventionen von Vereinen gingen ebenfalls ausschließlich an Arbeiterorganisationen, so die Amicale des conscrits, die Union sportive du travail d'Ivry, die Amicale ouvrière d'Ivry, die Chorale ouvrière d'Ivry, das Kino Studio Germinal und die Union fraternelle des HBM d'Ivry (Stadtarchiv Ivry DCM, Sitzung vom 12. März 1931).
} 
als republiktreue, reformistische Partei eine vermittelnde Rolle hätte einnehmen können, wurde durch die Allianz eines Großteils der Einwohnerschaft mit dem kommunistischen Stadtrat innerhalb eines Jahrzehnts weitestgehend verdrängt. Die faktische Abwesenheit der radicaux als politische Formation in Ivry zeigte ebenfalls, dass es keine politische Pufferzone zwischen dem extrem linken Arbeitermilieu und der klassischen Rechten gab. Der im Rahmen der Volksfronttaktik eingeschlagene Versöhnungskurs des PCF mit der SFIO führte zwar auch im lokalen Rahmen zu einer Allianz - obwohl die Kommunisten vorherige Annäherungsversuche der Ivryer SFIO-Sektion rüde abgewiesen hatten - letztendlich konnte sie sich nicht durchsetzen, zumal der PCF die ersten Erfolge der Volksfront 1936 emotional und ideologisch für sich vereinnahmte.

Die größte innergesellschaftliche Konfliktlinie verlief in Ivry jedoch nicht, wie zu vermuten wäre, entlang der großen nationalen Fragen und Einstellungen zu der bedrohlich werdenden internationalen Lage, sondern konzentrierte sich auf die Auseinandersetzung zwischen Kirche und katholischem Milieu einerseits und kommunistischer Partei und antiklerikalem Milieu ${ }^{74}$ andererseits. Damit wurde der innerfranzösische Grundkonflikt, welcher 1905 mit der Trennung von Kirche und Staat zu einem vorläufigen Waffenstillstand geführt hatte, aber Frankreich weiterhin spaltete, im lokalen Rahmen repetiert. Während schon die traditionelle dörfliche Gemeinschaft dem Ortsgeistlichen misstrauisch gegenüberstand ${ }^{75}$ und die kommunistische Partei in der Vorstadt in sozialer Hinsicht die Rolle der ländlichen Großfamilie ${ }^{76}$ übernahm, fiel die Übertragung ländlicher Denkschemata hier besonders leicht. Ivrys Geistliche sahen sich so permanenten Beschimpfungen auf der Straße ausgesetzt und beklagten die »Gottlosigkeit der Kommunisten«, die sich etwa darin widerspiegelte, dass die Einschreibungen zu den städtischen Ferienkolonien am Sonntagmorgen zur Zeit der Messe stattfanden. Verschiedene Versuche der Rechristianisierung der katholischen Arbeiterfamilien durch Mission oder Einbindung der Kinder und Jugendlichen in die Kirchengemeinden scheiterten am - mitunter physischen - Widerstand der kommunistischen Mehrheitsgemeinschaft. Auf Schulhöfen und Straßen lieferten sich junge Katholiken und Kommunisten erbitterte Kämpfe. Ihre kulturelle Zugehörigkeit war durch den Kruxifixring respektive das Hammer-und-Sichel-Emblem gekennzeichnet ${ }^{77}$. Dass die physische Durchsetzungskraft und die PCF-Platzherrschaft bei Ivrys Jugend Erfolg hatten, zeigten die Mitgliederbewegungen bei den Jugendorganisationen. Die organisierte kommunistische Jugend verdreifachte sich vom Anfang der 1930er Jahre bis 1936 auf dreihundert Mitglieder ${ }^{78}$, eben-

74 Girault, L'implantation, S. 105.

75 WeBER, La fin, S. 513-516.

76 Ibid., Kapitel »Familie«, S. 248-281.

77 Downs, Municipal Communism, S. 215.

78 Avant-garde, Le journal des jeunes, 8.2.1936. 
so musste eine zweite Betreuungsgruppe des Patronage laïque aufgemacht werden, weil immer mehr Kinder an den Aktivitäten teilnahmen ${ }^{79}$. Auch in der Frage der Konkurrenz der laizistisch-republikanischen Schule mit der klerikal geprägten école privée unterlag Letztere im Arbeitermilieu gegenüber dem gebührenfreien enseignement primaire der öffentlichen Schulen. So verfügten Ivrys Kirchengemeinden 1938 nur noch über zwei Schulen, die École Jeanne-d'Arc für Mädchen in der Rue de Paris und die École Saint-Michel für die Jungen an der Place de la République ${ }^{80}$. Drei Jahre zuvor hatte es noch zwei Jungen- und fünf Mädchenschulen gegeben, allerdings wurde schon zu diesem Zeitpunkt über die geringe Schülerzahl geklagt ${ }^{81}$.

Unter den Erwachsenen wütete der Konflikt eher verbal, war in seiner Wirkung jedoch genauso vehement wie die Schulhofkämpfe unter den Jungen, denn hier standen sich die lokale kommunistische Elite und der örtliche Klerus gegenüber. Bürgermeister Georges Marrane beraumte 1935 eine öffentliche Diskussion mit einem der drei örtlichen Priester, Abbé Garin, an, um mit ihm über das Thema »Kommunismus gegen Religion« zu streiten ${ }^{82}$. Parallel formierte sich ein Komitee der travailleurs sans dieu. Marranes Sprechstunden in einem der HBM-Komplexe fanden wiederum während der Sonntagsmesse statt ${ }^{83}$. Offensichtlich waren Provokation und Konfrontation ein übliches Kommunikationsmittel. Im September 1936 wandte sich einer der drei Priester direkt an den Abgeordneten Maurice Thorez und beschwerte sich, dass er erst über einen Plakataushang von einem Basketballspiel zwischen dem kommunistischen, von Marrane gegründeten Sportclub Étoile sportive du travail d'Ivry ${ }^{84}$ und dem Sporting Club chrétien erfahren und seiner Mannschaft untersagt habe, daran teilzunehmen. Er wehre sich damit gegen die Gewerkschaft CGT, zu deren Unterstützung dieser Sporttag durchgeführt werden solle, da sie in formeller Opposition zur Sozialdoktrin der Kirche stehe. Außerdem werte er diesen sportlichen Wettbewerb als Propaganda und wende sich direkt an Thorez »afin de dissiper toute équivoque, et d'éviter qu'à cette annonce publicitaire soit donné un commentaire qu'elle ne comporte pas $\ll^{85}$.

Zeigte sich hier also nur ein klassischer Konflikt in neuem Gewande oder hatte die Auseinandersetzung mit den Katholiken Konsequenzen für die Formierung und Konsolidierung des kommunistischen Milieus? Im Arbeitermilieu der Vorstädte herrschte eine laizistische Grundhaltung vor. Anderer-

79 Stadtarchiv Ivry, Loseblattsammlung von Michèle Rault, Archivleiterin, ohne Signatur.

80 Downs, Municipal Communism, S.215.

81 VAJDA, L'évolution, 1935, S. 17.

82 Downs, Municipal Communism, S. 216.

83 Le Travailleur de la banlieue sud, 5.10.1935.

84 APP, GA M2, Dossier Georges Marrane.

85 Stadtarchiv Ivry, Loseblattsammlung von Michèle Rault, Archivleiterin, Brief an Maurice Thorez vom 18.9.1936, ohne Signatur. 
seits waren viele Neubürger noch in der ländlichen Gesellschaft sozialisiert worden und hatten deren Denkmuster zum Teil in die Vorstadt mitgenommen. Die Funktion des Konflikts mit dem konservativ-katholischen Milieu lag wohl vor allem in der Sichtbarwerdung der Werte der kommunistischen Gemeinschaft. Denn diese versuchte, sich in allen Lebensbereichen von der ländlich-katholischen Welt abzugrenzen und dem städtischen Kommunismus zu einer klareren Identität zu verhelfen. Obwohl es in den 1930er Jahren noch Widerstand und Opposition gegen die kommunistische Hegemonie gab, befand sich Frankreichs kommunistische Partei im Einklang mit der Arbeiterschaft der Vorstädte und mit der Erfindung der Volksfront und dem altruistischen Kampf gegen Faschismus und Krieg auf dem Weg zu ihren größten politischen Erfolgen.

\subsubsection{Ivrys Weg in die Volksfront}

Nach der Etablierung des PCF als dominierende Milieupartei in ihren frühen Hochburgen Saint-Denis, Bobigny, Drancy, Vitry und Ivry-sur-Seine und trotz einer gewissen Abschwächung ihrer Schlagkraft nach dem Einschlagen der ultralinken Taktik »Klasse gegen Klasse « zeichnete sich eine Konkurrenzsituation zwischen kommunistisch regierten Vorstädten und der Parteiführung ab. Während sich in den municipalités communistes ein städtisches Eigenleben entwickelt hatte und die Parteibasis versuchte, ihre sozialen Probleme im Rahmen der lokalpolitischen Möglichkeiten zu lösen, konzentrierte sich das Politbüro weitestgehend auf den Parteiapparat - auch im internationalen $\mathrm{Zu}$ sammenhang - und orientierte sich zunehmend an Richtlinien, die sie direkt aus Moskau erhielt ${ }^{86}$. Dies machte die insgesamt in der kommunistischen Weltbewegung zu konstatierende Stalinisierung auch im französischen Kontext bemerkbar ${ }^{87}$. Die Konzentration auf die inneren Kräfte der Partei, ihre Radikalisierung und die damit verbundene Absonderung von anderen politischen und gesellschaftlichen Strömungen, wie sie unter den besonderen wirtschaftlichen und topographischen Bedingungen der Pariser Vororte deutlich hervorgetreten waren, veränderten sich erst nachdrücklich unter dem Eindruck der nationalsozialistischen Machtübernahme in Deutschland. Die sich verfestigende außenpolitische Isolierung der Sowjetunion und die bürgerkriegsähnliche Situation in Paris im Februar 1934 zwangen Stalin zu einem doppelten Strategiewechsel: Zum einen wurde der PCF nach der Zerschlagung der KPD zum wichtigsten Verbündeten in den Ländern Westeuropas,

86 Vgl. Annie Kriegel, Stéphane Courtors, Eugen Fried. Le grand secret du PCF, Paris 1997.

87 In der zeitgenössischen Berichterstattung der republikanischen »Banlieue de Paris« findet sich durchgängig der Vorwurf an die kommunistischen Stadtverwaltungen, »moscovite « zu sein, sich also nach den Vorgaben der Parteizentrale in Moskau zu richten. Interessanterweise wurde das Adjektiv »bolchevique« deutlich seltener in dieser Wochenzeitung gebraucht. 
zum anderen hatte das deutsche Beispiel die Konsequenzen einer Spaltung der Arbeiterbewegung klar vor Augen geführt, so dass eine Antwort darauf nur in einem Versöhnungskurs mit den Sozialdemokraten liegen konnte. Tatsächlich änderte der PCF seine Strategie im Juni 1934 nachhaltig. Er setzte fortan auf die Verbrüderung mit den Sozialisten und versuchte im Bündnis mit ihnen und den republiktreuen Radikalen eine Volksfront aufzubauen, die sich gegen die »faschistische« Bedrohung von außen, repräsentiert von den rechtsextremen Staatschefs Mussolini in Italien, Hitler in Deutschland und bald General Franco, und innen, hier insbesondere durch die rechtsextremen Croix-de-Feu unter Oberst de La Rocque, richtete.

Die strategische Wende des PCF wurde im Juni 1934 auf dem Parteikongress in Ivry vollzogen, nachdem Maurice Thorez noch während des Parteitags ein Telegramm von Stalin erhalten hatte. François Furet hat in seiner Interpretation des französischen Kommunismus diese Änderung der Parteistrategie und ihre innen- und außenpolitischen Implikationen als weichenstellend für die zukünftige Entwicklung der gesamten französischen Linken erklärt. Danach akzelerierte der Aufstieg des Nationalsozialismus in Deutschland nicht nur den engen Schulterschluss des französischen Kommunismus mit der Sowjetunion, sondern wirkte integrierend auf die gesamte Linke im Abwehrkampf gegen den Faschismus. Die Intensität der Ereignisse und die ihnen zugeordnete existentielle Bedeutung vermittelten einen Wertekanon, der insgesamt zu einer klaren und langfristigen Spaltung zwischen beiden politischen Lagern führte:

La violence des nazis et la stratégie du Front populaire décidée à Moscou ont polarisé le rapport droite/gauche autour du fascisme et du communisme: période capitale dans l'histoire politique contemporaine, car elle cristallise pour longtemps les sentiments et les idées $^{88}$.

Für unseren Forschungszusammenhang ist es wichtig zu klären, wie sich die Umsetzung der Parteistrategie auf der lokalen Ebene gestaltete und zu welchen Konsequenzen für die Identität in Ivrys Arbeitermilieu diese Verschiebung der Konfliktlinien führte. Prägte sie wirklich die Mentalität der Vorstadt nachhaltig? Entstanden in dieser Periode langfristige Verhaltensmuster, die das Verhältnis zum innenpolitischen Gegner und die internationalen Kontakte der Stadtgemeinschaft dauerhaft bestimmen sollten? Waren die Änderung der Parteistrategie und der Einfluss der Ideologie auch an der Basis so wichtig oder leitete sich das Selbstverständnis der Vorstadtbewohner auch aus anderen Faktoren ab? Lassen sich diese angenommenen mentalen Dispositionen an Handlungen ablesen und so methodisch erfassen? Diese kollektiven Erfahrungen der Stadtgemeinschaft in den 1930er Jahren sind für den Forschungszusammenhang der Erinnerungskultur vor allem deshalb von Bedeutung, weil sie den Erlebnishorizont der Gründer- und Aufbaugeneration

88 Furet, Le passé, S. 310. 
des städtischen Kommunismus in Ivry in einer Phase dokumentieren, in der sich das Milieu verfestigt hatte und gleichzeitig die Sinnausrichtung der Stadtgemeinschaft ihre Grundformierung annahm. Die innen- und außenpolitische Ereignisdichte der Zwischenkriegszeit sorgte dafür, dass dieser kurze Zeitraum der 1930er Jahre emotional sehr stark aufgeladen wurde und der französische Kommunismus mit Fragestellungen konfrontiert wurde, die seinen Charakter und Wertekanon langfristig prägen sollten. Die große Emotionalität, mit der diese Periode von den jungen Kommunisten in der Vorstadt gelebt wurde, markierte die Ereignisse der Zeit im individuellen wie kollektiven Gedächtnis und konnte so später leichter erinnert werden ${ }^{89}$. Euphorie und Aktionismus der Jahre 1934-1936/37 verbanden Gefühle und Erlebnisse und verdichteten die Stadtgemeinschaften durch die gemeinsamen Erfahrungen.

Bis zur politischen Etablierung der Volksfrontregierung und ihrem mehr oder weniger gescheiterten Versuch, zwischen Arbeitnehmern und Patronat $\mathrm{zu}$ vermitteln ${ }^{90}$, hatte sich schubweise erhebliches ökonomisches und politisches Konfliktpotential in der französischen Hauptstadt und ihren Vorstädten aufgebaut. Dieses reichte von der krisenhaften Entwicklung der Arbeitnehmerbeziehungen bis zur zunehmenden Bedrohung der politischen Stabilität durch die links- und rechtsextremen Bewegungen. Das Jahrzehnt nach Kriegsende war zunächst noch von wirtschaftlicher Konsolidierung unter erheblichem Rückgriff auf ausländische Arbeitskräfte gekennzeichnet. Nun führte der außenwirtschaftliche Druck durch die Gläubigerstaaten des Ersten Weltkrieges zu regelmäßigen Devaluationen des französischen Franc, heizte die inländische Währungsspekulation an und verschärfte die ökonomische Kri$\mathrm{se}^{91}$. In der lohnabhängigen, ohnehin von steigender Arbeitslosigkeit betroffenen Arbeiterschaft verursachte sie erhebliche Kaufkraftverluste.

In der industriell geprägten Pariser banlieue schlug sich diese Entwicklung besonders deutlich nieder. So stieg in Ivry die Zahl der Arbeitlosen von einigen hundert im Jahr 1930 kontinuierlich bis auf 2909 im Jahr 1935 an. Seit 1925 schrieb ein Gesetz vor, dass Gemeinden mit über 10000 Einwohnern ein bureau de placement einzurichten hatten. In den Hochzeiten der Ivryer Arbeitslosigkeit konnten trotz der städtischen Vermittlungsversuche jedoch nur wenige Arbeiter vermittelt werden. 1935 und 1936 waren es jeweils weniger als zweihundert ${ }^{92}$. Demgegenüber entließen Ivrys führende Industriebetriebe massenweise Personal, so der Schuhhersteller United Shoes Machinery Compagny de France, der 1926 noch 600 Arbeiter beschäftigte und dann sukzessive von 320 (1930) auf 200 (1932) reduzierte, um 1934 bei 160 anzukommen.

89 Assmann, Gedächtnis, S.39.

90 Jean-Paul Brunet, Histoire du Front populaire, Paris 1991, S. 79 f.

91 Borne, Dubief, La crise, S. 26, 33.

92 Stadtarchiv Ivry, Office départemental du placement et de la statistique du travail de la Seine et l'organisation des secours de chômage, Loseblattsammlung von Michèle Rault, Archivleiterin, ohne Signatur. 
Die Svenska Kullager Fabriken (SKF), ebenfalls einer der wichtigsten Arbeitgeber von Ivry, hatte 1927 noch 3000 Arbeiter, 1935 waren es lediglich 700; parallele Entwicklungen gab es bei der Compagnie des lampes und bei Lemoine. Weitere Fabriken wie die Automobilzulieferer Brasier und Ducellier, der Eisenbahnzulieferer Société française de matériel de chemin de fer und der Werkzeugmaschinenbauer Ernault hatten ihre Werke, in denen einige Jahre zuvor noch rund 1800 Arbeiter beschäftigt gewesen waren, 1935 ganz geschlossen. Gleichzeitig sackte das Lohnniveau für die verbliebene Arbeiterschaft in Ivry um bis zu 40 Prozent $\mathrm{ab}^{93}$.

Beide Phänomene hingen eng miteinander zusammen. So ergab sich gerade bei den niedriger qualifizierten Beschäftigten der Industriearbeiterschaft aufgrund der steigenden Arbeitslosigkeit erhebliche Konkurrenz um die verbleibenden Arbeitsplätze. Um dennoch ein finanzielles Auskommen zu haben, waren daher viele Arbeitssuchende bereit, auch gering bezahlte oder gelegentliche Arbeit anzunehmen. Für das relative Unvermögen, dem Arbeitslosenphänomen effektiv zu begegnen, war zudem der geringe Grad gewerkschaftlicher Organisation der französischen Arbeiterschaft verantwortlich, der eine abgesprochene Vorgehensweise gegenüber den Arbeitgebern verhinderte. Die Forderungen der Arbeiter artikulierten sich daher in der Regel in wilden Streiks, die die erste Hälfte der 1930er Jahre kennzeichneten und regelmäßig zu einer Niederlage der schwächer aufgestellten Industriearbeiter führten, obwohl auch die Unternehmer über keine ausgearbeitete Strategie im Arbeitskampf verfügten und ebenfalls kaum organisiert waren ${ }^{94}$. Stattdessen reagierten viele Fabrikbesitzer bei Arbeitsausständen mit Aussperrungen. Eine sehr übliche Form des Umgangs mit Streikenden - und dies erklärt den Einbruch bei den Löhnen - war die massenhafte Entlassung von Streikteilnehmern, die nach Beendigung des Streiks zu niedrigeren Löhnen wieder eingestellt wurden ${ }^{95}$. Angesichts der schwierigen außenwirtschaftlichen Situation, der Inflation und der angespannten Situation auf dem Arbeitsmarkt, die ebenfalls auf die Kaufkraft der Lohnabhängigen drückte, wurde auch in Ivry die Forderung nach Lohnerhöhung zentrales Anliegen der immer wieder auftretenden Streiks in einzelnen Betrieben ${ }^{96}$. Trotz vereinzelt ausgehandelter Erfolge wie Stundenlohnerhöhungen um 0,10 bis 0,50 Francs waren generell die Streiks in der Pariser Region von Niederlagen gekennzeichnet und verstärkten das Gefühl von Ohnmacht und Exklusion in den betroffenen sozialen Schichten. Ivrys kommunistischer Stadtrat bemühte sich indes weiter um die Unterstützung der von Erwerbslosigkeit betroffenen Familien. So wurde nicht nur finanzielle Unterstützung gewährleistet, es folgten

93 So in der Fabrik Lemoine in dem Zeitraum von 1928 bis 1935 (VAJdA, L'évolution, S.5).

94 Borne, Dubief, La crise, S. 155.

95 Ibid., S. 37-40.

96 Stadtarchiv Ivry, Statistiques des grèves, ministère du Travail, 1933, Loseblattsammlung von Michèle Rault, Archivleiterin, ohne Signatur. 
auch regelmäßig Spendenaufrufe und Kleidersammlungen; die Familien erhielten außerdem Kohlelieferungen, die Kinder kostenlose Schulspeisungen, und es gab »Volkssuppe « für die übrigen Betroffenen. 1935 ging bereits über ein Drittel des städtischen Budgets an Hilfeleistungen für die Arbeitslosen.

Die Verschärfung der wirtschaftlichen Situation und die Radikalisierung der politischen Extreme erhöhten generell den Hang zu physischen Auseinandersetzungen und offenem Austragen von Konflikten in den Fabriken, in den Straßen von Paris und den Vororten. Während das etablierte politische System der Dritten Republik nach dem Sturz von Laval 1932 weiterhin kriselte, bot dies dem PCF in seinen banlieue-Hochburgen die Gelegenheit, seine Kampfbereitschaft zu unterstreichen und die Mobilisierbarkeit seiner Anhängerschaft unter Beweis zu stellen. Als besonders vorteilhaft erwies sich dabei die Disziplinierung der Partei nach leninistischem Vorbild, die ihre Durchschlagskraft im Vergleich zu den traditionellen Honoratiorenparteien auf der Straße erheblich erhöhte und ihr äußeres Erscheinungsbild über Jahrzehnte prägen sollte ${ }^{97}$. Die Bolschewisierung des PCF implizierte das bewusste $\mathrm{Zu}$ rückdrängen von Bürgerlichkeit aus der Partei, die seit Mitte der 1920er Jahre darauf drängte, wichtige Positionen im Politbüro, aber auch im wachsenden Parteiapparat ausschließlich mit Arbeitern zu besetzen, so dass sich der PCF in dieser Phase durch eine große Homogenität sowohl der Mitgliedschaft als auch der Parteispitze auszeichnete. Die etwas später einsetzende Stalinisierung führte nicht nur zur verstärkten Ausrichtung auf die Moskauer Parteizentrale, sondern vor allem zur Durchsetzung des Führerprinzips, welches ein »Durchregieren« der Partei von oben nach unten möglich machte und direkte Auswirkungen auf die hier zu untersuchende Parteibasis hatte. Mit diesen Organisationsprinzipien unterschied sich der PCF in den 1930er Jahren grundlegend von den demokratischen Parteien wie der SFIO oder den Radikalen.

Zu Beginn der 1930er Jahre hatte sich der PCF zwar national ins politische Abseits begeben, doch verfügte er mit seiner Vielzahl an Vorfeldorganisationen wie der Association républicaine des anciens combattants (ARAC), der Internationalen Roten Hilfe, der Fédération sportive du travail, aber auch der kommunistischen Tageszeitung »L'Humanité«, welche auch bei Nichtkommunisten Verbreitung fand, über einen hohen Organisationsgrad gerade in der banlieue. ${ }^{98}$ 1932 hatten die einflussreichen kommunistischen Intellektuellen Henri Barbusse und Romain Rolland die Bewegung Amsterdam-Pleyel gegründet, mit der man versuchte, im Pariser Intellektuellenmilieu Fuß zu fassen ${ }^{99}$ und die

97 Courtois, Lazar, Histoire, S. 90f.

98 Borne, Dubief, La crise, S. 89.

$99 \mathrm{Zu}$ den wichtigsten Anhängern des PCF in den 1920er Jahren gehörte die Gruppe der Surrealisten um André Breton, die im Gegensatz zu vielen Sympathisanten im intellektuellen Milieu 1927 tatsächlich die Entscheidung traf, der kommunistischen Partei beizutreten. 1930 stellten sich die Surrealisten in Paris explizit in den Dienst der Sowjetunion, nachdem die lange Diskussion um Henri Barbusse, wie Literatur der Revolution dienen könne, beigelegt war (Michel Winock, Le siècle des intellectuels, Paris 1997, S.212-217). 
»Kulturarbeiter« zum Engagement für den Weltfrieden und gegen den Krieg zu animieren ${ }^{100}$. Hinter dem Einsatz für diese abstrakten Ziele standen die Beauftragten der Kommunistischen Internationale, darunter der Deutsche Willi Münzenberg, welche im Auftrag des Moskauer Exekutivkomitees die Idee unter der westeuropäischen Bevölkerung propagieren sollte, dass die Sowjetunion friedliebend und als Hort des welthistorischen Fortschritts um jeden Preis zu verteidigen sei ${ }^{101}$. Wichtig für die Wirkungsgeschichte dieser Propagandatätigkeit war, dass das Junktim Frieden gleich Verteidigung des »Vaterlandes des Sozialismus«, sprich der Sowjetunion, plausibel kommuniziert worden war und auch bei nichtkommunistischen Intellektuellen mit humanistischem oder pazifistischem Hintergrund breiten Anklang fand und den mangelnden Einfluss des PCF auf die Masse der Bevölkerung kompensierte ${ }^{102}$.

Auf der anderen Seite verdeutlichte die Präsenz von Abgesandten des Exekutivkomitees der Kommunistischen Internationale (EKKI) auf französischem Staatsgebiet die wachsende Vernetzung der internationalen kommunistischen Bewegung und die zunehmende Machtkonzentration und Zentralisierung in Moskau. Insbesondere nach dem Aufstieg von Stalins Protegé Maurice Thorez zum Generalsekretär 1930 wuchs der sowjetische Einfluss auf die französische Bewegung beträchtlich. Dies lag aber auch daran, dass mit dem Aufstieg Dimitri Manuilskis in der Moskauer Zentrale ein Vertrauter Stalins an die Macht gekommen war, der sich persönlich um einen ständigen Austausch mit Paris - Briefe, Direktiven, Berichte - kümmerte und Thorez so direkt kontrollierte. Anfang 1931 betrat der Slowake und Komintern-Gesandte Eugen Fried die Pariser Bildfläche und trat als externer Berater in den inneren Kreis von Maurice Thorez und seiner Frau Jeannette Vermeersch ein ${ }^{103}$.

Die Vernetzung der westeuropäischen und deutschen kommunistischen Bewegung verstärkte sich noch einmal nach der Machtübernahme Hitlers im Januar 1933, als vermutlich über 4000 deutsche Kommunisten vor der nationalsozialistischen Verfolgung nach Frankreich flohen. Neben den einfachen Parteimitgliedern, deren physische Existenz dort zwar zunächst gesichert war, aber angesichts der wirtschaftlichen und sprachlichen Schwierigkeiten auf sehr wackligen Füßen stand ${ }^{104}$, floh auch die deutsche Parteiführung nach $\mathrm{Pa}$ ris und tauchte dort unter. $\mathrm{Zu}$ den Politbüromitgliedern der KPD zählte auch der Lothringer Franz Dahlem, der aufgrund seiner Zweisprachigkeit am besten die Funktion eines Verbindungsmannes zwischen deutschen und französischen Kommunisten einnehmen konnte. Zudem hatte auch die Moskauer Führung Interesse daran, die deutschen Emigranten zu unterstützen, um mit Hilfe der französischen Partei den Widerstand in Deutschland gegen den

100 WinOcK, Le siècle, S. 246.

101 Ibid., S. 229.

102 Courtois, Lazar, Histoire, S. 113.

103 Ibid., S. 102-108.

104 Julia Franke, Paris - eine neue Heimat? Jüdische Emigranten aus Deutschland 19331939, Berlin 2000, S.23f. 
Nationalsozialismus aufrechtzuerhalten. Neben der Hilfestellung, die einfache Mitglieder unter Umständen von den schnell ins Leben gerufenen Hilfekomitees in Paris und Umgebung erfahren konnten ${ }^{105}$, wurden Franz Dahlem und seine Frau Catherine Dahlem direkt von Maurice Thorez geschützt, der sie in Ivry zunächst in dem neuen Wohnblock an der Place Philibert-Pompée, später - bis zu Dahlems Internierung 1940 - in der Rue Marat unterbrachte ${ }^{106}$. Der PCF hatte angesichts steigender Emigrantenzahlen, die teils aus politischen, teils aus wirtschaftlichen Gründen vor allem aus Polen und Italien ${ }^{107}$ nach Frankreich strömten, 1925 eine Unterorganisation, die Main-d'œuvre étrangère (MOE) gegründet, welche die Flüchtlinge in die Partei integrieren und politisch verfügbar halten sollten ${ }^{108}$. Nachdem Deutschland ebenfalls in rechtsextreme Hand geraten war und die Sozialfaschismusthese der KPD sie in die größte Existenzkrise ihrer Geschichte geführt hatte, geriet auch die ultralinke »Klasse gegen Klasse«-Taktik des PCF unter Plausibilitätsdruck und führte zur Etablierung neuer innerfranzösischer Bedrohungsszenarien ${ }^{109}$.

Der 6. Februar 1934 wurde in diesem Zusammenhang für die französische Linke zu einem Schlüsselerlebnis. Denn er bediente die Vorstellung eines unmittelbar bevorstehenden rechtsextremen Umsturzes und evozierte so ein versöhnendes Zugehen des PCF auf die Sozialisten, um die Republik und damit letztendlich auch das parlamentarische Regierungssystem zu verteidigen, dessen Vorteile man bereits im lokalen Zusammenhang zu schätzen gelernt hatte und für die Durchsetzung politischer Ziele nutzte. Zugleich stützte der 6. Februar die politische Imagination der extremen Linken, die sich durch die Ereignisse als kämpferische, revolutionäre und zugleich defensive Masse selbst entdeckte und neu definierte. In Teilen der französischen Bevölkerung war nach der Stavisky-Affäre und der generellen Instabilität der Kabinette Anfang der 1930er Jahre der Glaube an die Effizienz und Legitimität des parlamentarischen Systems aufgebraucht. Die Bereitschaft stieg, mit außerparlamentarischen Alternativen zu liebäugeln. Der Weg hierzu schien frei zu sein, denn der Pariser Polizeipräfekt Jean Chiappe, welcher in seiner Amtszeit Zusammenstöße auf der Straße verhindert hatte, war kurz zuvor abgesetzt worden. Die Pariser classes moyennes empfanden dies als Entzug >ihres< Präfekten, der sie vor den Kommunisten in der banlieue geschützt und in der Tat in diesen sieben Jahren große Zwischenfälle in Paris verhindert hatte. Trotz ei-

\footnotetext{
105 Ibid.

106 Vgl. Autobiographie von Franz Dahlem, Am Vorabend des Zweiten Weltkriegs, Berlin (Ost) 1977, S. 144-158. u. 353ff.

107 Zwischen 1921 und 1926 wanderten rund 1,5 Mio. Italiener und 1931 über 500000 Polen nach Frankreich ein, das bis zu diesem Zeitpunkt insgesamt rund 3 Mio. Immigranten aufgenommen hatte. Dies geschah nicht zuletzt, um den ungemeinen Verlust an männlichen Arbeitskräften durch den Ersten Weltkrieg aufzufangen (Courtois, Peschanski, RAYSKI, L'Affiche rouge, S.13).

108 Ibid., S. 19.

109 WirSCHING, Weltkrieg, S. 575-580.
} 
nes generellen Demonstrationsverbots nahmen der Druck der Straße und der Kampf um die Platzherrschaft in Paris schon während des Januarmonats zu. Zwar konnte zwei Tage zuvor noch eine systemoppositionelle Demonstration der Rechtsextremen verhindert werden, am 6.Februar 1934 jedoch stießen rechts- und linksextreme Verbände ${ }^{110}$ vor der Deputiertenkammer auf der Place de la Concorde in Paris gewaltsam aufeinander.

Die Ereignisse des Februar 1934 verlagerten den Ort der politischen Auseinandersetzung vom Parlament auf die Straßen von Paris. Zugleich forcierten sie die Selbstwahrnehmung der Pariser Bürger intra muros als vor dem Kommunismus zu schützende Mittel- und Oberklasse. Andreas Wirsching betont in seiner Studie über den politischen Extremismus in Paris die Bedeutung der lokalen Umstände, die zum 6. Februar geführt hatten. Er unterstreicht insbesondere den »Klassencharakter « des Pariser Stadtrats, der sich aus je vier Vertretern der zwanzig Stadtbezirke ohne Rücksicht auf deren Bevölkerungsdichte zusammensetzte, so dass insgesamt das etablierte Groß- und mittlere Bürgertum überrepräsentiert war, während die quartiers populaires nur unzureichendes Gehör in der Stadtversammlung fanden ${ }^{111}$. Unter diesem Gesichtspunkt lässt sich der 6. Februar auch als die Eroberung der Pariser Straßen durch die Massen aus der banlieue interpretieren. Denn es war charakteristisch für die Jahre 1934-1936, dass öffentliche Kundgebungen generell erheblich anstiegen. Danielle Tartakowsky hat in ihrer Studie über die »stratégies de la rue « die Zahl der politischen Demonstrationen, Versammlungen und Märsche für ganz Frankreich auf über tausend beziffert ${ }^{112}$. Während diese zu 87 Prozent von den Linksparteien organisiert wurden, stellte Paris eine absolute Ausnahme dar. Hier war die Verteilung von linken und rechten Demonstrationen ungefähr gleich; kommunistische Demonstrationen fanden vor allem in den Außenbezirken statt. Das physische Aufeinandertreffen beider politischen Strömungen, wie es am 6. Februar auf der Place de la Concorde geschehen war, stellte daher eine Ausnahme dar. Vielmehr besetzten rechte Verbände den öffentlichen Raum in der Stadtmitte und orientierten sich die Rue de Rivoli an der Jeanne d'Arc-Statue entlang Richtung Place de la Con-

110 Auf dem Platz gegenüber der Deputiertenkammer hatten sich auf der rechten Seite die Union nationale des combattants (UNC), die Solidarité française, die Jeunesses patriotes und die Camelots du roi und auf der linken Seite die kommunistische Association républicaine des anciens combattants (ARAC) versammelt. Gleichzeitig rückte die rechtsextreme Liga der Croix-de-Feu, aus dem Faubourg Saint-Germain kommend, auf den Sitz der Deputiertenkammer vor. Sie konnte zwar auf der vorliegenden Seine-Brücke von den mobilen Garden verteidigt werden, dennoch waren insgesamt 15 Tote und über 2000 Verletzte zu beklagen. Die Tatsache, dass es zu keinem rechtsextremen Umsturz, zumindest aber keinem weiteren Blutvergießen kam, war vor allem darauf zurückzuführen, dass der Oberst de La Rocque, seine Truppen der Croix-de-Feu von einem weiteren Vorrücken auf die Deputiertenkammer abhielt.

111 Wirsching, Weltkrieg, S. 471f.

112 Danielle Tartakowsky, Stratégies de la rue, 1934-1936, in: Le Mouvement social 135 (1986), S.31-62. 
corde, um dann die Champs-Élysées hoch bis zum Arc de Triomphe zu marschieren. Die Linke versammelte sich tendenziell im Osten der Stadt und demonstrierte von der Place de la Nation zur Place de la Bastille. Kommunisten und Sozialisten vereinnahmten mit dem mur des Fédérés ohnehin seit 1935 gemeinsam den Erinnerungsort auf dem Friedhof Père-Lachaise ${ }^{113}$.

Auch Ivrys Kommunisten waren intensiv an den Demonstrationen in Paris und der banlieue beteiligt und stießen dabei immer wieder mit dem Präfekten zusammen, was die oppositionellen Amis d'Ivry zu dem ironischen Kommentar veranlasste, Jean Chiappe sei ein exzellenter Freund Georges Marranes ${ }^{114}$. Im Dezember 1933 war noch ein Sternmarsch aus Vorortgemeinden wie Maisons-Laffitte im Westen, Malakoff und Villejuif im Süden sowie Ivry und Vitry im Südwesten nach Saint-Denis verboten worden, der eigentlich »les forces vives du prolétariat parisien« zusammenführen sollte ${ }^{115}$. Unter dem Eindruck des 6. Februar gewann die kommunistische Bewegung in Ivry jedoch wieder an Fahrt. Um die Partizipation möglichst vieler Genossen an der Demonstration in Paris zu gewährleisten, hatte die Stadtverwaltung von Ivry Omnibusse zur Verfügung gestellt, die den Transport der Demonstranten vom Rathaus nach Paris übernahmen. Die bis dahin stagnierenden Mitgliederzahlen gewannen in der Folgezeit wieder an Dynamik.

Als wichtigste Innovation ging aus der Februarbewegung in Ivry im März 1934 das 400 Mitglieder starke Lokalkomitee zum Kampf gegen Krieg und Faschismus hervor, in dem sich PCF, kommunistische Jugend, der Veteranenverband, der Mieterverein der HBM, die kommunistisch orientierte Gewerkschaft CGTU, aber auch 45 Prozent parteiungebundene Personen zusammengefunden hatten ${ }^{116}$. Parallel dazu wandte sich die lokale Sektion der SFIO in einem offenen Brief an den PCF und schlug die Bildung eines gemeinsamen antifaschistischen Komitees vor:

Chers camarades, la section socialiste d'Ivry rappelle les graves évènements des dernières semaines, où les dangers des mouvements profascistes sont apparus à tous. La section socialiste d'Ivry vous propose la constitution d'un comité de vigilance [..., qui] aurait pour tâche d'organiser sur le plan local la lutte contre le fascisme ${ }^{117}$.

113 Wirsching, Weltkrieg, Kapitel »Politische Liturgie: der politische Extremismus und seine Traditionen «, besonders S.333-348.

114 La Banlieue de Paris, 30.6.1933.

115 AN F7 13565, 1.12.1933 u. 2.12.1933.

116 Le Travailleur, 17.3.1934.

117 Der Parti d'unité prolétarienne (PUP) hatte sich in der Pariser Region sowie in den Mittelmeergebieten in der ersten Hälfte der 1930er Jahre in der Arbeiterschaft zur Konkurrentin des sektiererischen PCF entwickelt. Die "pupistes« traten in dieser Zeit bei den Stadtratswahlen in Ivry an, hatten sich also auch im lokalen linken Parteienspektrum etablieren können, blieben an Stimmen aber weit hinter dem Erfolg des PCF zurück. Im Januar 1935 machte die Ivryer Sektion der PUP dem PCF das Angebot einer gemeinsamen Wahlliste, das dieser aber klar zurückwies: »Les communistes d'Ivry [...] estiment que l'importance des élections municipales de 1935 nécessite que chaque parti se présente à la population laborieuse avec son programme et ses solutions « (Le Travailleur de la banlieue sud, 19. Januar 1935). 
Obwohl zumeist die abrupte Änderung der kommunistischen Taktik von »Klasse gegen Klasse « auf »Volksfront « betont und der Beginn des Einlenkens Thorez' auf den 30. Mai 1934 und den nachfolgenden Monat datiert wird $^{118}$, verschwammen diese Grenzen in Ivry. So betonte die lokale Sektion des PCF in ihrem ebenfalls offenen Antwortbrief vom März 1934, dass man zwar schon selbst ein Komitee gegen Krieg und Faschismus gegründet habe und daher die Notwendigkeit einer weiteren Vereinigung nicht sehen würde, man aber grundsätzlich bereit sei, auf lokaler Ebene mit der SFIO zusammenzuarbeiten, wenn diese eine konkrete Aktion plane: „Néanmoins, si votre comité de vigilance a une base d'action concrète, nous sommes prêts à lutter, et nous ébauchons même ici le petit programme d'action locale «119. Obwohl zunächst sozialpolitische Forderungen wie die Übernahme der kompletten Kosten für die Sozialversicherung durch die Arbeitgeber und den Staat erhoben wurden, konkretisierte sich dann die Beschreibung des »antifaschistischen Kampfes« vor Ort. So sollte faschistischen Organisationen jegliche Öffentlichkeit genommen, Plakate sofort entfernt und ihren Vertretern jede Möglichkeit verwehrt werden, in Ivry öffentlich das Wort zu ergreifen ${ }^{120}$. Ein zentrales Anliegen seitens des PCF blieb außerdem die Verteidigung des freien Verkaufs der Arbeiterpresse sowohl der Polizei als auch faschistischen Organisationen gegenüber und der Schutz der municipalité ouvrière und ihrer gewählten Vertreter vor jeglicher Attacke ${ }^{121}$.

Die Projektion des faschistischen Bedrohungsszenariums in die eigene städtische Gesellschaft und die von Thorez vertretene Volksfrontlinie erlaubten nun dem PCF, das schon früh begonnene Umwerben des Kleinbürgertums, der petits commerçants, zu verstärken, ohnehin die Sozialisten mit ins Boot zu holen und auch diejenigen Arbeiter anzusprechen, die »aus Tradition « ihre Kinder in kirchliche Obhut gäben, in der jetzigen Situation aber den Platz an der Seite ihrer frères de classe einnehmen müssten ${ }^{122}$. Tatsächlich wurden die traditionellen Gegner in Ivry, die christlich geprägte Rechte ${ }^{123}$, zur faschistischen Gefahr umdeklariert. Diese Verschwörung der faschistischen Ligen, die angeblich versuchten, in Ivry Fuß zu fassen und die Jugend in den Fabriken zu verführen, geschähe - so Marrane in einem öffentlichen Aufruf - heimlich mit der Komplizenschaft der Kirche und unter der Mithilfe der Polizei $^{124}$. Außerdem versuche man die städtische Kirmes auszubooten, in-

118 Courtols, Lazar, Histoire, S. 123f.

119 Le Travailleur, 4.3.1934.

120 Ibid.

121 Ibid

122 Le Travailleur, 30.6.1934.

123 Ibid.

124 Die Polizei wurde in der kommunistischen banlieue grundsätzlich als Gegner angesehen, dem man mitunter dadurch beizukommen suchte, dass das für die Polizei vorgesehene Budget einfach weggekürzt wurde. 
dem man den Gottesdienst, zu dem eine Gruppe der Jeunesses patriotes ${ }^{125}$ eingeladen worden sei, an einem Sonntagmorgen stattfinden ließe. Deshalb gelte es, dieser »Provokation « angemessen zu begegnen, wozu Marrane seine ganze Stadtbevölkerung aufrief.

Die Arbeit des lokalen Komitees gegen Krieg und Faschismus wurde gleichzeitig weiter ausgebaut. In den drei Stadtteilen gab es nun bestimmte Parteifunktionäre, die zu festen Sprechstunden Auskunft erteilten oder Beitrittsgesuche zum Komitee entgegennahmen, so in den HBM-Komplexen der Rue Denis-Papin und der Place Philibert-Pompée, in der Rue Raspail, im städtischen Dusch- und Badehaus in Petit-Ivry sowie an der Route de Choisy. Die Bewegung bekam auch deshalb immer mehr Zuspruch, weil Stadtrat und Stadtverwaltung es verstanden hatten, die größte lokale Existenzbedrohung, nämlich die Arbeitslosigkeit, in den Kontext des »antifaschistischen Kampfes« zu stellen und die Massen für diesen Kampf zu mobilisieren. Er stärkte ihre Identität als antifaschistische, kämpferische Kommunisten der Vorstadt. Feste boten Gelegenheit, durch politische Unterwerfungsgesten wie die öffentliche Akklamation die Führungsposition von Maurice Thorez zu unterstreichen (»Notre camarade Thorez fit applaudir et approuver la politique du $\mathrm{PC} \ll)^{126}$ und das Gemeinschaftsgefühl durch kollektives Singen der Internationale und mit Sowjetrufen zu stärken ${ }^{127}$. Die Selbstinszenierung von Ivrys PCF als kämpferische Massenpartei, die die Sache des Proletariats gegen die Pariser Obrigkeit und Bourgeoisie verteidigte, verband sich im öffentlichen Diskurs Georges Marranes mit relativ banalen Dingen wie der Verbreiterung von Gehwegen und der Verbesserung der kommunalen Infrastruktur, behielt aber ihren kämpferischen Duktus bei, weil in diesem konkreten Fall die municipalité diese Maßnahmen erst gegen den Widerstand der »pouvoirs publics« durchsetzen müsse ${ }^{128}$.

Als Georges Marrane und sein Stadtrat bei den Munizipalwahlen von 1935 mit absoluter Mehrheit wiedergewählt wurden, war der Vergemeinschaftungsprozess in Ivry schon weit fortgeschritten und die Omnipräsenz der Partei im Alltag der Einwohnerschaft zu einer Selbstverständlichkeit geworden. Der Wahlerfolg bestätigte eine zehn Jahre zuvor eingenommene politische Linie. Der Durchbruch des PCF als stärkste politische Kraft in der banlieue bei diesen Stadtratswahlen bedeutete hingegen auf nationaler Ebene nicht nur eine

125 Die Jeunesses patriotes, eine Gruppe, die unter den französischen rechtsextremen Verbänden neben den Croix-de-Feu am ehesten der Beschreibung einer faschistischen Organisation entsprach, hatte 1934 bereits an Attraktivität und damit an Mitgliedschaft verloren. Durch den Kontext des Februar 1934 aktualisiert, gewann für die Jeunesses patriotes das Bürgerkriegsszenario an Bedeutung, und ein bewusster Zusammenstoß mit den Ivryer Kommunisten kann als wahrscheinlich gelten. Zu den Jeunesses patriotes vgl. WIRSCHING, Weltkrieg, S. 476-492.

126 Le Travailleur, 13.10.1934.

127 Le Travailleur de la banlieue sud, 28.4.1935.

128 Le Travailleur, 13.10.1934. 
Vorwegnahme seines zukünftigen Gewichts in einer Koalition mit der SFIO und den radicaux, er manifestierte in gleicher Weise die endgültige Etablierung des roten Gürtels um die französische Hauptstadt.

\subsubsection{Neue nationalgeschichtliche Namensgebung in der Stadtlandschaft}

Mit der Einführung der Volksfronttaktik in der kommunistischen Partei war 1934 eine Hinwendung zur französischen Nationalgeschichte verbunden. War der PCF zuvor sozial und politisch isoliert gewesen, öffnete er sich auf Geheiß Stalins nicht nur der linken politischen Mitte, sondern suchte sich auch national, und hier insbesondere in der französischen Geschichte zu verorten. Während die Direktive einer gewissen historischen Autonomie an alle kommunistischen Parteien der Internationale ging, fiel sie in Frankreich auf besonders fruchtbaren Boden. Dies hing zum einen mit der Sonderstellung der Französischen Revolution in der marxistisch-leninistischen Geschichtstheorie zusammen, in der diese als Exempel für eine klassische bürgerliche Revolution fungierte und in der kommunistischen Wahrnehmung also ein Vorläufer der proletarischen Oktoberrevolution war. Zum anderen reaktivierte die Retrospektive auf die eigene Revolution das revolutionäre Selbstverständnis eines Teils der französischen Nation, die sich durch den Erfolg der Russischen Oktoberrevolution in dieser Identität bestätigt sah ${ }^{129}$. Der zeitlich nach hinten gerichtete Blick auf das 18. Jahrhundert bestätigte so in der Zwischenkriegszeit nicht nur die eigene revolutionäre Existenz, sondern unterstrich zugleich die Affinitäten des französischen wie russischen Volkes zu einem revolutionären Habitus, welcher nun im Kontext der Volksfronttaktik aktualisiert wurde und die Koalitionsfähigkeit des PCF als Teil des französischen peuple hervorhob. Zudem forcierte die historische Verortung des PCF in der französischen Nationalgeschichte das Gefühl seiner Anhänger, sich auf der historisch richtigen, fortschrittlichen und in die Zukunft weisenden Seite zu bewegen.

Maurice Thorez formulierte seit 1934 die Idee, dass es zwei Grundströmungen in der französischen Nation gebe, die sich seit der Französischen Revolution in ungebrochener Kontinuität gegenüberständen und deren revolutionärprogressiver Part in der gegenwärtigen Epoche von den Kommunisten (in der banlieue) repräsentiert würde, während er die kontrarevolutionär-reaktionäre Traditionslinie auf das Pariser Bürgertum projizierte ${ }^{130}$. Die von Thorez nach dem Sieg bei den Munizipalwahlen von 1935 hervorgehobene Analogie zwischen dem Faubourg Saint-Antoine während der Französischen Revolution - über diese von den Pariser Unterschichten bewohnte Ausfallstraße zog das Volk am 14. Juli 1789 Richtung Bastille und trug 1793 zum Fall der Girondis-

129 Winock, Le siècle, S. 174.

${ }^{130}$ Wirsching, Weltkrieg, Kapitel »Die revolutionäre Tradition Frankreichs, der Kommunismus und die Pariser Kommunetradition«, S. 334-342, hier S. 336. 
ten bei - und der banlieue in den 1930er Jahren wirkte indes grundlegend auf das Selbstverständnis seiner Einwohnerschaft.

Dem 14. Juli kam in diesem Zusammenhang eine Schlüsselstellung zu. Als französischer Nationalfeiertag in Erinnerung an die Französische Revolution in der Dritten Republik eingeführt, wurde er als bürgerlicher Feiertag mit einem Volksfest begangen. In dieser Orientierungsphase der Republik sollten auf diese Weise die mit ihr assoziierten Werte gestärkt und gefestigt werden. Seit 1935 deutete der PCF diesen Festtag stark um und stellte ihn in den Kontext einer revolutionären Erhebung gegen das Bürgertum ${ }^{131}$. Entsprechend scharf fielen die Reden von Thorez und Marrane am 13. Juli 1935 vor Ivrys Rathaus aus, als sie an 10000 Einwohner appellierten »d'arracher des mains de la bourgeoisie le 14 Juillet qui appartient à la classe ouvrière « ${ }^{132}$. Dieser Versammlung war ein Umzug mit roten Fahnen, Lampions und Musik in den drei Stadtvierteln vorausgegangen. Die politische Aufbruchstimmung, mit der dieser Vorabend zum 14. Juli in Ivry begangen wurde, symbolisierten zudem die von vielen getragenen Banderolen der Volksfront.

Am frühen Morgen des 14. Juli versammelten sich dann Ivrys Vereine und interessierte Teile der Einwohnerschaft, um die Rue Robespierre einzuweihen, die als Verlängerung der Rue de Paris Richtung Vitry zu diesem Zweck umbenannt und mit dem Namen des Protagonisten der Terrorphase der Französischen Revolution bedacht wurde. Obwohl in der zeitgenössischen historischen Forschung die verschiedenen Revolutionsphasen bekannt waren ${ }^{133}$, konzentrierte man sich in Ivry auf die Jakobinerherrschaft, was durch die Umbenennung der Rue Marat 1939 noch unterstrichen wurde. Dies wirkte einerseits auf die Legitimation des diktatorischen Herrschaftsanspruchs Stalins in der Sowjetunion und auch auf die damit verbundenen Säuberungswellen in der Partei. Andererseits hatten diese Umbenennungen einen identitätsvertiefenden Effekt auf die französischen Kommunisten, welche sich nun im Verbund mit der eigenen Nationalgeschichte und in der unmittelbaren Nähe zum revolutionären Russland fühlen konnten. Die Einordnung in die Geschichte revolutionärer Erhebungen, im öffentlichen Raum Ivrys nun symbolisch sichtbar gemacht und durch das Lenin-Stadion in seiner weltgeschichtlichen Dimension noch einmal deutlich hervorgehoben, wirkte zugleich bestätigend auf die kommunistische Gemeinschaft. Sie unterstrich ihre vermeintliche Rolle in der zukünftigen Entwicklung, die sich in der kommunistischen Perzeption ab 1934 als ein Aufeinanderprallen faschistischer und kommunistischer Bewegungen darstellte. Tatsächlich trat die Einigung zwischen lokalem PCF und der marginalisierten SFIO als Reaktion auf den 6. Februar 1934 ein, und so folgte der Einweihung der Rue Robespierre am Morgen des 14. Juli 1935

131 Rosemonde Sanson, Les 14 Juillet. Fête et conscience nationale, 1789-1975, Paris 1976, S.147f.

132 L'Humanité, 14. Juli 1935.

133 Wirsching, Weltkrieg, S. 335. 
eine geschlossene Teilnahme von Ivrys Kommunisten an der großen, gemeinsam mit der SFIO veranstalteten Demonstration an der Bastille. Hierzu versammelten sich die Ivryer Partei und Vereine an der Metrostation an der Porte d'Ivry und Porte de Choisy; die organisierten Bewohner der HBM sollten sich ebenfalls geschlossen dorthin begeben ${ }^{134}$.

$\mathrm{Zu}$ einem der wichtigsten Ereignisse wurde vier Jahre später die 150-Jahrfeier der Französischen Revolution stilisiert, zu deren Vorbereitung wieder ein Komitee gegründet wurde, dieses Mal unter dem Vorsitz von Maurice Thorez selbst ${ }^{135}$. In diesem Komitee engagierten sich in erster Linie die Lehrer aus den öffentlichen Schulen Ivrys, die sich für die kulturelle Vermittlung der Französischen Revolution verantwortlich fühlten. So waren die Direktoren der Mädchenschule von Ivry-Centre und der Direktor der Jungenschule von Petit-Ivry gemeinsam mit Georges Marrane als Vizepräsidenten tätig. Dass ihre Arbeit dennoch vom kommunistischen Deutungsansatz der revolutionären Ereignisse durchdrungen war, zeigte sich bei der offiziellen Bekanntgabe der Zusammensetzung dieses Ausschusses im »Bulletin municipal officiel « unter dem Bild Robespierres. Die Komiteemitglieder waren Vertreter der wichtigen kommunistischen Vorfeldorganisationen wie der ARAC, der Union des femmes de France, der Union des jeunes filles de France, der Amicale des HBM, des Comité local des syndicats ouvriers, der Vieux Travailleurs, der Jeunesse communiste, der Étoile sportive du travail d'Ivry und der Amis de l'URSS, aber auch einige kleine Einzelhändler und ein Vertreter der radikalsozialistischen Partei, der allerdings ebenfalls in der linken Menschenrechtsliga aktiv war ${ }^{136}$. Der Weg in die Vergangenheit, der demonstrativ über die eigene Nationalgeschichte führte, war so durch die Zeichen im öffentlichen Raum und die bewusste Erinnerung und Inszenierung der Revolution zu einem integrativen Bestandteil der kommunistischen Identität in der Vorstadt geworden.

\subsubsection{Bewunderung der Sowjetunion}

Eine weitere Facette kommunistischer Identität in den 1930er Jahren war die gesellschaftliche Bewunderung für die Sowjetunion. Dies lag zum einen in ihrer Eigenschaft als Zentrum der kommunistischen Weltbewegung begründet und sollte sich in der Zukunft durch die Rolle der Roten Armee beim Sieg über das nationalsozialistische Deutschland noch verstärken. Zum anderen war die angenommene historische Kontinuität von Französischer Revolution und Oktoberrevolution grundlegend für das Verständnis der Faszination, die Letztere auf Frankreich ausgeübt hat. Die Analogie von Jakobinerherrschaft und leninistisch-stalinistischer Terrorherrschaft war ein weiterer, späterer

134 Le Travailleur de la banlieue sud, 13. Juli 1935.

135 Bulletin municipal officiel, April 1939.

136 Ibid. 
Schritt, der sich aber in derselben Logik bewegte. Wichtig war zunächst einmal das Gefühl auf der französischen Linken - nicht nur bei den Kommunisten -, initiativ an einem weltgeschichtlich relevanten Ereignis mitgewirkt zu haben. Die Oktoberrevolution sahen sie in der Tradition der französischen Aufklärung, sie erfüllte viele mit Stolz ${ }^{137}$ und schuf eine emotionale Verbindung zum neu entstehenden Land der Sowjets. Die Interpretation des nationalsozialistischen Deutschlands als konterrevolutionäres Element ermöglichte diese gefühlte Nähe und verstärkte das Zusammengehörigkeitsgefühl vieler Franzosen mit dem sowjetischen Volk ${ }^{138}$. Hinzu kam, dass Stalin während dieser sogenannten »Dritten Periode« stets die antisowjetische Weltverschwörung beschwor und die Verteidigung der Sowjetunion als »Vaterland der Proletarier « zum obersten Gebot aller Kommunisten erklärte ${ }^{139}$. Sich selbst in der Kontinuität von Humanismus und Dreyfus-Affäre sehend, ließen sich viele Intellektuelle von diesem Konzept begeistern:

Ce qui était la tâche primaire des partis communistes du monde entier, leur raison d'être, donnait l'objet de la plus vaste mobilisation intellectuelle encore jamais réalisée par les communistes. Au moment même où Staline entamait la collectivisation des campagnes, qui devait se révéler un des épisodes les plus sanglants de l'histoire de l'URSS, bien des intellectuels d'Occident, à l'instar de Gide, prenaient fait et cause pour une révolution soviétique imaginaire ${ }^{140}$.

Tatsächlich bediente die UdSSR die politische Imagination der französischen Linken als staatsgewordene Utopie, als Fortsetzung und Inkarnation der Werte der Aufklärung, die über den Transmissionsriemen der Französischen und Russischen Revolution in die Sowjetunion transportiert worden waren. Der Kommunismus stand in diesem Zusammenhang nicht als totalitäres Regime da, sondern als Weiterentwicklung der Demokratie, die in Frankreich als republikanisches Modell verstanden wurde und in dieser Perzeption erst durch den revolutionären Zustand geadelt und zukunftsorientiert gemacht wurde. In diesem Sinne wurde die Sowjetunion als fortschrittlich, modern, als »Baustelle der Zukunft « ${ }^{141}$ angesehen, als Idee, die es zu verwirklichen galt. Gleichzeitig nährten die Vorstellung und das Gefühl, dass Russland aus dem Ersten Weltkrieg mit einem besseren politischen und wirtschaftlichen System als das französische hervorgegangen war, die Sehnsucht nach jenem fernen Land im Osten, von dem viele Meinungsführer enthusiastisch berichteten. Die konfuse Verbindung von antifaschistischer Grundhaltung gegenüber den Rechtsextremen im eigenen Land, dem Bedürfnis nach Friedenserhalt für Europa und der Verteidigung der Sowjetunion ließ bei vielen Intellektuellen das Gefühl für die Notwendigkeit eigenen politischen Engagements aufkommen. Sie ta-

137 Furet, Le passé, S. 312f.

138 Ibid. S.313.

139 Ibid.

140 WINOcK, Le siècle, S. 231.

${ }^{141}$ So eine Formulierung der französischen Autoren André Gide und Romain Rolland, zitiert nach Furet, Le passé, S. 325. 
ten sich in Form von Schriftstellervereinigungen und Kongressen zusammen, um auf die wachsende Kriegsgefahr und das Gefühl kultureller Bedrohung aufmerksam zu machen. So wurde 1932 in Paris die Association des écrivains et artistes révolutionnaires (AEAR) zur Verteidigung der Sowjetunion gegründet. Im Sommer 1935 folgte die Association internationale des écrivains pour la défense de la culture mit hundertzwölf Mitgliedern, deren zwölfköpfiges Präsidium mit so illustren Denkern wie Henri Barbusse, Romain Rolland, André Gide, Heinrich Mann, Thomas Mann, Maxim Gorki, Edward Forster, Aldous Huxley, Bernard Shaw, Sinclair Lewis, Selma Lagerlöf und Ramon del Valle-Inclán besetzt war. Obwohl sich nicht alle Literaten manipulatorisch in den Dienst der Sowjetunion stellen ließen ${ }^{142}$, war es doch charakteristisch für diese Organisationen, dass sie von den kommunistischen Propagandabeauftragten initiiert und politisch beeinflusst wurden. Mit der Idealisierung der Sowjetunion wurde zudem der erste Schritt in ein ungleichzeitiges Leben gemacht, das sich zwar im Alltag an der französischen Wirklichkeit orientieren musste, in seiner transzendenten Version aber die Sowjetunion zu einem paradiesischen Zustand erklärte, in welchem die französischen Werte von Freiheit, Gleichheit und Brüderlichkeit realisiert und zum Wohle aller umgesetzt würden.

François Furet betont in seiner Untersuchung über den Kommunismus im 20. Jahrhundert ausdrücklich den Umgang mit Altem und Neuem, mit dem rückwärts oder nach vorne Gewandten als Unterscheidungskriterium für die extremen Bewegungen. Die Frage des Verhältnisses zu den Werten von 1789 lassen diese Polaritäten besonders klar hervortreten. Während sich die Forderungen der Französischen Revolution in der linken Perzeption in den Revolutionen der nachfolgenden Jahrhunderte umsetzen ließen und somit in der Geschichte fortschrittlich und teleologisch wirkten, wollten der Nationalsozialismus und der italienische Faschismus als Gegenspieler dieses historischen Fortschritts das Alte konservieren ${ }^{143}$. Die rechtsextremen Bewegungen wendeten sich somit gegen $1789^{144}$. Aufgrund dieser polarisierenden Weltsicht, die sich mit den ungefilterten Gewalterfahrungen von 1934 deckte, erscheint die Erklärung plausibel, dass es sich bei den Verteidigern der UdSSR in Frankreich weniger um streng marxistisch-leninistisch ideologisierte Massen handelte. Vielmehr beherrschte sie das diffuse »sentiment du progrès humain ${ }^{145}$, dessen Mission dann erfüllt werden könne, wenn man sich auf die historisch richtige Seite stelle.

142 WINOCK, Le siècle, S. 229.

143 Diese Sicht stellt den NS als zu rückwärtsgewandt dar. Tatsächlich zeichnete er sich wohl durch die Gleichzeitigkeit von modernen und beharrenden Elementen und ein nichtkonservatives Selbstverständnis aus. Vgl. Riccardo BAVAJ, Die Ambivalenz der Moderne im Nationalsozialismus. Eine Bilanz der Forschung, München 2004.

144 Furet, Le passé, S. 325.

145 Ibid. 
Die große Bewunderung für die Sowjetunion in Teilen der französischen Bevölkerung und einem Großteil der humanistisch oder kommunistisch gesinnten Intellektuellen und Wissenschaftler in Frankreich wurde von sowjetischer Seite bewusst in Szene gesetzt und politisch instrumentalisiert. Das klassische Mittel hierzu war die Einladung zu einer Reise in die Sowjetunion ${ }^{146}$ mit der Option eines Besuchs bei Stalin persönlich. So reiste die Führungsriege des PCF regelmäßig zur Komintern nach Moskau. Aber auch französische Literaten waren sehr willkommen, denn sie sollten dazu beitragen, das schon frühzeitig inszenierte, positive Bild der Sowjetunion nach Frankreich zu transportieren. Die Wertschätzung, welche ihrer Arbeit von Seiten der kopfbetonten kommunistischen Entscheidungsträger entgegengebracht wurde - nicht zuletzt auch um die »Wissenschaftlichkeit « der kommunistischen Ideologie zu unterstreichen - machte viele geneigt und immun gegen die Wahrnehmung der Auswirkungen der stalinistischen Diktatur, die bei näherem Hinsehen durchaus erkennbar gewesen wären. Selbst die große innerparteiliche Säuberungswelle und die Prozesse gegen führende Sowjets 1937/38 wurde im französischen Intellektuellenmilieu kaum rezipiert. Unter den kommunistischen Schriftstellern zählten Romain Rolland, Marcel Cachin und Fernand Grenier, der auch der Vorsitzende der Organisation Amis de l'URSS war, zu den wichtigsten Moskaureisenden. Auch humanistisch orientierte Intellektuelle wie André Gide folgten den sowjetischen Einladungen. Allerdings endete dieser Besuch Gides aus Sicht der Sowjetunion in einem propagandistischen Desaster, veröffentlichte er doch nach seiner Rückkehr das Buch »Retour de l'URSS «, in dem er seinen Aufenthalt sehr kritisch würdigte und sich gegenüber den sowjetischen Verführungen wie Auszeichnungen, Großauflage seiner Werke etc. unbeeindruckt zeigte ${ }^{147}$. Französische Politiker wie der Radikale Édouard Herriot ließen sich hingegen die potemkinschen Dörfer in der Sowjetunion 1935 vorführen. Der Beistandspakt zwischen Pierre Laval und Stalin trug im gleichen Jahr dazu bei, dass die Verteidigungswürdigkeit der UdSSR als größer und die deutsche Gefahr somit als wachsend und real eingeschätzt wurde.

Noch weniger Resonanz für Kritik an der Sowjetunion war zu diesem Zeitpunkt in Ivry zu finden, wo die minoritäre, zurückgedrängte konservative Opposition immer wieder den Vorwurf der »Moskauhörigkeit « gegen die lokale Politikelite artikulierte. Ihr Sprecher Guerin kritisierte wöchentlich die »Sowjetisierung « Ivrys, in der rote Fahnen und andere Symbole der Zugehörigkeit zur kommunistischen Welt den öffentlichen politischen Raum beherrschten $^{148}$. Das gesamtgesellschaftliche Klima, das sich nach der Wende von 1934 ausbreitete, war indes auch in Ivry bestimmend und wirkte unter dem Ein-

146 Vgl. Fred Kupferman, Au pays des Soviets. Le voyage français en Union soviétique 1917-1939, Paris 1979.

147 WINOCK, Le siècle, S. 287-289.

148 La Banlieue de Paris, 30.7.1937. 
fluss und durch den Filter der kommunistischen Stadtverwaltung besonders nachhaltig auf Bewusstsein und Haltung seiner Einwohnerschaft. Nach der Zerschlagung der KPD, welche als Hoffnungsträgerin der KPdSU galt, hatte sich Stalin verstärkt dem PCF zugewendet, um einen strategischen Partner in Westeuropa zu haben. Infolgedessen hatte sich in der Sowjetunion ein ausgeklügeltes System entwickelt, ausländische und speziell französische Gäste zu empfangen ${ }^{149}$. Dass man dabei auch gezielt Meinungsführer aus der zweiten Reihe und Verantwortungsträger an der Pariser Basis ansprach, zeugte vom guten Informationsstand der Komintern, die mit ständigen Berichten ihres »Westeuropa-Beauftragten « Eugen Fried und durch Berichte des französischen Politbüros auf dem Laufenden gehalten wurde. Insofern war es sinnvoll, Meinungsvermittler einzuladen, welche über eine lokal begrenzte, aber einflussreiche Machtbasis in Frankreich verfügten und das ihnen vermittelte Bild der Sowjetunion - und ihrer Feindbilder - unmittelbar an ihre Wähler und Leser in der banlieue weitergeben konnten.

Neben den realpolitischen und sozialen Problemen, die Ivry als Sitz der Metall verarbeitenden Industrie kennzeichneten, erlebte die Stadt, dass sie trotz ihrer Randlage in der kommunistischen Geographie zusehends in die Konflikte involviert wurde, die die kommunistische Welt international bedrohten - etwa den Aufstieg des Nationalsozialismus, den Putsch des spanischen Generals Franco im Juli 1936. Dass sich Ivrys Bevölkerung mit ihrem Zuspruch für die kommunistische Partei auf dem historisch richtigen Weg befand, wurde ihr nicht nur von Maurice Thorez vermittelt, der regelmäßig zur Komintern nach Moskau reiste. Auch Bürgermeister Georges Marrane unternahm 1935 eine »Pilgerreise« in die Sowjetunion und konnte wie Thorez anschließend von den Fortschritten beim Aufbau des Sozialismus berichten. Zuvor war bereits der Chefredakteur der ab 1933 erscheinenden kommunistischen Lokalzeitung »Le Travailleur« und Mitglied des Stadtrats, Auguste Havez, drei Jahre lang in Moskau gewesen ${ }^{150}$. Sein Mitarbeiter Émile Zellner hatte ebenfalls Ende der 1920er Jahre einen Aufenthalt in der Sowjetunion verbracht, von dem er sich tief beeindruckt zeigte ${ }^{151}$.

\subsubsection{Ivrys Engagement im Spanischen Bürgerkrieg}

Einen Monat nach dem Ende der großen Streikbewegung in Frankreich, bei der sich Ivrys Industriebetriebe besonders hervorgetan hatten ${ }^{152}$, und der Bildung der Volksfrontregierung unter Léon Blum im Juni 1936 begann in Spanien der Bürgerkrieg zwischen den Verteidigern der republikanischen Ordnung und den Anhängern General Francos. Frankreich fühlte sich von

149 Furet, Le passé, S. 334.

150 La Banlieue de Paris, 18.11.1932.

151 Le Travailleur, 15.7.1972.

152 L'Humanité, 2. 6.1936. 
der Entwicklung in einem seiner wenigen Nachbarstaaten unmittelbar betroffen. Die Frage nach der Intervention in diesem Krieg wurde zu einer entscheidenden Belastungsprobe für die Regierung Blum, die sich entgegen dem Drängen der Kommunisten und anderer Befürworter entschloss, den republikanischen Truppen in Spanien nicht militärisch beizustehen. In der kommunistischen Welt wurde der Spanische Bürgerkrieg jedoch zum Symbol für den Freiheitskampf gegen die faschistische Gefahr. Gemäß der in den 1930er Jahren erwachsenen Formel der zunehmenden Bedrohung durch den Faschismus, dessen Welt bald auch Spanien zuzuordnen sei, fühlten sich viele junge Männer dazu aufgefordert, den Internationalen Brigaden in Spanien beizutreten und für Spaniens Rückkehr zur Republik zu sorgen. Zu den zahlreichen Spanienkämpfern zählten auch viele deutsche Emigranten, die vor Hitler ins Ausland geflohen waren und sich nun an der spanischen Front engagierten.

Ivrys Kommunisten fühlten sich direkt von der spanischen Frage und der Verteidigung der Republik betroffen und starteten eine groß angelegte Kampagne, um ihre Unterstützung in dieser existenziellen Frage zu verdeutlichen. In der Mobilisierung von Ivrys Einwohnerschaft geübt, intervenierte die kommunistische Stadtverwaltung gleich auf mehreren Ebenen. Zum einen stellte Ivry über sechzig junge Männer aus dem eigenen Arbeitermilieu ${ }^{153}$, die unter großem Zuspruch der Bevölkerung noch im Sommer nach Spanien aufbrachen, um ihren Beitrag zur Sicherung des Friedens in Europa und zur Bekämpfung des Faschismus zu leisten, wie es das Comité de vigilance contre le fascisme et la guerre schon zwei Jahre zuvor ausgegeben hatte. Zum anderen stellte sich mit zunehmender Dauer des Krieges die Frage nach der langfristigen Unterstützung der Freiwilligen und Opfer der kriegerischen Auseinandersetzungen. Der kommunistische Stadtrat entschied sich daher, die stadteigene Ferienkolonie Les Mathes an der südfranzösischen Atlantikküste für Verletzte und Bürgerkriegsflüchtlinge zu öffnen und mit städtischem Hilfspersonal auszustatten. Ab Mai 1937 beschloss der kommunistische Stadtrat außerdem, die Spanienhilfe auf die kriegsbetroffene Bevölkerung auszuweiten. Nach bekanntem Schema wurde ein Komitee unter Vorsitz des Beigeordneten Mazet gegründet, das sich für die Opfer des Bürgerkrieges in der baskischen Stadt Bilbao einsetzen sollte ${ }^{154}$. Treffpunkt für die verschiedenen Untergruppen dieses neuen Komitees waren die HBM-Wohnkomplexe, das Rathaus und die Badehäuser, also dieselben Orte, an denen schon das Antikriegs- und Antifaschismuskomitee gewirkt hatte. Interessant ist, dass sich Mazet bemühte, auch die Ivryer Katholiken mit ins Boot zu holen, indem er sich direkt schriftlich an den Ivryer Abbé Lorenzo wandte. Argumentativ griff

153 Auskunft Michèle Rault, Archivleiterin. Ivry stellte mit dem Pariser Vorort Aubervilliers die meisten Spanien-Freiwilligen aus den kommunistischen Vorstädten.

154 Brief von Mazet, cabinet du maire, an Abbé Lorenzo vom 7.5.1937, Loseblattsammlung von Michèle Rault, ohne Signatur. 
Mazet dabei auf den Umstand zurück, dass es sich bei Bilbaos Bevölkerung mehrheitlich um Katholiken handele, deren Frauen und Kinder von Hungersnot bedroht seien, und dass man aus humanitären Gründen und den »sentiments [...] de fraternité « heraus diesen Menschen zu Hilfe eilen müsse ${ }^{155}$. In seinem Antwortschreiben erteilte Abbé Lorenzo diesem Anliegen eine Absage, da er rein politische Absichten hinter dieser Kampagne vermutete:

Décidées à ne pas prendre parti dans le douloureux conflit qui déchire l'Espagne, elles [les organisations catholiques] estiment ne pouvoir s'associer à une manifestation qui ne semble pas étrangère aux considérations d'ordre politique, à en juger par les termes de l'affiche récemment apposée sur les murs d'Ivry ${ }^{156}$.

Außerdem verwies der Geistliche darauf, dass die katholischen Vereine Ivrys jene Association des dames de la charité unterstützten, die von der Katholischen Kirche explizit damit beauftragt worden war $^{157}$.

1936/37 entstand so eine charakteristische Verhaltensweise für Ivrys Beteiligung an außenpolitischen Konflikten. Die kommunistische Partei fühlte sich nicht zuletzt durch ihre weltweite Vernetzung mit den wichtigsten Konfliktherden in Europa verbunden. Ihre Anhänger in der Pariser banlieue sahen sich in die Verantwortung genommen. In den zurückliegenden Jahren waren Orte wie die Gemeinschaftsräume in den Sozialwohnungskomplexen entstanden, in denen man glaubte, durch eigenes Engagement auf das weltgeschichtliche Geschehen Einfluss nehmen zu können. Die politische Mobilisierbarkeit der Bevölkerung in den kommunistischen Vorstädten und ihre soziale und materielle Disziplinierung durch die municipalité communiste verstärkten das Gefühl der Unmittelbarkeit und direkten persönlichen Betroffenheit von internationaler Politik. Hinzu kam die kommunistische Ideologie, welche die Bedeutung nationaler Zugehörigkeit negierte und hinter dem internationalen Klassendenken zurückstehen ließ.

Zudem erwartete der PCF den Sieg der spanischen Republik, wenn man nur genügend kämpfen würde, wie auch in der französischen Innenpolitik die Abwehr des Faschismus Aufgabe des Individuums und der kommunistischen Gemeinschaft sei. Der Handlungsspielraum im Spanienkrieg wurde von der französischen Linken viel höher eingeschätzt, als es der Realität entsprach. Zudem war die offizielle Position Frankreichs grundsätzlich nicht so klar, wie es Léon Blums Nicht-Interventionspolitik suggerieren wollte. Denn trotz dieser offiziellen Regierungsposition hatte etwa der Intellektuelle André Malraux beim Kriegsministerium eine Fliegerstaffel >ausleihen< können, mit der er aktiv in das Kriegsgeschehen in Nordspanien eingriff ${ }^{158}$. Ohne stille Duldung des Ministeriums und der Armee wäre dies nicht möglich gewesen. Auf der anderen Seite wirft dieser Eingriff Malraux' ein Licht auf die epo-

155 Ibid.

156 Ibid.

157 Ibid.

158 Jean Lacouture, Malraux. Une vie dans le siècle 1901-1976, Paris 21976, S. 216-220. 
chenspezifische Mentalität der französischen Linken und auch vieler Intellektueller, die glaubten, sich mit Aktionismus und individuellem Einsatz von ihnen diagnostizierten Fehlentwicklungen entgegenstellen zu können. Der innenpolitische Durchbruch der Volksfront in Frankreich hatte dieser Euphorie Vorschub geleistet.

Für das kommunistische Zusammenrücken in Ivry spielte der Aufbau außenpolitischer Problemfelder indes eine Schlüsselrolle, forcierte er doch die allgemeine Kampfbereitschaft gegenüber dem politischen Gegner, der sich hier in Form von faschistischen Regierungen zeigte. Zur inneren Sinnstiftung trug im gleichen Zeitraum 1936/37 der verstärkte Rekurs auf die revolutionären Ereignisse in der französischen Nationalgeschichte bei. François Furet interpretiert die Entwicklung dieser revolutionären Identität, wie sie typisch für den französischen Kommunismus der 1930er Jahre war, als eigentlichen Ausgangpunkt für die Blindheit oder Ignoranz des PCF gegenüber Fehlentwicklungen in der Sowjetunion. Der starke Rekurs des Kommunismus auf die Französische Revolution und die Gedankenwelt des späten 18. und 19. Jahrhunderts habe es ihm unmöglich gemacht, den Totalitarismus des 20. Jahrhunderts zu erkennen ${ }^{159}$ und ihm somit kritisch zu begegnen. Dementsprechend hätten Frankreichs Kommunisten den Unterschied zwischen Demokratie und Diktatur nicht realisieren können. Dieser sei vielmehr durch die revolutionäre Perspektive überdeckt worden. Es ist auch möglich, dass die republikanische Identität, auf deren Boden sich der städtische Kommunismus erst hatte entwickeln können, nicht als spezifisch französische Entwicklung erkannt und daher die Abwesenheit und das Ende der Monarchie in Russland als gleichbedeutend mit der Einführung einer republikanisch-demokratischen Ordnung wie in Frankreich angenommen wurde.

Tatsächlich ignorierte die Ivryer municipalité jegliche Kritik an der Sowjetunion und unterstrich im Gegenteil die Attraktivität dieses neuen Gesellschaftsmodells für die Arbeiterschaft. Als André Gide 1935 sein Buch »Retour de l'URSS « veröffentlichte und damit in Paris für viel Furore sorgte, lehnte Marrane jegliche Auseinandersetzung mit diesem Thema ab, obwohl ihn der spitzfindige Kommentator in der »Banlieue de Paris« von Henri Guilhamon explizit dazu aufrief ${ }^{160}$. Vier Jahre später, als Ivry die Feierlichkeiten zur 150-Jahrfeier der Französischen Revolution vorbereitete, hatte sich nach vierzehn Jahren kommunistischer Herrschaft die offizielle Geschichtsdeutung des PCF weitestgehend durchgesetzt und das Verhältnis zur Sowjetunion war klar definiert. Der uneingeschränkte Zugriff des Stadtrats verortete die Einwohnerschaft an einer entscheidenden Stelle des historischen und weltpolitischen Koordinatensystems, so dass sie sich sowohl auf der revolutionären,

159 Furet, Le passé, S. 361.

${ }^{160}$ La Banlieue de Paris, 13.8.1937. Es ist davon auszugehen, dass Marrane die oppositionelle Lokalzeitung »La Banlieue de Paris« regelmäßig las, da er in Artikeln des »Travailleur« gelegentlich Bezug darauf nahm. 
fortschrittlich orientierten Seite der französischen Bevölkerung wiederzufinden schien als auch über die Partei und ihre internationalen Beziehungen als Teil einer verheißungsvollen Zukunft sehen konnte ${ }^{161}$. Bei einer Einwohnerschaft, die vor allem aus Hoffnung auf eine bessere, modernere Zukunft aus der französischen Provinz in die Stadt gezogen war ${ }^{162}$, trafen diese Erwartungen auf offene Ohren, zumal die Berichte und Bilder aus der Sowjetunion, wie sie von einigen Vertrauensleuten aus dem Rathaus oder durch offizielle Ausstellungen der mairie vermittelt wurden, schon ahnen ließen, wie die $\mathrm{Zu}$ stände auch in der banlieue sein könnten, wenn sich die Partei nur entsprechend durchsetzen könnte. Wie stark die politische und kulturelle Formierung der ersten kommunistischen Gemeinden 1939 war, zeigte sich in dem Moment, als sich die innen- und außenpolitischen Prämissen grundsätzlich wandelten.

\subsection{Akteure und Vernetzung der Résistance während der deutschen Besatzung}

Die Unterzeichnung des Hitler-Stalin-Paktes im August 1939 traf den PCF völlig unerwartet und stürzte ihn in die größte Krise seiner Existenz. Von Stalin nicht über diese außenpolitische Kehrtwende informiert, geriet die Führung der kommunistischen Partei sowohl gegenüber ihrer Mitgliedschaft als auch gegenüber der französischen Bevölkerung in Erklärungsnot, hatte sie doch in den Jahren zuvor Hitler und den Faschismus mit allen Mitteln bekämpft und zum Hauptfeind der französischen Arbeiterschaft stilisiert. Dass sich jetzt ausgerechnet das »Vaterland des Sozialismus«, die »Heimat der Arbeiter « mit dem außenpolitischen Feind par excellence verbündete, konnte auch treuen Parteimitgliedern nur schwer vermittelt werden. Die Reaktion vieler war denn auch der prompte Austritt aus jener Partei, die erst drei Jahre zuvor nach dem Wahlerfolg der Volksfront den größten Mitgliederzuwachs ihrer Geschichte erlebt hatte und im Sommer 1939 mit 270000 Mitgliedern die am besten organisierte französische Partei war ${ }^{163}$. Die Kommunisten erschienen nun als Verräter im eigenen Land. Die Situation spitzte sich im September nach dem deutschen Überfall auf Polen und dem Einmarsch der Roten Armee in Ostpolen noch einmal dramatisch zu. Die Regierung Daladier reagierte am 26. September 1939 mit einem Dekret, das die kommunistische Partei Frankreichs und ihre Vorfeldorganisationen verbot.

Für den PCF bedeutete dies faktisch die Zerschlagung der Partei. Die Bilanz im ersten Trimester 1940 nach sechs Monaten Parteiverbot und Ab-

161 François Furet zufolge war dieser Fortschrittsglaube letztendlich wichtiger und motivierender als das Festhalten an einem orthodoxen Marxismus (FURET, Le passé, S.325).

162 Weber, La fin, S. 413-422.

163 Courtois, Lazar, Histoire, S. 173. 
drängung der politischen Führung in die Illegalität war verheerend: Von den 44 ehemaligen PCF-Abgeordneten der Deputiertenkammer waren $38 \mathrm{zu}$ je fünf Jahren Haft unter Verlust ihrer staatsbürgerlichen Rechte verurteilt worden. Außerdem waren 2718 gewählte Stadträte und Abgeordnete der Generalräte abgesetzt worden. 1100 juristische Verfahren waren eingeleitet und 3400 Verhaftungen vorgenommen worden; 1500 Kommunisten wurden sofort verurteilt. Außerdem wurden 700 kommunistische Beamte abgesetzt, 550 Verdächtige in Überwachungslager gebracht und 620 Gewerkschaften aufgelöst ${ }^{164}$.

Schließlich betraf das Verbot auch diejenigen Kommunisten, die sich als Mitglieder anderer europäischer kommunistischer Parteien wie der KPD oder der KPI vor der Verfolgung im eigenen Land nach Frankreich geflüchtet hatten. Nach dem deutschen Einmarsch in Polen erschienen zudem die deutschen Flüchtlinge besonders verdächtig, in Frankreich gegen die pazifistischen Anstrengungen der Regierung zu wirken. Sie wurden aufgefordert, sich bei der Präfektur zu melden. Auf die Kooperation und das Verständnis der französischen Behörden bauend, von der die Auslands-KPD annahm, dass sie in ihnen vor allem die Oppositionellen gegenüber dem nationalsozialistischen Regime sehen würden und nicht die Verbündeten der Sowjetunion, forderte Franz Dahlem als Vertreter der KPD-Führung in Paris die in Frankreich verharrenden deutschen Kommunisten dazu auf, sich freiwillig bei den Präfekturen zu melden. Dahlem unterlag dabei einer folgenschweren Fehleinschätzung der französischen Situation. Die Regierung Daladier betrachtete die repressive Ausländerpolitik als ein legitimes und auf Friedenserhalt ausgerichtetes Mittel, den Feind im Inneren zu bekämpfen. Zudem unterschätzte Dahlem nach der Erfahrung der machtvollen Volksfrontbewegung den institutionellen Antikommunismus der Pariser Polizeibehörden, die trotz des relativen Machtgewinns der Partei die banlieue weiterhin genau überwachten.

\subsubsection{Ivry als Ort von Repression, Anpassung und Widerstand}

Daher ist es nicht erstaunlich, dass die Vorstädte trotz der legalen politischen Hegemonialstellung des PCF nach den Stadtratswahlen von 1935 in besonderem Maße von den polizeilichen und administrativen Repressionen betroffen waren. Zunächst erging ein Erlass des Pariser Präfekten, die Verwaltungsspitze der municipalités communistes durch sogenannte Sonderdelegationen zu ersetzen. Gleichzeitig wurde der Druck auf die kommunistischen Stadträte erhöht, sich vom PCF zu lösen. Sie konnten einer Verhaftung nur entgehen, indem sie sich offiziell in einem Schreiben von der kommunistischen Partei distanzierten. Viele Mitglieder kamen dem nach, waren sie doch von der außenpolitischen Wendung überrascht und enttäuscht. Auch in Ivry wurde eine délégation spéciale unter dem Vorsitz von Henri Jacquelin eingesetzt, 
welcher selbst in Paris wohnte. Weitere Delegationsmitglieder waren die stadtbekannten Anhänger der rechten Liste, der Arzt Henri Perreau und der rechte Gegenkandidat von Georges Marrane aus dem Jahr 1935, Jean Jardel. Sie übernahmen die Geschäfte im Rathaus laut Dekret vom 4. Oktober 1939, während der kommunistische Stadtrat seines Amtes enthoben wurde. Anscheinend war die Herrschaftssituation im Herbst 1939 noch ambivalent, denn erst am 20. Januar 1940 schickte der Pariser Präfekt Ivrys kommunistischen Stadträten eine erneute Mitteilung, dass sie ihrer Funktion enthoben seien ${ }^{165}$. Diese Mitteilung wurde ihnen von einem Beamten persönlich übergeben und unterstrich noch einmal den Zusammenhang, dass die Suspendierung vom Amt direkt auf die fortgesetzte Zugehörigkeit zur kommunistischen Partei zurückzuführen sei. Trotz der massiven Auflösungserscheinungen der Partei konnte Ivrys PCF-Sektion als einzige der banlieue rouge all ihre Stadträte als Mitglieder halten. Kein Stadtrat gab dem Druck aus Präfektur und Innenministerium nach und verließ die Partei, zu stark waren Milieuzusammenhalt und die innerstädtische Vernetzung von Partei und Stadtverwaltung. Es erwies sich darüber hinaus als konspirativ vorteilhaft, dass Venise Gosnat, obwohl er sein Amt als Beigeordneter im Januar 1940 verloren hatte, bis zum 16. Mai das HBM-Büro weiterleitete ${ }^{166}$. Auf diese Weise konnte er Kontakt zum Rathaus halten, das er in seiner Funktion als Direktor des Wohnungsamtes jeden Tag aufsuchen musste, und so den Zugriff auf Büroräume und -material sichern. Dies wurde für den Aufbau eines geheimen Parteiapparats und den Druck der illegalen »Humanité « benötigt. Venise Gosnat gehörte auch zu denjenigen, die aus der zweiten Reihe nachrückten, als der sichtbare Parteiapparat im Herbst 1939 zusammenbrach. Ivrys Bürgermeister Georges Marrane stand hingegen seit 1936 als Vorsitzender des Conseil général de la Seine in direktem Kontakt mit dem Präfekten und war in der politischen Szene der Pariser Region als Bürgermeister einer der wichtigsten PCF-Hochburgen persönlich bekannt. Er war einer der Ersten, die in die Illegalität flüchteten und ihr Äußeres veränderten, um nicht erkannt zu werden ${ }^{167}$. Weniger prominente Kommunisten Ivrys machten zunächst wie gewohnt weiter. Venise Gosnat übernahm im Sommer 1940 die illegale Funktion des Parteisekretärs der Pariser Südregion, nachdem der vorherige offizielle Amtsinhaber, Maurice Gunsbourg, gegen die Deutschen mobilisiert und dann kriegsgefangen worden war ${ }^{168}$.

165 Stadtarchiv Ivry, 1K 5/6, Schreiben des Präfekten an Ivrys Stadträte vom 20.1.1940.

166 Jean Chaumeil, Venise Gosnat. Un militant exemplaire du mouvement ouvrier français, Paris 1974, S. 119.

167 APP, GA M2, Dossier Georges Marrane.

168 Maurice Gunsbourg gelang es danach, aus einem Kriegsgefangenenlager zu flüchten, bevor er im März 1942 am Mont Valérien von den Deutschen erschossen wurde (CHAUMEIL, Gosnat, S.117). 
Trotz dieser Resistenzen erlebte Ivry wie viele Vorstädte aus dem Département de la Seine massive Repressionen gegen die politisch aktive und gewerkschaftlich organisierte Arbeiterschaft. Der Zugriff der Polizei auf die cités, wie die HBM-Wohnkomplexe oft genannt wurden und wo die Mitglieder des PCF mehrheitlich wohnten, konnte vor allem deshalb so schnell erfolgen, weil im Rahmen der Streikwelle von 1936 umfangreiche Register mit Informationen über die Streikenden und ihre Anführer angelegt worden waren. Auf diese griffen die Ordnungsbehörden nun zurück ${ }^{169}$. Zudem waren die führenden Kommunisten ohnehin durch ihre langjährige Tätigkeit in den Vorstädten und die monatlich abgefassten Polizeiberichte bekannt. Die verbleibenden Anhänger des PCF wurden nach ihrer Verhaftung in Internierungslagern ${ }^{170}$ zusammengefasst, in denen sie bis auf weiteres in Gewahrsam blieben. In Ivry erfolgte eine erste Verhaftungswelle im Mai 1940. Zwar wandte sich der neue Bürgermeister Henri Jacquelin zuvor noch einmal persönlich an Venise Gosnat und Hippolyte Marquès und verlangte, dass sie sich von der Partei trennen sollten. Marquès führte an der Route de Choisy ein HotelRestaurant, wo sich das französische Politbüro regelmäßig getroffen hatte. Als beide an der Partei festhielten, wurden sie zwei Tage später verhaftet und auf die Île d'Yeu gebracht ${ }^{171}$. Danach erfolgte die Internierung in ein Lager in Riom-ès-Montagnes. Dort saßen auch Ivrys Stadträte Édouard Quincey, Joseph Micalef, Jean Mazet und Louis Bertrand sowie der Bruder von Georges Marrane, André Marrane, ein. Insgesamt wurde das Département de la Seine mit einer hohen Dichte engagierter Kommunisten besonders stark von den repressiven Maßnahmen der Regierung getroffen. So wurden seit 1940 mehrere tausend Menschen verhaftet und interniert, was im Verhältnis zur Stadt Paris überproportional viele waren ${ }^{172}$. Zudem wurden die rückkehrenden Spanienkämpfer, bei denen es sich ja ebenfalls vor allem um Kommunisten und Anhänger anderer linker Gruppierungen und Parteien handelte, direkt von den französischen Behörden an der spanischen Grenze abgefangen und in die Internierungslager Le Gurs und Le Vernet gebracht. Im April 1940 verschärfte sich noch einmal die Gesetzgebung. Kommunisten wurden mit der Todesstrafe bedroht, da ihre Parteiarbeit nun als Vaterlandsverrat gewertet wurde ${ }^{173}$.

Die Auflösungstendenzen und die Folgen der Zerschlagung zeigten sich jedoch nicht nur auf den unteren Organisationsebenen der Partei, auch die Führung befand sich in einem katastrophalen Zustand. Nach der aus dem Bündnisfall resultierenden Kriegserklärung Frankreichs an Deutschland waren Maurice Thorez und einige andere Mitglieder des Politbüros mobilisiert

169 Stadtarchiv Ivry, Liste nominale, 1936.

170 Vgl. Denis Peschanski, La France des camps. L'internement 1938-1946, Paris 2002.

171 Chaumeil, Gosnat, S. 119.

172 Peschanski, La France, S. 335.

173 Courtois, Lazar, Histoire, S. 176. 
worden. Thorez flüchtete daraufhin recht schnell über Belgien in die Sowjetunion. André Marty hatte sich im Spanischen Bürgerkrieg engagiert und konnte sich ebenfalls nach Moskau absetzen. Lediglich Jacques Duclos, Benoît Frachon, Arthur Ramette und Maurice Tréand verblieben im Großraum Paris und versuchten, die Rumpfpartei zu reorganisieren und auf ein Leben in der Illegalität vorzubereiten ${ }^{174}$. Nach Stéphane Courtois' und Marc Lazars Interpretation zählte zu diesen Vorbereitungen auch Jacques Duclos' Brief an den Kammerpräsidenten Édouard Herriot, in dem er sich um die Rekonstitution der ehemaligen kommunistischen Parlamentsfraktion als potentielle Fürsprecherin eines Friedens mit Hitler bemühte. Als Reaktion darauf wurden Mitte Oktober 1939 vierunddreißig ehemalige Abgeordnete verhaftet und in das Pariser Gefängnis La Santé gesperrt. Die restlichen siebenundzwanzig Fraktionsmitglieder schworen der Partei ab. Im März 1940 erfolgte dann der Prozess gegen die ehemalige kommunistische Fraktion der Deputiertenkammer. Die Staatsanwaltschaft warf ihr vor, sich trotz des Parteiverbots rekonstituiert zu haben. Das Prozessurteil traf die Beschuldigten hart: Jeder wurde zu fünf Jahren Haft plus Verlust der staatsbürgerlichen Rechte verurteilt. Zuvor waren bereits Maurice Thorez und André Marty in Abwesenheit zu sechs Jahren Gefängnis und Aberkennung der französischen Staatsangehörigkeit verurteilt worden ${ }^{175}$.

Stéphane Courtois und Marc Lazar sehen in dieser Vorgehensweise einen weiteren Schritt zur Stalinisierung der Partei, wodurch mehr Disziplin als überlebenswichtige Voraussetzung für den Fortbestand in der Illegalität erreicht werden sollte. Die wachsende äußere Bedrohung konnte zudem das Zusammenrücken der Übriggebliebenen favorisieren und ihre Selbstverteidigungsreflexe hervorrufen ${ }^{176}$. Auf der anderen Seite ist fraglich, ob die Parteiführung das tatsächliche Ausmaß der Konsequenzen des Hitler-Stalin-Paktes richtig einschätzte und ihren realen Ausschluss aus der französischen Öffentlichkeit schon in dieser Weise antizipierte. Vielleicht lag bei der von Duclos eingeschlagenen Legalitätstaktik nicht grundsätzlich die Erwartung zugrunde, dass der französische Staat die Republik und die staatsbürgerlichen Rechte auch den Kommunisten gegenüber weiterhin garantieren würde. Zumindest die Reaktion von Franz Dahlem als Führer der KPD spricht dafür. Nach seinem vergeblichen Versuch, die Polizeibehörden bei einem Verhör am 16. September 1939 in der Pariser Polizeipräfektur von der Aufrichtigkeit seines Kampfes gegen den Nationalsozialismus und der Notwendigkeit einer deutschrussischen Verständigung für den Friedenserhalt in Europa zu überzeugen, wandte sich Franz Dahlem am 20. März 1940 aus dem Lager Le Vernet erneut 
an das Innenministerium ${ }^{177}$. Dieses Mal verlangte er, aus Frankreich ausreisen zu dürfen, nachdem ihm ein legitimer Aufenthalt als Asylsuchender verweigert worden sei. Am 4. September 1939 hatte er sich gemeinsam mit seinen Parteifreunden Paul Merker, Paul Bertz und Siegfried Raedel in dieser Angelegenheit an Édouard Daladier gewandt. Für den Fall einer Zurückweisung eines Aufenthaltsgesuchs wolle er zumindest eine ordentliche Unterkunft außerhalb des Lagers bekommen, wo er sich um seine persönlichen Belange kümmern könne ${ }^{178}$. Trotz dieser relativ formalen Forderung verzichtete Dahlem unterdes nicht darauf, seine langfristige Vision einer europäischen Friedensordnung zu unterstreichen, in der die Allianz zwischen der Sowjetunion, Frankreich und Deutschland den Frieden sowohl in Ost- und Südosteuropa als auch im Westen garantieren würde:

Le but de la politique étrangère poursuivie par mes amis et moi-même est: une amitié étroite et une alliance entre la nouvelle Allemagne libre, l'URSS et la France, ce qui garantirait la paix dans une Europe dans laquelle l'indépendance nationale et le droit illimité de disposer d'elles-mêmes seraient garantis à toutes les nations opprimées aujourd'huil ${ }^{179}$.

Im Prinzip benutzte Dahlem hier bereits die später von der DDR gegenüber Frankreich vorgebrachten Argumente für ihre staatliche Anerkennung als eben jenes »neue und freie Deutschland « und für den französischen Einsatz zugunsten einer europäischen Friedensordnung im Rahmen der Konferenz für Sicherheit und Zusammenarbeit in Europa (KSZE).

Franz Dahlem befand sich bei Abfassung dieses Briefes im November 1939 vermutlich schon seit drei Monaten im Quartier B des Lagers Le Vernet, das für »Extremisten« vorgesehen war. Dann war dem Vorschlag des Spezialkommissars Bernheim Folge geleistet worden, der in einem Gutachten an den für Le Vernet zuständigen Präfekten des Departements Ariège nicht nur den politischen Werdegang Dahlems genau nachzeichnete, sondern sein Festhalten an Moskau trotz der außenpolitischen Wende kritisierte ${ }^{180}$. Als zusätzliches Problem benannte Bernheim die Staatsangehörigkeit Dahlems. Zwar hatte er als Gegner der Nationalsozialisten seine deutsche Staatsangehörigkeit verloren, hatte aber als gebürtiger Lothringer Anrecht auf die französische Staatsbürgerschaft. Darüber hatte ihm im Januar 1934 die Ivryer Stadtverwaltung ein Zertifikat ausgehändigt ${ }^{181}$. Außerdem bestätigte eine Wohnungsbescheinigung des Ivryer Wohnungsamtes vom 6. September 1939, dass Dahlem seit

177 Dokumentationszentrum des Musée de la Résistance, fonds Albert Ouzoulias, carton 2, Brief von Franz Dahlem an den Innenminister vom 20.3.1940.

178 Ibid.

179 Ibid.

180 Dokumentationszentrum des Musée de la Résistance, fonds Albert Ouzoulias, carton 2, Gutachten des Spezialkommissars Bernheim an den Präfekten von Ariège in Foix vom 18.11.1939.

181 Ibid. 
Juli in der Rue Parmentier Nr. 40 wohnte ${ }^{182}$. Die Sonderdelegation hatte die kommunistisch anklingenden Straßen umbenannt, so dass aus der Rue Marat nun die Rue Parmentier geworden war. Es ist davon auszugehen, dass Venise Gosnat Franz Dahlem diese offizielle Bescheinigung noch schnell für die französischen Behörden ausgestellt hatte, damit dieser eine möglichst kohärente und legale Biographie vorweisen konnte.

Während Dahlem versuchte, von Le Vernet aus die deutsche Partei zu leiten, war die Lage ihres französischen Äquivalents während der Monate nach dem Parteiverbot weiterhin schwierig. Wichtigstes Anliegen blieb die Wiederherstellung der Kommunikationslinien zwischen Moskau und der französischen Führung und von dort aus an die Basis in Frankreich. Maurice Thorez war Anfang November 1939 nach seiner Desertierung in Moskau angekommen, wo sich André Marty bereits aufhielt. Zur gleichen Zeit wurde in Brüssel eine illegale Anlaufstelle aufgebaut, woran Eugen Fried, Jacques Duclos und Maurice Tréand beteiligt waren. Per Radiosender und über Kontakte mit der sowjetischen Botschaft in Belgien standen sie mit der Komintern in Moskau in Verbindung, während Benoît Frachon weiterhin in Paris blieb ${ }^{183}$. Angesichts der vielen Festnahmen und auch aufgrund der Truppenmobilisierung blieb es schwierig, Kontakt zur Basis aufzubauen. Wichtigstes Kommunikationsmittel war die Parteizeitung »L'Humanité«, deren Druck nun offiziell verboten war. Am 26. Oktober 1939 erschien die Zeitung erstmals wieder als rudimentäre Ausgabe, die aber dafür sorgte, dass wichtige Parteikontakte wiederhergestellt werden konnten ${ }^{184}$. Zu ihrer Herstellung war die Infrastruktur des Ivryer Rathauses genutzt worden. Venise Gosnat hatte dort Papier und Druckmaterial besorgen können, auf dem die Zeitung gedruckt und dann heimlich in Ivry, Vitry, Villejuif, Bagnolet und Montreuil verteilt werden konnte ${ }^{185}$.

Der Zustand der kommunistischen Partei Frankreichs während der »drôle de guerre «, also jener Periode zwischen der offiziellen Kriegserklärung an Deutschland und den tatsächlichen kriegerischen Auseinandersetzungen mit den deutschen Truppen, die sich seit dem 10. Mai 1940 westwärts bewegten und zunächst die Niederlande, Luxemburg und Belgien besetzt hatten, war der einer reduzierten illegalen Rumpfpartei, die innerhalb weniger Jahre nach dem Erfolg der Volksfront und der sozialen Wertschätzung der von ihr vertretenen Wählergruppen aus der offiziellen französischen Gesellschaft herausgedrängt worden war und das Gros ihrer neu gewonnenen Anhängerschaft verloren hatte. Allerdings konnte die Führung des PCF auch nach dem Parteiverbot auf sein Netzwerk persönlicher Beziehungen in der Pariser banlieue zurückgreifen, das er sich während seiner Etablierung als dominierende

182 Ibid.

183 Courtois, Lazar, Histoire, S. 174.

184 Ibid.

185 ChaumeIL, Gosnat, S. 118. 
Milieupartei der 1930er Jahre aufgebaut und durch die Besetzung strategisch wichtiger Stellen im Lokalverband abgesichert hatte.

Als die deutschen Truppen am 14. Juni 1940 in Paris einrückten, war der PCF weitestgehend führungslos. Einen Tag später erreichten aber Jacques Duclos, Maurice Tréand und Eugen Fried vermutlich in einem sowjetischen Diplomatenfahrzeug aus Brüssel kommend die französische Hauptstadt und hatten auch alsbald wieder Kontakt zu Jean Catelas, einem der in Paris gebliebenen Kader, welcher die Beziehungen zur Basis wieder verstärken konnte ${ }^{186}$. Allerdings blieb der Kontakt mit Moskau bis zum 6. August 1940 unterbrochen, so dass Duclos und Tréand zunächst auf sich allein gestellt waren und weiterhin die von Stalin ausgegebene Legalitätstaktik verfolgten, die sie letztendlich dazu brachte, die politische Situation grundlegend falsch einzuschätzen: Der kommunistischen Ideologie folgend, betrachteten Duclos und Tréand den Krieg als imperialistisch und machten die französische Regierung und das Bürgertum für die Niederlage Frankreichs voll verantwortlich. In den ankommenden deutschen Besatzern sahen sie zunächst Verhandlungspartner, mit denen eine Rückkehr in die Legalität möglich zu sein schien. Duclos und Tréand betrachteten die Deutschen in dieser Phase nicht als zu bekämpfende Besatzer, sondern gingen aufgrund der Kooperation zwischen Stalin und Hitler von Bündnispartnern aus, in deren friedenssichernder Allianz auch Frankreich einen Platz finden würde ${ }^{187}$. Kurzfristig versuchte die PCF-Führung in Paris daher, bei der deutschen Propagandastaffel die Erlaubnis einzuholen, die »Humanité« wieder legal erscheinen zu lassen ${ }^{188}$. Nachdem diese am 19. Juni 1940 erteilt wurde, wurden Maurice Tréand und der Rechtsanwalt Robert Foissin verhaftet. Dieser hatte den Kontakt zu den Deutschen hergestellt. Auf Initiative des deutschen Botschafters Otto Abetz wurden sie jedoch wieder freigelassen und sechs Tage später zu einem Gespräch empfangen, bei dem Abetz ihnen eine taktische Falle stellte und die angebliche deutsche Position der kommunistischen Perzeption anglich. Danach sei die militärische Niederlage der französischen Bourgeoisie zu verdanken und nur das Volk könne Frankreich wieder erheben. Und das Volk seien die Kommunisten ${ }^{189}$.

Tatsächlich versuchte Abetz mit diesem taktischen Hakenschlag, den lange propagierten Antifaschismus des PCF ins Leere laufen zu lassen und die französischen Kommunisten in die eigene Propagandatätigkeit in Frankreich einzubinden: Während der ersten Hälfte des Juli 1940 kam es zu einigen Treffen zwischen beiden Seiten, bei denen über diese Möglichkeiten verhandelt wurde. So einigte man sich am 4. Juli, eine Ausgabe von »Ce soir « anstelle der »Humanité« erscheinen zu lassen, in der die französische und die englische Regierung heftig attackiert wurden und der Akzent auf Friedenserhalt gesetzt

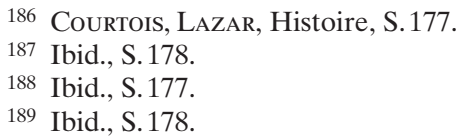


wurde. Gleichzeitig verlangte der PCF die Rehabilitation seiner Mitglieder und ihre Wiedereinsetzung in ihre politischen Funktionen vor dem Parteiverbot ${ }^{190}$. Knappe zehn Tage später wurde erneut über eine kommunistische Beteiligung an der Ausgabe einer volksnahen Tageszeitung »La France au travail« gesprochen. Erst im August erhielt Jacques Duclos wieder Anweisungen aus Moskau, die ihm ein vorsichtigeres Umgehen mit Abetz verordneten, insbesondere um die verbleibenden Parteimitglieder zu schützen, deren Vorgehen nach wie vor illegal war. Als Benoît Frachon nach der Flucht vor den deutschen Truppen wieder zurück nach Paris kam, war er ebenso wie weitere Führungskader, die in anderen Landesteilen verharrten, entsetzt von dem unvorsichtigen Vorgehen Duclos, zumal nun viele Funktionäre des PCF immer offener ihre Rathäuser und Gewerkschaftslokale zurückforderten und somit ihre Deckung nach fast einem Jahr in der Illegalität aufgaben. Am 5. August erging dann eine neue Anweisung an die französische PCF-Führung, die Verhandlungen mit den Deutschen zu beenden ${ }^{191}$.

Diese Episode aus dem Sommer 1940 zeigte, in welchem Maße sich die kommunistische Führung an den Vorgaben der Komintern orientierte und Stalins direkten Anweisungen fügte. Von einer offensichtlichen Allianz zwischen Deutschland und der Sowjetunion ausgehend, erkannte der PCF in dieser Situation die deutschen Besatzer zunächst nicht als Gegner, sondern folgte der ideologisch vorgeprägten Sichtweise, die die Verantwortlichen für das französische Desaster im innenpolitischen Gegner erblickte. Von dieser Spaltung der französischen Gesellschaft versuchten die Deutschen zu profitieren, indem sie die verbleibende PCF-Führung in dieser Sichtweise bestärkten. Erst nach dem Rückpfiff aus Moskau und der vorsichtigen Rekonstituierung der Parteiführung im August 1940 wurde dies als strategische Sackgasse erkannt. Die Partei schaffte es, sich aus ihrer exponierten Lage zurückzuziehen. Die mit dem Einzug der deutschen Truppen angenommene Veränderung der innenpolitischen Grundkonstellation trat allerdings erst in dem Moment ein, als das Schreckensszenario der weltkommunistischen Bewegung Wirklichkeit wurde und die Sowjetunion im Frühsommer 1941 von Deutschland angegriffen wurde. In diesem Moment hatte die Welt des PCF wieder ihre klare, traditionelle Ordnung der Zeit vor dem Hitler-Stalin-Pakt angenommen, und die Partei ging mit Verve an ihre Aufgabe, die Sowjetunion zu verteidigen. Die neue französische Parteistrategie bestand nun im Widerstand gegen die Wehrmacht, um so ihre Kampfkraft im Westen zu zermürben und vom Osten abzuziehen.

Mit der Suspendierung des kommunistischen Stadtrats im Herbst 1939 und seiner endgültigen Absetzung im Januar 1940, der sukzessiven Entmachtung seiner Mitglieder in den wichtigsten Gremien der Stadt, den Verhaftungen und Internierungen der PCF-Anhänger schien die Macht der Kommunisti-

190 Ibid., S. $178 f$.

191 Ibid., S. 180. 
schen Partei in Ivry äußerlich gebrochen zu sein. Mit Henri Jacquelin war ein Vertrauter des Präfekten zunächst zum Vorsitz der ersatzweise eingesetzten délégation spéciale gekommen, der sich sowohl als ehemaliger Mitarbeiter der Präfektur, aber auch bei der Pariser bourse de travail einen Namen gemacht hatte. Die bourses de travail waren in den 1930er Jahren im gesamten Département de la Seine entstanden, um der wachsenden Arbeitslosenzahl durch eine lokale Arbeitsvermittlung zu begegnen. Insbesondere die kommunistischen Stadtverwaltungen hatten diese >Arbeitsämter < gefördert und sich so in den Dienst ihrer Klientel gestellt. Eines der Hauptargumente für die Einsetzung Jacquelins in Ivry waren denn auch seine guten Kontakte und Kenntnisse im Arbeitermilieu, die er sich aufgrund seiner Tätigkeit erworben hatte. Gleichzeitig zeichnete ihn in den Augen des Präfekten aus »qu'il a vivement combattu les communistes avec les socialistes anti-marxistes «192.

Trotz seines demonstrativen Antikommunismus versuchte Henri Jacquelin wie die Vorgängerstadtverwaltung und auf Weisung des Präfekten, die sozialen Belange der Einwohnerschaft in den Mittelpunkt seines Amtes zu stellen ${ }^{193}$. Im Interview mit der Zeitung »Aujourd'hui « im Februar 1943 bezeichnete er dies als wichtigstes Instrument, um gegen den Kommunismus vorzugehen:

Le calme règne dans la commune [...]. De toutes mes forces je m'emploie à combattre la misère: je suis convaincu que c'est la meilleure, la seule façon de désarmer le communisme. Je suis, d'ailleurs, prodigieusement aidé dans ma tâche par la générosité de nombreux industriels et commerçants et par la bonne volonté des travailleurs ${ }^{194}$.

Tatsächlich waren die Seine-Kommunen seit Beginn der Besatzung in erster Linie um die Versorgung der Bevölkerung und die im Laufe des Jahres 1940 massiv anwachsende Arbeitslosigkeit besorgt ${ }^{195}$.

Unter Jacquelins Vorsitz wurden nach dem Vorbild Marranes eine ganze Reihe von Vereinen als Gegenentwurf zu den kommunistischen Organisationen gegründet, die deren Aufgaben zum Teil übernahmen ${ }^{196}$. Im Juni 1941 wurde das Centre d'orientation professionnelle de la banlieue sud-est de Paris gegründet, das bereits eineinhalb Jahre nach seiner Entstehung über 2700 Kinder und Jugendliche empfangen hatte, um sie über spätere berufliche Möglichkeiten zu informieren ${ }^{197}$. Ein Jahr zuvor war das Centre d'enseignement ménager et d'information familiale entstanden, das - in einem Nebengebäude des Rathauses untergebracht - zur Aufgabe hatte, sich um Ivrys Familien zu

\section{APP, GA J2, Dossier Henri Jacquelin.}

193 Stadtarchiv Ivry, 1 K 5/6, Le préfet de la Seine à messieurs les présidents des délégations spéciales, 24.10.1939.

194 Aujourd'hui, 18.2.1943.

195 AN F/1cIII/1187, Rapport mensuel du préfet de la Seine, 8.8.1940, 13.9.1940 u. 3.2.1941.

196 In diesem Sinne auch das Schreiben des Präfekten, vgl. Stadtarchiv Ivry, 1 K 5/6, Le préfet de la Seine à messieurs les présidents des délégations spéciales, 24.10.1939.

197 APP, GA J2, Dossier Henri Jacquelin. 
kümmern. Dabei ging es sowohl um materielle als auch ideelle Unterstützung. Neben der Vermittlung von Kenntnissen im Bereich Hauswirtschaft und Textilverarbeitung kümmerten sich die Mitarbeiter des Zentrums um Hilfe für Mütter. Ihnen stand seit Januar 1941 zusätzlich die Maison de la mère zur Verfügung, in der eine Mütterberatung stattfand und eine Krippe für Kinder bis zu drei Jahren eingerichtet war.

Zum umfassendsten Sozialwerk unter Jaquelin avancierte das Euvre fraternelle ivryenne d'assistance aux victimes de guerre, eine Dachgesellschaft unter der Patronage der Stadtverwaltung und des Rotes Kreuzes, der ihm angeschlossenen Hilfsgesellschaft für Kriegsverletzte, den Kriegsordenträgern, den Anciens Combattants, der Association des dames françaises sowie Ivrys Konservativen, die sich schon vor der Absetzung der kommunistischen Stadtverwaltung in den oppositionellen Amis d'Ivry zusammengetan hatten ${ }^{198}$. Interessant ist, dass dieses Sozialwerk bereits im Herbst 1939 gegründet wurde. Die Ivryer Ortsgruppe bemühte sich im Dezember um Aufnahme beim Secours national, dessen Präsident Philippe Pétain war ${ }^{199}$. Dies war nur eine der Grußadressen der eingesetzten Stadtverwaltung an den Maréchal, weitere Unterwerfungsgesten an ihn folgten. Darüber hinaus zeigte die Zusammensetzung der Leitung des Euvre fraternelle ivryenne, dass mit dem neuen Stadtrat auch die ehemaligen politischen Gegenspieler des PCF in Ivry an die Macht gekommen waren. Im Verwaltungsrat saßen Henri Jacquelin als Ehrenpräsident sowie Jean Jardel und der Arzt Henri Perreau als Präsidenten ${ }^{200}$. Durch die Integration der Amis d'Ivry und der Harmonie - der konservativen Gegenbewegungen zum PCF -, wurden nicht nur deren klar wahrnehmbare Repräsentanten wie Henri Guerder, dessen spitzfindige Artikel gegen die kommunistische Stadtverwaltung in den Jahren zuvor den journalistischen Gegenpol zu den Traktaten des »Travailleur « dargestellt hatten, sondern auch das minoritäre konservative Restmilieu in das Vereins- und Verwaltungsnetz Ivrys einbezogen. Es dominierte nun den städtischen Raum und demonstrierte seine Präsenz etwa durch Sammlungen auf dem Markt für die Kriegsopfer und -gefangenen ${ }^{201}$.

Ivrys Konservative schafften es zudem, nach der Absetzung des Stadtrates die wichtigsten lokalen Ämter neu zu besetzen. Der Pariser Präfekt bestätigte Jacquelin als Vorsitzenden der Sonderdelegation und ernannte ihn dann zum Bürgermeister. Seine Beigeordneten waren der frühere Kandidat der Deputiertenkammer, Bériot, und der Spitzenkandidat der rechten Liste, Dr. Perreau. Bei einer Reorganisation der Stadträte und -verwaltungen in der Pariser banlieue nach Anweisungen der Regierung in Vichy im Mai 1941 wurden zudem nur solche Personen zu Stadträten ernannt (und nicht gewählt!), die sich auszeichneten durch »une moralité indiscutable, aussi bien dans leur vie

198 Stadtarchiv Ivry, 5 H 4/5, Euvre fraternelle ivryenne.

199 Ibid.

200 Ibid.

201 Ibid. 
publique que dans la vie privée, et d'un dévouement absolu à la politique du maréchal, chef de l'État «202. Die Zusammensetzung des neuen Stadtrats erfolgte nach strengen Proporzregeln, die der Vichy-Trias von »Famille, Travail, Patrie« entsprachen und jeweils einen Familienvater, einen Arbeiter, eine Frau für Soziales und ausschließlich christliche Franzosen als Mitglieder forderten $^{203}$. Tatsächlich waren dann in den verschiedenen Vereinen und Wohltätigkeitsorganisationen jene Personen vertreten, die sich nach Auskunft der Polizei durch »gute Moral«, Zugehörigkeit zur katholischen Kirche und ein rechtschaffenes Leben auszeichneten ${ }^{204}$. Auffallend bei diesem Personenkreis war, dass es sich durchgehend um Mitglieder der lokalen Unternehmerschicht oder um Vertreter der freien Berufe handelte. So war Jean Jardel, Jahrgang 1891, in der Direktion der Ivryer Brennerei Vins du Postillon tätig, Bériot war Direktor der Établissements Muller in Ivry und außerdem Vizepräsident der Union industrielle et commerciale du canton d'Ivry. Seit Mai 1941 war er stellvertretender Bürgermeister. Dass er schon 1938 die Schwächung des kommunistischen Milieus herbeizuführen versucht hatte, zeigte sich, als er in seinem Unternehmen bevorzugt Mitglieder der Doriot-Partei Parti populaire français (PPF) eingestellt hatte ${ }^{205}$. Diese war zwar wesentlich nationaler als der in internationalistischer Tradition verhaftete PCF, in Organisationsstruktur, sozialer Ausrichtung und schließlich durch seinen ursprünglich kommunistischen Gründungsvater dennoch das rechte Äquivalent des PCF.

Während das politische und kulturelle Machtvakuum mit Anhängern der politischen Rechten mit Affinitäten zu Pétain aufgefüllt wurde, stellt sich die Frage, wie das kommunistische Milieu auf den Wegfall seiner politischen Führung, sei es durch Verhaftung, sei es durch deren Untertauchen, reagierte. Methodisch ist die Antwort schwierig zu fassen, da das Erinnerungsmonopol nach 1944/45 in Ivry wieder in der Hand des PCF lag und im Stadtarchiv kaum Unterlagen aus dieser Periode überliefert sind, die über das bloße Verwaltungsgerüst hinausgehen. Lediglich andeutungsweise schimmert die vielfältigere Realität Ivrys während der Besatzungszeit dort durch, wo überformte Erinnerung und Opfergedenken die erinnerte Zeit als einen Monolith der Résistance suggerieren wollen. Auch in den Monatsberichten des Seine-Präfekten an den französischen Innenminister finden sich nur selten Hinweise auf das Verhältnis der banlieue-Bevölkerung zu den ehemaligen Repräsentanten der kommunistischen Partei. Nur im Januar 1942 wurde darauf hingewiesen, dass es noch eine gewisse Sympathie bei einigen für ihre ehemaligen Stadträte gebe, die Mitglieder des heimlichen, nachrückenden Parteiapparats in der Bevölkerung hingegen nicht bekannt seien ${ }^{206}$.

202 Stadtarchiv Ivry, 1 K 5/6, Le préfet de la Seine à monsieur Jacquelin, Henri, 12.5.1941.

203 Ibid.

204 APP, GA J2, Dossier Henri Jacquelin.

205 Ibid.

206 AN F/1cIII/1187, Rapport mensuel du préfet de la Seine, 1.1.42. 
Es ist bereits deutlich geworden, dass Ivrys kommunistische Partei Opfer der präfektoralen Repressionen und der deutschen Besatzungsmacht geworden war. Neben den Châteaubriant-Opfern wurden zahlreiche andere Bürger und Kommunisten Ivrys Opfer von Erschießungen, Internierungen und Deportationen in deutsche Konzentrationslager. Nach einem Todesregister des Stadtarchivs wurden 37 Menschen mit Wohnort in Ivry erschossen, darunter befanden sich sowohl die beiden Mitglieder der Pariser MOI-FTP als auch die drei in Châteaubriant Ermordeten ${ }^{207}$. Achtzehn Ivryer Kommunisten wurden von verschiedenen Erschießungskommandos auf dem Mont Valérien hingerichtet; bei fünf Opfern ist der Todesort Ivry angegeben, wobei unklar bleiben muss, ob dies tatsächlich der Fall war oder ob der Erschießungsort unbekannt war und aus administrativen Gründen Ivry angegeben wurde. Ein Ivryer Kommunist wurde 1941 im Pariser Gefängnis La Santé guillotiniert, ein FFIMitglied wurde ein Jahr später in Compiègne erschossen. 1944 ließen weitere zehn Ivryer über Frankreich verteilt ihr Leben, weil sie in Befreiungskämpfe bei den FFI oder in andere Zusammenhänge verwickelt waren ${ }^{208}$.

Es ist bemerkenswert und entspricht den Linien der kommunistischen Milieubildung, dass viele der späteren Todesopfer in den städtischen HBM gewohnt hatten, also direkt aus den Hauptlinien des Milieus stammten: Sechs Hingerichtete kamen aus der Rue Marat und jeweils zwei aus der Rue DenisPapin und von der Place Philibert-Pompée ${ }^{209}$. Die Verteilung derjenigen Einwohner von Ivry, die während der Deportation starben, war hingegen anders gelagert und lässt deutlich erkennen, dass es sich hierbei nicht ausschließlich um politisch, sondern auch um ideologisch motivierte Repression handelte. Von den zweiundsechzig Bürgern Ivrys, die während der Deportation nach Mittel- und Osteuropa gestorben waren, hatten lediglich drei in der Rue Marat gelebt, die zudem ausdrücklich als »Politische« gekennzeichnet waren. Ein weiteres Opfer war Bewohner der HBM an der Route stratégique ${ }^{210}$. Bei weniger als der Hälfte aller Ivryer Deportationsopfer handelte es sich hingegen um aschkenasische Juden, die durch die Emigration nach Frankreich bereits eine Etappe auf der Flucht vor Armut und Antisemitismus hinter sich hatten $^{211}$. Namen und Geburtsorte der Menschen lassen darauf schließen, dass vermutlich neunundzwanzig von ihnen jüdischer Herkunft waren, darunter sieben Kinder, die teilweise schon in Frankreich geboren worden waren. Als Todesort sind hauptsächlich die deutschen Vernichtungslager im Osten, namentlich Auschwitz oder das Durchgangslager im Nordosten von Paris, Drancy, angegeben. Fünf von Ivrys politischen Deportierten starben hingegen

207 Stadtarchiv Ivry, 27 W 1, Avis de décès.

208 Ibid.

209 Ibid.

210 Ibid.

211 Zur Situation der aus Deutschland emigrierten Ostjuden in Frankreich vgl. Franke, Paris, S. 200-212. 
in Dachau, zwei in Flossenbürg, jeweils einer in Mauthausen und Sachsenhausen, zwei in Buchenwald ${ }^{212}$.

Auch unter den ehemaligen kommunistischen Stadträten gab es erhebliche Opfer. Während Georges Marrane die Zeit in der Résistance überstand und sein Stellvertreter Venise Gosnat durch Marranes mutige Befreiungsaktion im Internierungslager Riom-ès-Montagnes freikommen und den kommunistischen Widerstand in der Bretagne organisieren konnte, überlebten mindestens sieben von dreißig die deutsche Besatzung nicht, sei es durch Erschießung, sei es durch Tod in den Konzentrationslagern ${ }^{213}$. Vier von ihnen waren deportiert worden, hatten aber die Lager überlebt, ebenso wie zwölf weitere Stadträte, die teilweise in französischen Internierungslagern inhaftiert gewesen waren ${ }^{214}$.

Tatsächlich hat sich die Übergangszeit vom Verbot des PCF bis zum realen Machtübergang an die Gruppe um Jacquelin in Etappen vollzogen. Ein Schreiben des Präfekten weist darauf hin, dass einige demokratisch gewählte kommunistische Stadträte in der banlieue zunächst an ihren Ämtern festhielten und die Übergabe der Rathäuser an die délégations spéciales nicht akzeptierten $^{215}$. Trotz der schlechten Quellenlage ist anzunehmen, dass die von der Nachfolgestadtverwaltung angebotenen Sozialwerke von der Bevölkerung angenommen wurden, zumindest weist die Zahl der berufsberatenen Jugendlichen darauf hin. Ein weiteres Indiz dafür, dass die Ablehnung zumindest materieller Anreize in der Ausnahmesituation der Besatzung nicht grundsätzlich gewesen sein kann, ist, dass sich immerhin 264 Ivryer Arbeiter ab 1940 gegen Entgelt beim Straßenausbau und der Verstärkung des Forts von Ivry beteiligten ${ }^{216}$. Achtzehn von ihnen lebten in den HBM an der Place PhilibertPompée, in der Rue Marat, an der Route stratégique oder in der Rue DenisPapin, waren also in das Ivryer Arbeitermilieu integriert. Dafür spricht auch, dass ein Bruder von zwei Baustellenarbeitern 1944 als politisch Deportierter in Buchenwald umgekommen ist ${ }^{217}$.

Auf der anderen Seite spricht die Verhaftung von besonders vielen und jungen Menschen aus Ivry wegen Widerstandsakten in der Zeit zwischen dem Herbst 1939 und dem Jahr 1941 für die hohe Dichte und den starken Zusammenhalt innerhalb des kommunistischen Milieus und den Gehorsam gegenüber der Parteiführung. Außerdem waren die Sicherheitsmechanismen des kommunistischen Widerstandes in dieser Phase noch nicht ausgefeilt, so dass vergleichsweise viele Verhaftungen aufgrund der Unvorsichtigkeit und mangeln-

212 Stadtarchiv Ivry, $27 \mathrm{~W}$ 1, Avis de décès.

213 Stadtarchiv Ivry, 1K 5/6, Liste des membres de l'ancien conseil municipal, élus le 5 mai 1935, qui étaient en fonction au $1^{\mathrm{er}}$ septembre 1939, o. D. (vermutlich Herbst 1944).

214 Ibid.

215 Stadtarchiv Ivry, 1 K 5/6, Le préfet de la Seine à messieurs les présidents des délégations spéciales, 24.10.1939.

216 Stadtarchiv Ivry, 5 H 4/3, Fiches du personnel.

217 Stadtarchiv Ivry, 27 W 1, Avis de décès. 
den Erfahrung der Widerstandskämpfer vorgenommen werden konnten. Von den Zeitgenossen wurden im Rückblick als Argument für die Widerstandshandlungen immer wieder die Handlungsanweisungen von der Partei und die Loyalität ihr gegenüber angegeben ${ }^{218}$, die offensichtlich trotz oder gerade wegen der äußeren Bedrohung nicht in Frage gestellt wurde. In dieser Zeit vor dem Mai 1940, als die délégation spéciale noch nicht fest im Rathaus etabliert war, hatte der PCF noch relativ guten Zugang zu den Verwaltungsgebäuden und konnte sich persönliche Gegenstände (Georges Marrane), Druckpapier (Venise Gosnat) oder Schreibmaschinen (Gaston Garnier) beschaffen ${ }^{219}$. Die Widerstandsakte bestanden zu diesem Zeitpunkt aus dem Druck und der Verteilung von Flugblättern, deren Inhalt von der Parteiführung vorgegeben wurde und sich oft gegen die französische Außenpolitik richtete. Auch die ersten illegalen Ausgaben der »Humanité« wurden in Ivry vervielfältigt, andere Schriften entstanden aufgrund der Informationen, welche Thorez' Sekretär Pierre Rigaud an die Ivryer Genossen weitergab. Mit Hilfe von Marranes langjähriger Sekretärin und einem Heizer konnten in dieser Zeit noch Flugblätter im Rathaus selbst gedruckt werden, ohne dass die neue Stadtverwaltung dies gemerkt hätte 220 . Danach wurde das Druckzentrum zweimal verlegt - zunächst in eine Schule im Zentrum, wo man eine Schreibmaschine nutzen konnte, die aus einem Nebengebäude des Ivryer Parteisitzes entwendet wurde, danach in das gegenüberliegende Gebäude der HBM an der Route stratégique, wo die Ehefrau eines PCF-Mitgliedes die Flugblätter abtippte 221.

Neben der Verteilung von Flugblättern in den Briefkästen und den Ivryer Fabriken wie der SKF oder Genève war ein weiteres wichtiges Mittel das Kleben von Plakaten und das Beschriften der örtlichen Mauern mit prokommunistischen und antideutschen Parolen. Zu diesem Zweck gingen in der Regel zwei oder drei junge Leute gemeinsam vor. Einer >stand Schmiere $<$ und achtete darauf, dass die anderen, von der Polizei unbemerkt, ihre Anschläge und Aufschriften anbringen konnten.

Das wichtigste Widerstandszentrum auf Ivrys Stadtgebiet waren aber sicherlich die HBM, weil hier die größte soziale Kontrolle ausgeübt werden konnte. Yvonne Zellner berichtet in ihrer Erinnerung, dass sie und ihr Mann Émile nach dem Hitler-Stalin-Pakt den anderen Bewohnern in der Rue Marat Nr. 40 begründeten, warum sich beide Diktatoren verbündet hatten ${ }^{222}$. Also hatte es durchaus auch in Ivrys parteikonformem Milieu Überraschung und Zweifel an der plötzlichen Wendung Stalins gegeben. Dennoch war die Bindung an den PCF so stark, dass dieser fundamentale Kurswechsel in dieser kommunistischen Hochburg akzeptiert wurde und die Anhänger des PCF aus den HBM

218 Vgl. ausführlich Ivry, fidèle à la classe ouvrière.

219 Dans les souvenirs de Gaston Garnier, in: ibid., S. 35-37, hier S. 35.

220 Ibid.

221 Ibid., S. 37.

222 Témoignage d'Yvonne Zellner, in: ibid., S. 32. 
wie Émile Zellner, Henri Pourchasse, Lucien Trégaut oder Climonet zunächst eine dreimonatige Gefängnisstrafe für ihr Festhalten an der Partei in Kauf nahmen $^{223}$. Die Dichte der Bindungsstruktur wird auch in dem Bericht von Lucienne Robin deutlich, die die Schließungs- und Protektionsmechanismen beschreibt, mit denen die Bewohner der Rue Marat auf die Bedrohung durch die französische Polizei reagierten ${ }^{224}$. Zum einen war es üblich, dass Personen, nach denen die Polizei fragte, von ihren Nachbarn verleugnet wurden. Zum anderen hatten die Kinder kommunistischer Familien ein Frühwarnsystem entwickelt und meldeten im gesamten Gebäudekomplex, wenn sich ein Polizeifahrzeug näherte. Auf diese Weise war es den HBM-Bewohnern möglich, unmittelbar belastendes Material rechtzeitig verschwinden zu lassen ${ }^{225}$.

Auf der anderen Seite wies das Milieu auch Brüche auf. So wurde etwa Georges Gosnats Ehefrau in der Rue Marat von einer Nachbarin wegen Flugblattherstellung denunziert, daraufhin verhaftet und nach Deutschland deportiert. Dennoch waren tendenziell die homogene Lebenssituation und die engen sozialen Bindungen in den Wohnquartieren ausschlaggebend für nichtkonformes Verhalten gegenüber dem französischen Staat und für Solidarität im Milieu. Die Loyalität gegenüber der Partei und die dichte nachbarschaftliche, freundschaftliche und auch familiäre Vernetzung der HBM-Mieter bildeten die Grundlage für eine mögliche Teilnahme am kommunistischen Widerstand. Zudem funktionierte die vertikale Kommunikation zwischen Parteiführung, mittleren Kadern und Basis in Ivry besonders gut. Gesichter von Vertrauensleuten waren von Parteitagen, Demonstrationen, parteinahen Organisationen und durch persönliche Vorstellung bekannt. Die traditionelle bolschewistische Organisation in Ivry sicherte die politische und organisatorische Verlässlichkeit der Parteibasis ${ }^{226}$. So warb der Gewerkschafter und späteres Mitglied des PCF-Militärkomitees, Eugène Henaff, noch vor der Verhaftungswelle im Herbst 1940 Ivrys Parteimitglied Mathurin Le Moullac an, um erste Widerstandskomitees an seinem Arbeitsplatz, dem Krankenhaus Hôtel-Dieu in Paris, und in anderen Krankenhäusern aufzubauen. Die vereinbarte Methode zielte darauf ab, die vor dem Krieg bestehenden Personennetzwerke für den Widerstandskampf zu reaktivieren:

Je recevais chez moi la visite du camarade Eugène Hénaff et nous mettions sur pied les premiers comités populaires de la Résistance dans les hôpitaux et les services publics en contactant les militants d'avant-guerre au fur et à mesure de leur démobilisation pour ceux qui n'avaient pas été faits prisonniers ${ }^{227}$.

223 Ibid.

${ }^{224} \mathrm{Au} 40$ de la rue Marat. Souvenirs de Lucienne Robin, in: ibid., S. 67.

225 Ibid.

${ }^{226}$ Parteidisziplin und Gehorsam gegenüber der Führung wurden von dieser auch vehement eingefordert. Einerseits entsprach dies den leninistischen Prinzipien, andererseits erforderte die besondere Bedrohungslage in der Résistance absolute Verlässlichkeit (Courtois, Lazar, Histoire, S.193).

227 Mathurin Le Moullac, Un incessant combat, in: Ivry, fidèle à la classe ouvrière, S. 67. 
Henriette Schmitt, die seit 1932 in Ivry lebte und in den 1930er Jahren zwei Jahre lang die Moskauer Parteischule besucht hatte, erhielt ebenfalls den Auftrag, unterbrochene Personenkontakte wiederherzustellen. Sie war enge Mitarbeiterin des PCF-Führungsmitglieds Arthur Dallidet, welcher im Mai 1942 am Mont Valérien hingerichtet wurde. ${ }^{228}$ Darüber hinaus verhalf sie Fernand Grenier nach seiner Flucht im Juni 1941 aus dem Internierungslager in Châteaubriant zu neuen Papieren. Im Oktober 1942 wurde sie verhaftet ${ }^{229}$. Fernand Grenier spielte 1943 eine Schlüsselrolle bei der Allianzbildung zwischen dem PCF und General de Gaulle in London. Nach Vorgesprächen mit einem seiner wichtigsten Repräsentanten in Frankreich, dem Obersten Rémy, fuhr Grenier im Januar 1943 mit ihm zu Verhandlungen nach London. Obwohl dies eine Allianz mit Vorbehalten war und Kommunisten und Gaullisten weiterhin um die Führung der Résistance in Frankreich konkurrierten, markierte sie doch die Öffnung des PCF gegenüber den anderen Widerstandsgruppen $^{230}$.

Das gleiche Schema vertikaler Anweisung durchzieht andere Erinnerungsberichte, wie jenen von Émile Zellner: »À la suite d'un premier cadrage, je dois travailler au service propagande du secteur, puis je dois attendre et repasser au camarade chargé des cadres auprès du comité central. Je le rencontre, je le reconnais, c'est Lacazette ${ }^{231}$. Gleichzeitig findet sich die durchgängige Argumentation, dass für die zahlreichen Verhaftungen, welche bis zur Verbesserung der Sicherheitsmaßnahmen im Herbst 1942 große Teile des kommunistischen Widerstandes in die Hände von Polizei und Gestapo fielen ließen, die »traîtres « verantwortlich seien, die bei der Polizei geredet hätten. Tatsächlich gab es spektakuläre Verratsfälle wie im Rahmen der Affäre Joseph Dawidowiczs, an deren Ende der »Verräter«, der der Folter nicht mehr hatte standhalten können, vom PCF exekutiert wurde ${ }^{232}$. Die Diabolisierung der »Verräter « hatte auf die Widerstandskämpfer disziplinierende Wirkung, wurden doch die Abweichler ohne Rücksicht auf die Umstände gnadenlos ausgestoßen und verloren jegliche soziale Anerkennung ${ }^{233}$.

Die generationenübergreifende Bindekraft des kommunistischen Milieus wirkte auch in der Illegalität fort. Exponierte Ivyer Familien waren oft gleichzeitig und mehrfach von Verhaftung, Internierung, Tod und Deportation betroffen. Von dem Ehepaar Robin überlebte nur die Ehefrau Lucienne. Vital

228 Courtois, Lazar, Histoire, S. 188.

229 Ivry, fidèle à la classe ouvrière, S.59. Vgl. auch Stadtarchiv Ivry, 27 W 1, Avis de décès.

230 Courtois, Lazar, Histoire, S. 190-193.

231 Ivry, fidèle à la classe ouvrière, S. 43; Régine Lacazette-Leriche war mit Lacazette bis zu seiner Hinrichtung verheiratet. Zum engeren Kreis ehemaliger kommunistischer Widerstandskämpfer gehörend, heiratete sie später den hier sehr aktiven Fernand Leriche.

232 Vgl. das Kapitel »Die Affaire Dawidowicz«, in: Courtois, Peschanski, Rayski, L'Affiche rouge, S. 283-289.

233 Courtois, Le PCF, S. 272 f. 
Marquès verlor seinen Vater Hippolyte. Georgette Rostaing, Verantwortliche der in der Illegalität entstandenen kommunistischen Union des jeunes filles de France starb 1944 in Auschwitz, ihr Bruder Pierre 1945 achtzehnjährig in der Deportation. Die Familie Prunières erlebte die Deportation und Kriegsgefangenschaft von mindestens zwei ihrer vier Söhne. Oft erhielten die überlebenden Söhne den Auftrag, die Verantwortung für die Familie und auch das politische Erbe des Vaters zu übernehmen. So schrieb Jean Poulmarch vor seiner Exekutierung in Châteaubriant an seine Frau Laurence: »Que notre Claude sache comment son père est mort et qu'il poursuive la route que son père a tracée, envers les parents, les amis, les camarades d'Ivry «234.

Typisch ist auch das Beispiel von Roland Le Moullac, Sohn des Stadtrats Mathurin Le Moullac. Er beschreibt seine Mitwirkung an Widerstandsakten als eine ganz natürliche Folge, quasi ein Hineinrutschen in die Résistance, ohne dass dazu viel Anleitung von außen notwendig gewesen wäre. Schon seine Kindheit sei stark vom kommunistischen Milieu und den lokalpolitischen Aktivitäten der mairie geprägt worden, wie es bei vielen Altersgenossen kommunistischer Eltern der Fall war: »Mes souvenirs se confondent avec ceux d'autres enfants de militants. 1938-1939, je me revois jouer au patronage avec les petits Espagnols hébergés par la municipalité d'Ivry «235. Erste Pläne zu kleineren Sabotageakten wurden danach mit anderen jugendlichen Kommunisten an Ivrys Befestigungsanlage geschmiedet. Hier beschloss man, die Wochenschauen im Kino zu stören, indem Puder von der Balkonbrüstung gestreut wurde 236 . Obwohl Roland Le Moullac als Sohn eines ehemaligen Stadtrats unter besonderer Aufsicht der Polizei stand, nahmen er und seine Freunde quasi in jugendlicher Unbeschwertheit an antideutschen Demonstrationen teil, besorgten sich bei einer der Propagandaausstellungen der deutschen Besatzer im Pariser Wagram-Saal Propagandamaterial, das sie dann mit einer Kinderdruckmaschine zum kommunistischen Informationsblatt umfunktionierten $^{237}$. Bis zu seiner Verhaftung im Oktober 1942 verteilte Roland Le Moullac Flugblätter in Ivry.

Trotz dieser vielfältigen Abwehr des Besatzungsregimes und der fortbestehenden An- und Einbindung in den geheimen Parteiapparat, in dem führende Lokalpolitiker eine wachsende Rolle spielen sollten, tat sich Ivry in der Wahr-

\footnotetext{
${ }^{234}$ Ivry, fidèle à la classe ouvrière; Der handschriftliche Brief von Jean Poulmarch ist Ivrys Stadtarchiv von der Familie zur Verfügung gestellt worden. Betrachtet man die Karriere, die Guy Môquets Abschiedsbrief posthum in der französischen Öffentlichkeit gemacht hat, und den Personenkult, der daraus entstanden ist, lohnt es sich, als Quelle für die Ereignisse in Châteaubriant diesen letzten zweiseitigen Brief eines Erwachsenen heranzuziehen. Schließlich zählte auch er zu den 27 erschossenen Geiseln der Hinrichtung vom 21. Oktober 1941.

235 Roland Le Moullac, Avec l'enthousiasme de la jeunesse, in: Ivry, fidèle à la classe ouvrière, S.73f.

236 Ibid.

237 Ibid.
} 
nehmung der präfektoralen Ebene nicht besonders hervor. Immer wieder kam es auch in anderen Kommunen der Pariser banlieue $\mathrm{zu}$ gelegentlicher Verteilung von Flugblättern oder zu kommunistischer Mund-zu-Mund-Propaganda $^{238}$. Die Hauptsorge der Bevölkerung blieb mit der fortschreitenden Kriegsdauer ihre Lebensmittel- und Energieversorgung, von deren Knappheit besonders die stark industrialisierten Vororte betroffen waren. Die Menschen litten unter der Last des Alltags und zeigten sich für politische Fragen wenig aufgeschlossen ${ }^{239}$. Auf der anderen Seite zeigte sich hier sicherlich der disziplinierende Effekt, der von den Repressionen der Besatzungsmacht ausgegangen war: »L'attitude de la population [des arrondissements de Paris et des communes de la Seine] se caractérise dans son ensemble par un sentiment de résignation $\ll^{240}$. Insbesondere die ersten massiven Geiselerschießungen in Châteaubriant im Herbst 1941 hatten die Menschen zutiefst schockiert. Von den Behörden wurde dies jedoch auf die Wirkung der »ausländischen Propaganda«, sprich der kommunistischen Partei, zurückgeführt.

\subsubsection{Lokale Politiker und ausländische Emigranten in den Organisationen des kommunistischen Widerstandes}

Mit dem deutschen Überfall auf die Sowjetunion 1941 begann für die französische kommunistische Partei eine neue Phase ihrer Existenz. Nun galt es, der Sowjetunion durch den bewaffneten Kampf gegen die Deutschen in Frankreich beizustehen und die Kampfkraft der Wehrmacht so dauerhaft zu schwächen. Gab es bei einigen aufgrund der Bürgerkriegserfahrung in Spanien eine gewisse Grundkenntnis im Umgang mit Waffen, war dies für das Gros der kommunistischen Widerstandskämpfer neu, zumal der Kampf gegen die Besatzer aus der Illegalität heraus geschehen musste, also mit den geordneten Strukturen einer Armee nichts gemein hatte. Als vorteilhaft hierfür erwies sich die starke Parteidisziplin des PCF, die er durch seine bolschewistische und stalinistische Ausrichtung in der Zwischenkriegszeit erworben hatte. Durch die frühzeitige Einführung der Dreierstruktur - ein politisch Verantwortlicher, ein Verbindungsmann und ein technisch Verantwortlicher - konnte ein Grad an Heimlichkeit erreicht werden, der es der Abwehr und der Gestapo erschwerte, Zugriff auf größere Teile des illegalen Parteiapparats zu bekommen. Dennoch war gerade die Anfangszeit des kommunistischen Widerstands in Frankreich sowohl in der besetzten als auch in der freien Zone von starken Verlusten gekennzeichnet. In dieser Zeit wurden ganze Widerstandsnetze entdeckt und brutal zerschlagen ${ }^{241}$.

238 AN F/1cIII/1187, rapport mensuel du préfet de la Seine, 1.12.1941 u. 1.3.1942.

239 Ibid., 31.10.1942.

240 Ibid., 1.11.1941.

241 Courtois, Le PCF, S. 241. 
Träger des kommunistischen Widerstandes waren zunächst diejenigen, welche aus dem Parteiapparat hervorgegangen waren. Sie waren den Verhaftungen infolge der Repressionspolitik entgangen und hatten nicht zuletzt durch die Auflösung der legalen Parteistützpunkte in den kommunistischen Rathäusern der banlieue ihre unmittelbare berufliche Verpflichtung verloren. Douzou betont besonders diesen Aspekt der Verfügbarkeit als Voraussetzung für die individuelle Teilnahme an der Résistance. Zugleich hebt er die Prädisposition der zuvor in den Jugendorganisationen der Partei engagierten Jugend hervor $^{242}$, sich in die langsam entstehenden geheimen Strukturen der Linksparteien zu integrieren.

Die Strategie des PCF nach seinem Eintritt in den aktiven Widerstand verfolgte das Ziel, Deutschland als Besatzungsmacht zu schwächen. Konkret und vor Ort zielte sie darauf ab, den Feind durch unmittelbare Widerstandsaktionen und Sabotageakte zu bekämpfen. Das erste wichtige Ereignis in diesem Zusammenhang stellte die Ermordung eines deutschen Soldaten in der Pariser Metrostation Barbès am 21. August 1941 durch Pierre Georges dar, der sich in seiner späteren Rolle als Anführer eines Korps der Francs-tireurs partisans (FTP) »Colonel Fabien« nannte. Als Reaktion auf dieses Attentat wurden die ersten Todesurteile gegen drei führende Kommunisten ${ }^{243}$ gefällt und am 24. September 1941 vollstreckt. Am 19., 20. und 21. Oktober schickte die Organisation spéciale, eine Spezialeinheit, welche den bewaffneten Kampf des PCF seit dem Sommer 1941 leitete, jeweils ein Attentatskommando nach Rouen, Nantes und Bordeaux, um die Konzentration des Widerstandes auf Paris zu entzerren und dort einen wirkungsvollen Schlag gegen die deutsche Militäradministration auszuüben. Der Anschlag von Nantes richtete sich gegen das Fahrzeug des Obersten der dortigen Kommandantur, also einen hochrangigen deutschen Offizier. Aus Rache für dessen Tod wurden daraufhin, einem direkten Befehl Hitlers folgend ${ }^{244}$, am 22. Oktober 1941 fünfzig Geiseln aus dem Internierungslager Châteaubriant exekutiert. Darunter befanden sich siebenundzwanzig Kommunisten, die meistenteils aus dem Großraum Paris stammten.

Sie wurden im Rahmen einer groß angelegten Verhaftungswelle im September 1941 festgenommen, nachdem in den Wochen zuvor die gewerkschaftlichen Aktionen intensiviert worden waren. Die Gewerkschaft CGT und der PCF hatten vor den Fabriken der Pariser Region protestiert, Delegationen zu den Arbeitgebern entsandt und sich so öffentlich exponiert ${ }^{245}$. Die größere Aktivität und die öffentliche Präsenz von weiterhin verbotenen Organisatio-

${ }^{242}$ Laurent Douzou, L'entrée en résistance, in: Olivier Wieviorka (Hg.), La Résistance, une histoire sociale? Paris 1997, S.9-20, S. 15.

${ }^{243}$ Es handelte sich um Jean Catelas, Jacques Woog und Adolphe Guyot (CourToIs, LAZAR, Histoire, S.186).

${ }^{244}$ Delacor, Attentate, S. 33.

245 Courtois, Le PCF, S. 150. 
nen evozierte die Aufmerksamkeit der französischen und deutschen Behörden. Infolgedesssen konnten Ende September große Teile der Verantwortlichen der CGT verhaftet werden, nachdem zuvor das Druck- und Verteilerzentrum der illegalen Gewerkschaftspresse entdeckt worden war ${ }^{246}$. Die Ivryer Bürger Henri Pourchasse, Delegierter der Pariser Eisenbahner, und Jean Poulmarch, Pariser Sekretär der Chemiegewerkschaft und Mitglied in der CGT-Führung, und Désiré Granet, Sekretär der CGT - Untergewerkschaft Papier-Carton - zählten zu den Hinrichtungsopfern ${ }^{247}$. Alle drei Männer waren stark mit der kommunistischen und gewerkschaftlichen Bewegung in Ivry verwoben. Ihre Angehörigen lebten zum Teil in den cités der Stadtverwaltung. Obwohl Désiré Granet in den Nachbarort Vitry gezogen war, galt er weiterhin als »enfant d'Ivry«. Dass die Betroffenen offensichtlich nicht mit dieser brutalen Entwicklung gerechnet hatten, zeigt der letzte Brief von JeanMarie Poulmarch an seine Frau Laurence vom 21. Oktober, in dem er zwar die abendliche Ankunft des deutschen Exekutionskommandos vermerkte, gleichzeitig aber darauf verwies, dass erst einmal abzuwarten und Ruhe zu bewahren sei $^{248}$.

Die Ereignisse von Châteaubriant stellten für die Entwicklung und Rezeption des kommunistischen Widerstands in Frankreich eine wichtige Etappe dar und wirkten sich nachhaltig auf die Beziehungen zwischen deutschen Besatzern und den besetzten Ländern auch über Frankreich hinaus aus ${ }^{249}$. So riefen die Erschießungen der fünfzig Geiseln internationale Proteste - darunter des Präsidenten der USA, Franklin Roosevelt - hervor und sorgten für weltweites Entsetzen ${ }^{250}$. Außerdem stellten sie eine entscheidende Zäsur im Verhältnis zwischen Wehrmacht und französischer Bevölkerung dar und leiteten eine Periode massiv eskalierender Gewalt zwischen der Besatzungsmacht und den kommunistischen Widerstandskämpfern ein. Die Kommunisten engagierten sich weiterhin in direkten Sabotage- und Attentatsaktionen, die Vergeltungsmaßnahmen von deutscher Seite nahmen hingegen immer größere Dimensionen an. Insgesamt kam es während der deutschen Besatzung zur Erschießung von fast 30000 französischen Geiseln ${ }^{251}$.

Den Erschießungen von Châteaubriant folgten am 15. Dezember 1941 hundert Exekutionen am Mont Valérien bei Paris. Unter den Opfern befanden sich der kommunistische Journalist Gabriel Péri und Lucien Sampaix, am 7. März folgte Pierre Semard, im Mai die Kommunisten Cadras, Dallidet, Solomon, Politzer, Decour, Pican, Dudach, Bauer. Am 14. April 1942 wurden in Nordfrankreich dreiundzwanzig Personen erschossen. Im März waren es im

246 Ibid., S. 151.

247 Ibid., S. 247.

248 Stadtarchiv Ivry, Abschiedsbrief von Jean-Marie Poulmarch an seine Ehefrau Laurence vom 21. Oktober 1941, ohne Signatur.

249 Delacor, Attentate, S. 35-40.

${ }^{250}$ Lazar, Courtois, Histoire, S. 187.

251 Delacor, Attentate, S. 60. 
Großraum Paris vierzig. Am 11. August 1941 folgten achtundachzig Erschießungen, im September $118^{252}$. Als diese blutigen Repressionsmaßnahmen dennoch keine abschreckende Wirkung im Sinne einer Beendigung der Widerstandsakte zeigten, führten die Deutschen erste Deportationsmaßnahmen von Regimegegnern in die deutschen Konzentrationslager durch. So begann die verheerende Praxis der Deportationen in den Osten Europas ${ }^{253}$.

Diese erste Widerstandsphase dauerte bis 1942 und war von schweren Verlusten im kommunistischen Widerstand geprägt. Die Bilanz des PCF war erschreckend. Dem Ergebnis von zweihundert getöteten deutschen Soldaten standen Hunderte aufgedeckte Kader und der Verlust tragender Netzwerke wie derjenigen von Danielle Casanova, Georges Politzer, Dallidet und Decour entgegen ${ }^{254}$. Auf der anderen Seite versuchte der PCF, sich aufgrund seiner Aktionen und der Masse an Blutopfern als besonders patriotische Partei $\mathrm{zu}$ profilieren. Gleichzeitig gelang es, Organisationsstrukturen aufzubauen, die den kommunistischen Widerstand bis zum Kriegsende tragen sollten. Die politische Führung wurde nun von einem militärischen Komitee unterstützt, das sich aus Charles Tillon, Eugène Hénaff, André Ouzoulias, Jules Dumont und Georges Beyer zusammensetzte. In dieser Funktion bündelten sie weitere parteiinterne Unterorganisationen wie die Organisation spéciale, die Jeunesses communistes und die Main-d'œuvre immigrée (MOI) ${ }^{255}$ und versuchten so, die Schlagkraft der kommunistischen Widerstandsbewegung nachhaltig zu erhöhen. Nachdem im Herbst 1941 der unmittelbare bewaffnete Kampf in den Vordergrund gerückt war und längerfristige taktische Organisationen wie den Front national zunächst verdrängte, intensivierte der PCF auf Geheiß Stalins im Frühjahr 1942 noch einmal die militärischen Anstrengungen und gründete die Organisation der paramilitärischen Freischärler Francstireurs partisans (FTP). Diese fanden sich in freien Gruppen zusammen, die sich vornehmlich in die Wälder zurückzogen und nach diesem Aufenthaltsort »maquis« genannt wurden. Aber auch diese ersten militärischen Verbände, die sich auf potentielle Kämpfe im Rahmen einer möglichen Befreiung vorbereiteten, überlebten das Jahr 1942 nicht. Im September 1942 wurde der Chef der FTP Nord, Debarge, aufgedeckt, es folgte der Generalstab. Die erste FTP-Gruppe wurde vollständig liquidiert. Zudem verurteilten weite Teile der französischen Bevölkerung, France libre unter Charles de Gaulle in London und andere Widerstandsbewegungen das radikale Vorgehen der kommunistischen Partei und zeigten keinerlei Sympathie und Unterstützung ${ }^{256}$.

252 Courtois, Lazar, Histoire, S. 188.

253 Die Idee, politisch und »rassisch « unliebsame Personen nach Osten zu deportieren und sich ihrer damit zu entledigen, ist möglicherweise aus diesem Zusammenhang der Gewalteskalation in Frankreich entstanden.

254 Courtois, Le PCF, S. 241.

255 Ibid., S. 65.

256 Ibid. u. Jean-François Muracciole, Histoire de la Résistance en France, Paris ${ }^{3} 2003$, S. 65 . 
Die Effektivität der Widerstandsanstrengungen des PCF verbesserte sich hingegen um die Jahreswende 1942/43. Zu den wichtigsten Veränderungen gehörte die Einführung eines neuen Sicherungssystems durch Auguste Lecœur, das die weitere Dezimierung der Partei dauerhaft verhindern sollte ${ }^{257}$. Öffentliche Orte für konspirative Treffen mit anderen Parteimitgliedern wurden nun vermieden. Ebenso wichtig war, dass sie sich absolut vergewisserten, bei solchen Treffen nicht verfolgt zu werden. Obwohl hierzu lange und mühsame Wege in Kauf genommen werden mussten, erwies sich das neue System als sehr effizient. Nach der fatalen Aufdeckung des kommunistischen Widerstandskämpfers Brossard, der über hundert Biographien von Parteikadern bei sich trug, fielen nur noch selten ganze Widerstandsnetze in die Hände der Polizei. ${ }^{258}$ Die neuen Sicherheitsvorkehrungen griffen.

Mit dem Front national (FN) verfügte der PCF außerdem über eine Organisation, die andere Widerstandsbewegungen integrieren konnte. Im Herbst 1942 war der PCF aus Moskau angewiesen worden, die politische Isolierung aufzugeben und stattdessen für eine möglichst breite nationale Allianz unter kommunistischer Führung zu sorgen ${ }^{259}$. Innerparteilich war Ivrys untergetauchter Bürgermeister Georges Marrane bereits im Mai 1941 mit der Gründung des Front national beauftragt worden. Seit dem 11. November 1939 war Marrane untergetaucht und hielt sich nach der deutschen Invasion in der Südzone auf. Nach den großen Verhaftungen im Frühjahr 1942 hatte er zunächst mit Léon Mauvais, später mit Raymond Guyot und Francine Fromont die Parteileitung übernommen ${ }^{260}$. Nach dem Vorbild der Volksfrontbewegung der 1930er Jahre sollte sie das Zusammenwirken möglichst vieler Résistancekräfte auch aus dem bürgerlichen Lager initiieren ${ }^{261}$. Dennoch wurden Marranes Anstrengungen immer wieder von anderen politischen Organisationsfragen in den Hintergrund gedrängt und überlappt. Im Juli 1942 begann er Sondierungsgespräche mit der Sozialistin Suzanne Buisson, die dann aber im Dezember abbrachen ${ }^{262}$.

Die eigentliche Wiederbelebung des Front national, dessen Einigungskonzept auch in Konkurrenz zu de Gaulles nationalem Widerstand stand, fand erst im Frühjahr 1943 statt. Der Kommunist Pierre Villon gründete in diesem Zeitraum ein sechsköpfiges Führungskomitee, und der FN breitete sich in allen französischen Departements aus ${ }^{263}$. Trotz der vorgegebenen weltanschaulichen Offenheit war diese Widerstandsorganisation de facto in kommunistischer Hand. Denn ihre Schlüsselpositionen waren durchgehend mit Kommunisten besetzt. Auf diese Weise hatte der PCF auch in Hinsicht auf die Zeit

257 Courtois, Le PCF, S. 358.

258 Ibid.

259 Ibid., S. 66.

260 Courtois, Le PCF, S. 241.

261 Muracciole, Histoire de la Résistance, S. 22.

262 Courtois, Le PCF, S. 282.

263 Courtois, Lazar, Histoire, S. 192. 
der Befreiung ein Machtinstrument in der Hand, mit dem er seinen Einfluss über die Parteigrenzen hinaus in der Résistancebewegung und bei der politischen Neuverteilung 1944/45 geltend machen konnte.

Dem neuerlichen Vorstoß zur Ausweitung des Front national kam die geringere Ablehnung des PCF in der französischen Bevölkerung entgegen, zeigte sich doch sein natürlicher Verbündeter, die Rote Armee, gegenüber Deutschland enorm widerstandsfähig. Der absehbare Sieg in Stalingrad führte für die französischen Parteibrüder zu einem Prestigegewinn, der sich auch in der anwachsenden Bereitschaft junger Männer zeigte, lieber in die »maquis « zu flüchten statt den im Februar 1943 eingeführten Service de travail obligatoire (STO) zu verrichten ${ }^{264}$. Gleichzeitig konnten sie so ihre patriotische Haltung demonstrieren, als deren Träger sich der PCF immer stärker zu exponieren suchte. Denn mit dem höheren Organisationsgrad hatte sich auch die Vorstellung eines patriotischen Befreiungskampfes entwickelt, und dieser dominierte nun die letzte Phase der deutschen Besatzung.

$\mathrm{Zu}$ den Spezifika der kommunistischen Widerstandsbewegung in Frankreich gehörte, dass ausländische Emigranten einen Teil der Widerstandsarbeit übernahmen. Dies galt zum einen für die deutschsprachige, aus der KPD oder den zentraleuropäischen Parteien hervorgegangene Emigration, die sich um die Unterstützung von Widerstandskämpfern in Deutschland bemühte oder die in Frankreich stationierten deutschen Soldaten zu beeinflussen suchte. Zum anderen verfügte der PCF über ein Netzwerk nichtdeutscher kommunistischer Emigranten, die sich mit Attentaten und Sabotageakten am Widerstandskampf beteiligten. Die Darstellung der Vielfalt des kommunistischen Widerstandes ist für das Verständnis der späteren Verengung der Perspektive auf die Résistancezeit von Bedeutung, da so ein Vergleichshorizont zwischen gelebter und erinnerter Zeit entsteht. Zudem ist der deutschsprachige Anteil an der französischen Widerstandsbewegung weniger wegen seiner Wirkung auf die Besatzer - welche gering war - von Bedeutung, sondern eher wegen seiner Funktion als gemeinsame Referenz und transnationale Verbindung von deutschen und französischen Kommunisten nach dem Zweiten Weltkrieg. Insbesondere im Hinblick auf die späteren Beziehungen mit der DDR traten ehemalige deutsche Emigranten wie Franz Dahlem, Gerhard Leo oder Hermann Axen als kulturelle Mittler auf und versuchten, an gemeinsame Erfahrungen aus der Résistance anzuknüpfen.

Eine der wichtigsten Widerstandsorganisationen des PCF auf paramilitärischem Gebiet waren die Francs-tireurs partisans der Main-d'œuvre immigrée (FTP-MOI). Die ursprüngliche Main-d'oeuvre étrangère war vom PCF in den 1920er Jahren zu dem Zweck aufgebaut worden, in Frankreich arbeitenden oder emigrierten Kommunisten eine Empfangs- und Integrationsstruktur zu bieten, in der sie - nach Sprachgruppen geordnet - Ansprechpartner und 
Gleichgesinnte finden würden. So sollten sie den in ihren Heimatländern begonnenen politischen Kampf fortsetzen und mit den Schwierigkeiten der Emigration besser fertig werden können. Zunächst in Konkurrenz zu den kommunistischen Parteien der Emigrationsländer stehend, und um der Bildung eigenständiger politischer Gruppierungen vorzubeugen, hatte der PCF mit der MOI eine ihm untergeordnete Auffangstruktur gefunden, die dem leninistischen Prinzip einer einzigen kommunistischen Partei pro Land Genüge tat. Während sich die MOI ursprünglich an Arbeiter und Kleinhandwerker richtete, gewann seine Integrationsarbeit in Frankreich eine zunehmend politische Konnotation, galt es doch immer öfter, auch politische Flüchtlinge - zunächst aus dem mussolinischen Italien, dann aus dem nationalsozialistischen Deutschland - zu unterstützen. Außerdem wuchs in der gesamten Zwischenkriegszeit der Anteil mittel- und osteuropäischer Juden, die vor allem aus Polen und den ehemaligen österreichischen Gebieten stammten, erheblich an und ließ so die jiddische neben der italienischen Sprachgruppe zur wichtigsten werden ${ }^{265}$. Entsprechend den großen Einwanderungslinien und Industrieballungen war die Organisation der MOI in den Industriegebieten Nordfrankreichs, am Mittelmeer und im Rhônetal sowie im Großraum Paris mit einem Schwerpunkt im Stadtzentrum am größten.

Während des Widerstandskampfes führte der Armenier Missak Manouchian die FTP-MOI-Gruppe in Paris an; die interregionale Leitung hatte der polnischstämmige Jude Joseph Epstein inne. Bis zu ihrem Sturz im November $1943^{266}$ hatten sie eine Stadtguerillagruppe in Paris aufgebaut, die in mehreren spektakulären Anschlägen der Besatzungsmacht merkbaren Schaden zugefügt hatte ${ }^{267}$. Der Zulauf zu dieser Spezialeinheit in Paris entstand als Reaktion auf die groß angelegte Razzia in den jüdischen Vierteln von Paris vom 16./17. Juli 1942, in denen viele junge Männer ihre Angehörigen verloren hatten. Als letzten Ausweg sahen sie bewaffnete Terrorakte an, da sie für ihr Leben ohnehin keinen Ausweg und keine Perspektive mehr sahen ${ }^{268}$. Diese zum Teil sehr jungen Leute waren nach dem Ersten Weltkrieg in einem schlecht integrierten jüdischen Milieu aufgewachsen, das seine sozialrevolutionäre oder kommunistische Affinität aus den mittel- und osteuropäischen Ursprungsländern mit ins republikanische und vor antisemitischen Ausschreitungen vermeintlich sichere Frankreich gebracht hatte. Jiddischsprachige Publikationen, die sich an die Arbeiter und Kleinhandwerker richteten, bildeten eine Klammer um dieses Milieu und sorgten gleichzeitig für Parallelität zum PCF.

265 Courtois, Peschanski, RaYski, L'Affiche rouge, S. 24-27.

266 Vgl. hierzu das Kapitel »Die dritte große Fahndung - Der Zusammenbruch der FTPMOI im November 1943«, in: ibid., S. 255-282.

267 Allein im Zeitraum vom Juni bis November 1943 war diese FTP-MOI-Gruppe für vermutlich 40 Anschläge im Großraum Paris verantwortlich (ibid., S.295).

268 Ibid., S. 123-125. 
Die Anschläge dieser Widerstandsgruppe konzentrierten sich auf den Großraum Paris, wo die Gruppenmitglieder auch ihre Verstecke und Treffpunkte hatten. Obwohl die direkten individuellen Angriffe auf deutsche Wehrmachtsangehörige in Paris stattfanden und Sabotageakte auf das weitere, mit dem Zug erreichbare Umland ausgelagert wurden, diente die banlieue als Hinterland und Rückzugsgebiet, in dem konspirative Treffen abgehalten und für Wohnraum gesorgt werden konnte. So war beispielsweise der ehemalige Spanienkämpfer und MOI-Angehörige Celestino Alfonso im Sommer 1943 in eine Wohnung in Ivry platziert worden und besaß darüber hinaus einen heimlichen Wohnsitz in dem südwestlich von Paris gelegenen Vorort Issy-les-Moulineaux ${ }^{269}$. Alfonso gehörte zu den wichtigsten Führungskadern der FTP-MOI-Gruppe und direkten Vertrauten von Missak Manouchian. Als die französische Polizei diese dritte und letzte überlebende Gruppe der Stadtguerilla aufdeckte - ihr waren seit Anfang 1943 bereits zwei große Fahndungen vorausgegangen -, bereitete die deutsche Propaganda diesen Umstand spektakulär auf. Paris wurde im Februar 1944 mit roten Propagandaplakaten plakatiert, die ironisch hinterfragten: »Des libérateurs? La libération par l'armée du crime«. Dabei wies dieses als »Affiche rouge« bekannt gewordene Propagandaplakat vornehmlich auf die jüdische Abstammung der Verhafteten hin und nannte die Zahl der den jeweiligen Personen zur Last gelegten Attentate. In diffamierender Absicht wurden von den zehn dargestellten Personen zwei als ungarische und fünf als polnische Juden bezeichnet, darunter der in Ivry lebende Robert Witchitz. Bei Missak fand sich lediglich der Zusatz »Armenier«, bei Celestino Alfonso stand »roter Spanier«, bei Spartaco Fontano »italienischer Kommunist «. Auch in dem gleichzeitigen Prozess vor einem deutschen Kriegsgericht wurde noch einmal ausdrücklich auf antisemitische Verschwörungstheorien Bezug genommen, nach denen die Juden mit Hilfe des internationalen Kommunismus ihr »Gastland « missbrauchten und die »zweitausendjährige Kultur Europas« gegen sie zu verteidigen sei ${ }^{270}$. Zweiundzwanzig der dreiundzwanzig zum Tode Verurteilten wurden am 21. Februar 1944 am Mont Valérien in Suresnes hingerichtet ${ }^{271}$.

Es ist so ausführlich auf die Organisation der MOI eingegangen worden, weil sie einerseits die Bandbreite des kommunistischen Widerstands in Frankreich widerspiegelt, andererseits Anknüpfungspunkte für die lokalkommunistische Erinnerungskultur in Ivry nach 1945 bot, auf die an späterer Stelle einzugehen sein wird. Zudem war die MOI die formale Klammer für den Widerstand der deutschsprachigen kommunistischen Emigranten in Frankreich, auf dessen Grundlage ab Sommer 1940 der Travail allemand (TA) und ab November 1943 das Comité Allemagne libre pour l'Ouest (CALPO) agieren

269 Stadtarchiv Ivry, 27 W 1, Fiches des fusillés.

270 Courtois, Peschanski, Rayski, L'Affiche rouge, S. 273.

271 Ibid., siehe auch Stadtarchiv Ivry, 27 W 1, Registrierung von Celestino Alfonso und Robert Witchitz. 
konnte ${ }^{272}$. Der Travail allemand begann seine Arbeit im Sommer 1941, als der PCF den slowakischen Kommunisten Artur London damit beauftragte, eine entsprechende Sektion aufzubauen ${ }^{273}$. Sie sollte defätistisches Propagandamaterial herausgeben und unter der Besatzungsarmee verteilen. Als wichtigste Publikation ging daraus der »Soldat im Westen « hervor, der sich im Titel an eine tatsächliche Wehrmachtszeitschrift anlehnte, jedoch klar die propagandistische Beeinflussung der Wehrmachtsangehörigen zum Ziel hatte. Zudem versuchte der Travail allemand, durch gezielte Ansprache von deutschen Soldaten - in der Regel durch gut deutsch sprechende Frauen - Verbindungen ins Innere der Wehrmacht zu schaffen und auf diese Weise deutsche Soldaten zum Desertieren, Überlaufen in die französische Résistance oder - einmal an die russische Front versetzt - in die Rote Armee zu animieren. Schließlich sollten Knotenpunkte der deutschen Besatzungsarmee gezielt von Mitarbeitern des TA unterwandert werden, die an wichtigen strategischen Stellen Informationen abfangen, Sabotage leisten, unbemerkt Post verschicken oder falsche Papiere besorgen konnten. Als Übersetzer oder Person mit guten Deutschkenntnissen angeworben, sollten sie an solch wichtigen Stellen wie den Kommandanturen, Flughäfen oder Feldpoststellen arbeiten ${ }^{274}$.

Der Grad der Teilnahme an der französischen Résistance oder am politischen Geschehen in Frankreich konnte sehr unterschiedlich ausfallen. Zudem war die Anzahl der deutschen Kommunisten als potentielle Widerstandskämpfer in Frankreich begrenzt. Betrachtet man dann noch diejenigen, welche nach Kriegsende Karriere in der DDR machten, konzentriert man sich auf einen kleinen, aber langfristig wirksamen Kreis ${ }^{275}$. Zu ihm gehörte Gerhard Leo. Als Kind einer jüdischen Anwaltsfamilie 1933 mit den Eltern nach Paris geflohen, ging Leo zunächst in Frankreich in die Schule und trat dann als junger Erwachsener dem kommunistischen Widerstand bei, wo er im TAZweig eingesetzt wurde. In einer deutschen Kommandantur tätig, war er als Übersetzer beauftragt, an militärische Informationen zu kommen ${ }^{276}$. Als Remigrant in der DDR machte Leo später im Komitee der antifaschistischen Widerstandskämpfer beim ZK der SED Karriere. Dann kehrte er als Korrespondent des »Neuen Deutschland « nach der Anerkennung der DDR und Akkreditierung von Journalisten zurück nach Paris. Ebenfalls im französischen

\footnotetext{
272 Dokumentationszentrum des Musée de la Résistance, fonds thématique Résistance allemande, carton 111, CALPO, Origine, activité et rôle du Comité Allemagne libre pour l'Ouest, o. D.

273 Courtois, Peschanski, Rayski, L'Affiche rouge, S. 126.

274 Ibid., S. 100.

275 Franz Dahlem befand sich tatsächlich in relativ privilegierter und exponierter Position, während ein Großteil gerade der jungen, unbekannten Männer unter den dramatischen und elenden Lebensverhältnissen litt, wie das Beispiel von Hermann Axen zeigt (Hermann Axen, Ich war ein Diener der Partei. Autobiographische Gespräche mit Harald Neubert, Berlin 1996, S.30-32).

276 Gerhard Leo, Frühzug nach Toulouse, Berlin (Ost) 1988.
} 
Widerstand war der spätere erste Botschafter der DDR in Paris, Ernst Scholz. Wie viele andere MOI-Mitarbeiter hatte er zunächst am Spanischen Bürgerkrieg teilgenommen und sich dann, der allgemeinen linken Bewegung folgend, in der Résistance engagiert ${ }^{277}$. Auch Hermann Axen, seit 1966 als ZKSekretär für die Abteilung Internationale Verbindungen zuständig und somit eine Schlüsselfigur der DDR-Außenpolitik, war schon als ganz junger Mann 1938 aus Leipzig nach Frankreich geflohen, nachdem sein in der kommunistischen Bewegung engagierter Bruder von Nationalsozialisten ermordet worden war. Als Mitglied der kommunistischen Jugend und in der illegalen Parteiarbeit tätig, befand er sich auch selbst in unmittelbarer Lebensgefahr ${ }^{278}$. In Paris auf sich allein gestellt, fand er dort wieder Anschluss an das auffangende kommunistische Milieu. Axen nahm zwar nicht am französischen Widerstand teil, weil er dem Aufruf zur Internierung 1939 gefolgt war. Infolge des deutschen Einmarschs wurde er zunächst 1942 nach Auschwitz, dann 1945 nach Buchenwald deportiert, wo er aufgrund seiner guten Sprachkenntnisse in der Identität eines Franzosen überleben konnte ${ }^{279}$. Ebenfalls nicht in den unmittelbaren Widerstand involviert, aber als temporärer Westemigrant, ist außerdem der spätere Chef der Abteilung Auslandsinformation beim ZK der SED, Albert Norden, zu nennen, der sich bis 1937 in Frankreich aufhielt. Als KPD-Redakteur in Essen hatte er in den 1920er Jahren Kontakt mit den französischen Genossen. Seine Kenntnisse über Frankreich insbesondere in der Besatzungszeit waren sowohl für die Auslandspropaganda im Zuge der Anerkennungsbewegung für die DDR von Interesse als auch im Kontext der Prozesse gegen deutsche Kriegsverbrecher, in welchen seine Abteilung belastendes Material zur Verfügung stellte ${ }^{280}$. Ferner gehörte zu diesem Kreis Walter Ulbricht, der mit der erzwungenen Westwärtsbewegung der KPD vor seinem Moskauer Exil nach Paris kam. Bei seiner Nachkriegskarriere in der SED konnte er dann aber seinen latenten Rivalen Dahlem hinter sich lassen. Während seines Frankreichaufenthaltes vor dem Verbot der französischen Partei war er in jedem Falle mit der PCF-Führung in Kontakt und auch den französischen Behörden bekannt.

Franz Dahlem nahm vor seiner Internierung eine wichtige Stellung in den Parteibeziehungen zwischen PCF und KPD ein und konnte für sich in Anspruch nehmen, als einer der obersten Vertreter der Weimarer KPD von Anfang an gegen den Nationalsozialismus Stellung bezogen und vom republikanischen Frankreich aus den Widerstand gegen Deutschland nach 1933 organisiert zu haben. Dieser Widerstand bestand zum einen aus Verschickung, Transport und Organisation der Verteilung von Propagandamaterial nach und

277 Vgl. Ernst Scholz, Als ich Alfred Alinger hieß, in: Dora Schaul (Bearb.), Résistance. Erinnerungen deutscher Antifaschisten, Berlin (Ost) ${ }^{3} 1985$ (Erstauflage 1973), S.166-175.

278 Axen, Diener, S.13.

279 Ibid., S. 46.

${ }^{280}$ Herf, Memory, S. 170-175. 
in Deutschland, der Erstellung von Radiosendungen, die nach Deutschland gesendet wurden, und der Abfassung von Positionspapieren der KPD. Obwohl sich Dahlem ab 1937 regelmäßig als politischer Kommissar bei den Internationalen Brigaden in Spanien aufhielt, blieb der unmittelbare Kontakt nach Frankreich zunächst dadurch erhalten, dass seine Frau Catherine unter dem Namen Weber weiterhin in den HBM an der Place Philibert-Pompée in Ivry wohnen blieb, und auch die beiden gemeinsamen Kinder zumindest eine Zeitlang dort verweilten. Nach der Internierung Dahlems - hiervon waren ausschließlich die deutschstämmigen Männer betroffen -, die ihn zunächst in die Pariser Sportstadien Colombes und Roland-Garros und schließlich in das französische Lager Le Vernet führte, und dem Einmarsch der deutschen Truppen war es ebenfalls seine Frau Catherine, die seit August 1940 die Verbindung zur französischen Partei, ihren Widerstandsgruppen, namentlich der Organisation spéciale und der MOI, organisierte ${ }^{281}$. Dahlem versuchte, den Travail allemand vom Internierungslager aus zu koordinieren, während sich seine Frau als vorgebliche Elsässerin in der Toulouser Region niedergelassen hatte und den Informationsfluss sicherte. Zu diesem Zweck besuchte sie Franz Dahlem regelmäßig in Le Vernet, überbrachte und nahm Nachrichten entgegen. Außerdem versuchte sie, die dem Paar bekannten deutschen Kommunisten in der Südzone zu identifizieren, gegebenenfalls zu verstecken und für den Widerstand einzusetzen ${ }^{282}$. Neben der Verantwortung für die Emigrierten hatte Catherine Dahlem zudem eine Druckerei ausfindig gemacht, in der das in deutscher Sprache erscheinende Propagandamaterial gedruckt und unter ihrer Koordination verteilt werden konnte. Gemeinsam mit der Verbindungsagentin Marguerite Montré aus Limoges war sie für die Verbindung mit dem aktiven, nicht internierten Zweig des TA zuständig und kam hierzu regelmäBig nach Paris, um sich mit den Kommunisten Artur London und Otto Niebergall zu treffen, der der deutschen Gruppe vorstand, sowie mit Grojnowski, der an der Spitze der nationalen MOI stand ${ }^{283}$.

$\mathrm{Zu}$ den wichtigsten Kontakten Catherine Dahlems bei der französischen Partei zählte Georges Marrane, welcher sich ja ebenfalls in der Südzone befand und bis zur Überstellung Dahlems in das Gefängnis von Castres im November 1941 mehrfach versucht hatte, ihn aus dem Lager Le Vernet zu befreien ${ }^{284}$. Georges Marrane war anscheinend mutig und geschickt genug, solche Vorhaben zu realisieren, hatte er doch bereits seinem Bruder André Marrane und seinem lokalen Genossen Venise Gosnat im Oktober 1940 beim Ausbruch aus dem Lager von Riom-ès-Montagnes in der Auvergne gehol-

281 Dokumentationszentrum des Musée de la Résistance, fonds André Ouzoulias, carton 2, Résistance allemande, attestation de Jean Chaumeil pour Catherine Dahlem, 12.5.1972.

282 Ibid.

283 Courtois, Peschanski, Rayski, L'Affiche rouge, S. 100.

284 Dokumentationszentrum des Musée de la Résistance, fonds André Ouzoulias, carton 2, Résistance allemande, attestation de Jean Chaumeil pour Franz Dahlem, 12.5.1972. 
fen $^{285}$. Als regionaler Verantwortlicher des Front national traf sich Marrane regelmäßig im Haus von Catherine Dahlem in Toulouse mit dem Verantwortlichen des TA in der Toulouser Region, dem deutschen Kommunisten Walter Beling ${ }^{286}$. Nach der Überstellung ihres Ehemannes an die Gestapo im August 1942 und seiner Deportation nach Mauthausen musste sie sich zwar konsequent verstecken, wirkte aber beim Komitee Freies Deutschland für den Westen mit und war nach der Befreiung in dieser Organisation in Paris als Sekretärin tätig ${ }^{287}$. Georges Gosnat brachte sie 1945 in Paris zum Bahnhof, von wo aus sie zurück nach Berlin fuhr.

Dieses Komitee - das westliche Äquivalent zum nach der deutschen Kapitulation in Stalingrad gegründeten Komitee Freies Deutschland für den Osten - war in die Arbeit des TA eingebettet und setzte diese im Grunde fort. Die Mitglieder dieser deutschen Widerstandsorganisation versuchten, während der Besatzung möglichst viele Soldaten »umzudrehen « oder zum Desertieren zu veranlassen. Dann sollten sie sich den Reihen der französischen FTP anschließen. Im Zuge der Befreiung bemühte es sich um Anerkennung als legitime und legale »antihitlerische ${ }^{288}$ Organisation, die sich um die deutschen vorhandenen und potentiellen Kriegsgefangenen kümmern wollte. Im Oktober 1944 stellte das CALPO bei den Militärbehörden einen Antrag, in dem es forderte, als alleinige Organisation anerkannt zu werden, die die Kriegsgefangenen- und Internierungslager besichtigen und die Beziehungen zu den verschiedenen französischen Regionen gewährleisten könnte ${ }^{289}$. Dabei berief sich das Komitee auf seine engen Kontakte zur französischen Résistance. Es setzte sich unter der kommunistischen Leitung von Otto Niebergall aus dem Sozialdemokraten Karl Hoppe ${ }^{290}$, dem saarländischen Zentrumsabgeordneten Kümmel, dem Kölner Gewerkschafter Klein und dem Mitglied der DVP Dr. Müller ${ }^{291}$ zusammen. Gemäß der regionalen Verteilung der Forces fran-

285 Chaumeil, Gosnat, S. 121.

${ }^{286}$ In der frühen Phase der Résistance waren auch Otto Niebergall und Alexander Abusch in der Toulouser Region aktiv (Centre de documentation du musée de la Résistance, fonds André Ouzoulias, carton 2, Résistance allemande, attestation de Jean Chaumeil pour Franz Dahlem, 12.5.1972.).

287 Ibid., attestation de Jean Chaumeil pour Catherine Dahlem, 12.5.1972.

288 Interessant ist der Wechsel der Terminologie. In dieser Phase wurde nicht mehr »antifaschistisch «, sondern »anti-allemand « und dann »anti-hitlerien « verwendet.

289 Dokumentationszentrum des Musée de la Résistance, fonds thématique Résistance allemande, carton 111, CALPO, Forderungsliste des CALPO, ohne Titel, 31.10.1944.

290 Biographisches Handbuch der deutschsprachigen Emigration nach 1933, hg. v. Institut für Zeitgeschichte und von der Research Foundation for Jewish Immigration unter der Gesamtleitung v. Werner RöDER und Herbert A. StRauss, München u. a. 1980, S. 315.

291 So werden die politischen Zuordnungen in der Quelle genannt. Allerdings ist die kommunistische Dominanz offensichtlich. Denn nicht nur die Leitung ging von der KPD aus, auch das SPD-Mitglied Hoppe trat 1945 zu den Kommunisten über. Während für die Genannten Kümmel und Klein keine weiteren biographischen Angaben gefunden werden konnten, handelte es sich bei »Dr. Müller« vermutlich um den ehemaligen Spanienkämpfer und Kommunisten Hubert Müller, der 1949 zur SPD in Ludwigshafen übertrat (ibid., S.533). 
çaises de l'intérieur (FFI), welche in der Befreiungsphase aus den FTFP und den »maquis« hervorgegangen waren, sollten die Gesandten des CALPO über Frankreich verteilt die zentralen Ansprechpartner in den Kriegsgefangenenlagern werden. Dies diente einerseits dazu, eigene Leute, die auf Anweisung in der Wehrmacht verblieben waren, aber wichtige Hinweise gegeben hatten, aus den Kriegsgefangenen herauszufiltern, aber gewährleistete andererseits auch die moralische »Erziehung «, die in den Lagern zu leisten sei ${ }^{292}$ Tatsächlich hat eine Anerkennung des CALPO und seines deutschen Freikorps im Midi ${ }^{293}$ lediglich durch das Befreiungskomitee der Toulouser Region stattgefunden ${ }^{294}$. Handlungsfreiheit in den Kriegsgefangenenlagern und materielle Unterstützung durch die provisorische Regierung, wie sie von den Verantwortlichen gefordert worden waren, lehnten die Behörden Ende 1944 entschieden ab, obwohl Henry Rol-Tanguy, Chef der FFI des Großraums Paris, in einem persönlichen Brief darum gebeten hatte ${ }^{295}$. Vermutlich fürchtete man die kommunistische Unterwanderung der Kriegsgefangenenlager und mögliche »Umerziehung «, also Stalinisierung der Gefangenen, um sie für einen neuerlichen Militäreinsatz für die Sowjetunion zu gewinnen. Außerdem ist die Datierung dieser endgültigen Absage an das Gesuch des CALPO wichtig, denn im Dezember 1944 war der innerfranzösische Machtkampf um die legale Nachfolge des Vichy-Regimes schon zu Gunsten de Gaulles ausgefallen.

\subsubsection{Die Rolle des PCF bei der Befreiung von Paris und seiner Vorstädte}

Die Libération, die Befreiung Frankreichs von der deutschen Besatzung durch die kämpfenden Truppen der Résistance unter Beteiligung der Bevölkerung 1944, gehörte zum Gründungsmythos der Vierten Republik ${ }^{296}$. Unter weitgehender Ausblendung des Anteils der westalliierten Armeen an der realen Zurückdrängung der Wehrmacht vom französischen Staatsgebiet symbolisierte der Akt der »Befreiung « die einige und unteilbare Nation, wie sie bereits in der Französischen Revolution postuliert worden war. In der »Résistance-Koalition « zwischen der France libre unter Führung Charles de Gaulles und den Kräften der territorialen Widerstandsbewegungen, an deren Spitze sich seit 1943 der PCF unter dem Pseudonym des Front national gedrängt hatte, präsentierte sich die »nation unie et indivisible « in neuem, modernerem Kleid. Obwohl die Rivalität zwischen beiden politischen Strömungen hinter

${ }^{292}$ Dokumentationszentrum des Musée de la Résistance, fonds thématique Résistance allemande, carton 111, CALPO, Forderungsliste des CALPO, ohne Titel, 31.10.1944.

293 Ibid., Origine, activité et rôle du Comité Allemagne libre pour l'Ouest, o.D.

294 Ibid., Extrait de la convention, o. D.

295 Ibid., Brief des General Leyer an den militärischen Generalgouverneur von Paris, 15.12.1944.

296 Pierre Nora, Gaullistes et communistes, in: Ders. (Hg.), Les lieux, Bd.2, S. 2489-2532, hier S. 2502. 
den Ereignissen des August 1944 nur einen historischen Moment lang verdeckt wurde, blieb sie doch auch während der Befreiung von Paris und ihrer Folgeereignisse sichtbar und prägte das Verhältnis des letztendlich unterlegenen PCF zu de Gaulle nachhaltig. Die von den Kommunisten als Aufstandsbewegung inszenierte Befreiung von Paris spaltete trotz dieser gemeinsamen historischen Referenz die beiden politischen Lager dauerhaft und sorgte langfristig für die Entwicklung zweier unterschiedlicher Gedächtnistraditionen ${ }^{297}$, die sich gegenseitig weitestgehend ausblendeten.

Charles de Gaulle zog am Ende der Gefechte zwischen den abziehenden deutschen Truppen und der französischen Panzerdivision unter General Leclerc am 25./26. August 1944 als Repräsentant des Freien Frankreichs in die Hauptstadt ein. Als zentrales Anliegen formulierte er dabei die Anerkennung Frankreichs als kriegsführender Staat und Siegermacht nach endgültigem Ende der Kriegshandlungen. De Gaulle ging vom Fortbestand der Dritten Republik aus und verwarf daher den Gedanken, die Republik, wie es nach einer Revolution in Frankreich bisher üblich gewesen war, vom Balkon des Pariser Rathauses auszurufen ${ }^{298}$. Stattdessen vergewisserte er sich seiner politischen Legitimation durch Akklamation der Massen auf den ChampsÉlysées, welche er am Nachmittag des 26. August unter massiver Beteiligung der Bevölkerung Richtung Place de la Concorde hinunterschritt ${ }^{299}$. Während de Gaulle sich also eine staatsmännische Attitüde vorbehielt und seinem Handeln strategische Überlegungen zugrunde legte, hatten die Kommunisten eine andere, weniger legalistische Konzeption von der Befreiung der symbolträchtigen französischen Hauptstadt. Dem leninistischen Revolutionsprinzip folgend, sollte der Aufstand gegen die Besatzungsmacht revolutionären Charakter haben und von der kommunistischen Partei an der Spitze geleitet werden. Unter ihrer Führung und mit großer Anteilnahme der Bevölkerung sollte die Befreiung von Paris den Bruch mit der unmittelbaren Vergangenheit, d.h. dem Vichy-Regime und der Besatzungsmacht, darstellen. Die Ausrufung der Republik würde den Beginn einer neuen politischen Ära unter kommunistischem Vorzeichen unterstreichen. Die Inszenierung der »insurrection«, des Aufstandes in Paris gegen die Besatzungsmacht im August 1944, wurde so zu einem der wichtigsten Pfeiler kommunistischen Selbstverständnisses im Nachkriegsfrankreich ${ }^{300}$, auch wenn diese kämpferischen Auseinandersetzungen in der Hauptstadt und ihren Vororten militärisch obsolet waren. Die Rolle der Westalliierten bei der Befreiung Frankreichs und insbesondere der Amerikaner wurde vom PCF in der Folgezeit hingegen ebenso wenig zur Kenntnis genommen wie die Tatsache, dass sich lediglich fünf französische

297 Ibid.

298 Henri Michel, La libération de Paris, Brüssel 1980, S. 91.

299 Ibid., S. 93.

300 NorA, Gaullistes, S. 2502. 
Städte aus sich selbst heraus befreien konnten ${ }^{301}$. In allen anderen Fällen hatten die westalliierten Soldaten diese Aufgabe übernommen. Die Selbstbefreiung der französischen Hauptstadt zählte in der französischen Rezeption deshalb in erster Linie aufgrund ihrer symbolischen Wirkung als Akt des nationalen Widerstands und der heroischen Überwindung der bitteren Niederlage von 1940.

Um den Anteil des PCF an der Befreiung von Paris, aber auch sein machtpolitisches Kalkül auf regionaler und nationaler Ebene besser bewerten zu können, ist eine genauere Analyse seiner taktischen Vorgehensweise und seiner territorialen und institutionellen Präsenz im Großraum Paris notwendig. Die Umstände der Befreiung von Ivry und die Beteiligung seiner Bürger im Kampf gegen die abziehenden deutschen Soldaten standen in diesem Zusammenhang exemplarisch für die Rückeroberung der vormals kommunistisch regierten banlieue. Sie nahmen sich daher als Ende der Fremdherrschaft im doppelten Sinne aus. Zum einen symbolisierten sie den Rückzug der deutschen Wehrmacht, zum anderen das Ende der vichyorientierten Sonderdelegationen an der Spitze der kommunalen Stadtverwaltungen. Diese standen in den Augen der Kommunisten für das andere, reaktionäre Frankreich und hielten ihr ureigenes Gebiet in der Vorstadt besetzt, welches die Partei in der Zwischenkriegszeit in der legalen politischen Auseinandersetzung erstritten hatte. Georges Marrane als Vizepräsident des Comité parisien de libération (CPL) und damit in exponierter nationaler Position stehend, personifizierte darüber hinaus für Ivry die Verbindung zwischen nationalem Befreiungskampf, kommunistischem Machtanspruch und Implikation der Bevölkerung in den Vorstädten.

Militärisch spielte die Befreiung von Paris im Gesamtszenario der entstehenden Westfront eine eher unwichtige Rolle, weshalb die amerikanische Militärführung das Vorrücken auf die Hauptstadt auch einem Offizier der restituierten französischen Armee, nämlich dem Kommandanten der 2. französischen Panzerdivision, Jacques-Philippe de Hauteclocque, genannt Leclerc, überließ. Die eigenen Truppen verfolgten die Wehrmacht weiter nord- und südwärts. Die Hintergründe für diese Entscheidung der amerikanischen Militärführung waren vielfältig. Zunächst wollten sich die Amerikaner in ihrem Vormarsch nach Osten nicht aufhalten lassen. Die Einnahme von Paris hätte eine mehrtägige Verzögerung bedeutet, da die Bevölkerung mit Lebensmitteln hätte versorgt werden müssen. Zudem bestand das Risiko, dass die kämpfenden französischen Truppen nach der Rückeroberung ihrer Hauptstadt nicht mehr bereit und willens gewesen wären, die Wehrmacht weiter bis nach Deutschland zu verfolgen ${ }^{302}$. Außerdem war sich der amerikanische Generalstab durchaus der symbolischen Bedeutung von Paris für die französische Innenpolitik bewusst, in die keine unmittelbare Einmischung gewünscht

301 Courtois, Lazar, Histoire, S. 206.

302 Michel, La libération, S. 17. 
wurde ${ }^{303}$. Man übte insgesamt Zurückhaltung und stellte auch General de Gaulle trotz seiner Bitte an Eisenhower keine amerikanischen Soldaten zur Verfügung, die die Legalität seines Herrschaftsanspruches unterstrichen hätten $^{304}$. Das entscheidende Argument für die militärische Überflüssigkeit eines bewaffneten Aufstands im Pariser Großraum lag schließlich darin begründet, dass die Wehrmacht am 19. August 1944 ohnehin von Hitler den Befehl zum geordneten Rückzug erhalten hatte. Tage zuvor hatten der Generalstab und der Militärkommandant für Frankreich Paris schon verlassen. Der Befehl an den erst am 7. August neu ernannten Militärkommandanten von Paris ${ }^{305}$, General Dietrich von Choltitz, lautete denn auch, die Ordnung aufrechtzuerhalten und sämtliche Formen von Aufstand oder Terrorismus zu unterbinden, um möglichst viel Kriegsmaterial und Soldaten unversehrt aus Frankreich herauszulotsen und für die Front im Osten einsetzbar zu halten ${ }^{306}$. Im Gegensatz zu den Alliierten war Paris deshalb für die Wehrmacht von erheblicher strategischer Bedeutung, weil hier die Seine-Brücken zum großen Teil unzerstört geblieben waren und ein schneller und geordneter Truppenabzug über sie möglich war. Die in Paris arbeitenden Dienste und Truppenteile konzentrierten sich deshalb auf die Vorbereitungen zur Standortaufgabe.

Der PCF hingegen stellte den bewaffneten Aufstand gegen die Besatzungsmacht im Sommer 1944 ins Zentrum seiner strategischen Überlegungen. Denn schon seit dem Übergang in die aktive Résistancephase im Sommer 1941 begann die nationale Führung, ihr Engagement als nationalen Befreiungskampf zu interpretieren. Militärisch erstarkt und seit über einem Jahr um die offene oder verdeckte Platzierung ihrer Leute in den wichtigsten Gremien der Résistance bemüht, ging es der Partei zu diesem Zeitpunkt nicht nur um Machtdemonstration, sondern auch um den Erfolg ihres Politikkonzepts. An dessen Anfang stand der Massenaufstand der Basis. Dies sollte sich in einer revolutionären Bewegung fortsetzen, um am Ende die Machtübernahme des PCF zu sichern. In Absprache mit Moskau - die Verbindung wurde weiterhin über Jacques Duclos aufrechterhalten - versuchte der PCF während des Sommers 1944, durch gezielte Aufwiegelung in einzelnen Städten eine solche Massenbewegung entstehen zu lassen. Oft endeten diese lokalen Erhebungen jedoch in einem Blutbad, das von den zurückkehrenden deutschen Divisionen angerichtet wurde ${ }^{307}$. Insgesamt konnten sich die Kommunisten mit ihrem revolutionären Impetus angesichts einer kriegs- und besatzungsmüden $\mathrm{Be}$ völkerung nicht durchsetzen.

303 Ibid.

304 Ibid., S. 90.

305 Die Verwicklung der Militärführung in Frankreich in das Hitler-Attentat vom 20. Juli 1944 hatte die Ernennung einer neuen Führung in Paris zur Folge.

306 Michel, La libération, S. 15.

307 So der tragische Fall von Tulle, wo die SS-Division Das Reich am 8. Juni 194499 Einwohner hängte und 149 weitere deportierte, oder die Auslöschung des Dorfes Oradoursur-Glane in Zentralfrankreich (CourToIs, LAZAR, Histoire, S. 205). 
Der Pariser Fall stellte hingegen eine Ausnahme dar. Hier spitzten sich innerhalb weniger Tage wichtige, richtungweisende Entscheidungen zu, die sowohl das Ende der Besatzung als auch von Vichy-France implizierten und die Frage nach der politischen Zukunft aufwarfen. De Gaulle plante nunmehr als alleiniger Vorsitzender des Comité français de la Libération nationale (CFLN) die neu einzusetzende Exekutive bis ins Detail vor und hatte dabei besonders die Kontinuität des Staates und seiner Aufgaben im Blick. Um einen nahtlosen Machtübergang zu gewährleisten, hatte er seine Emissäre nach Paris geschickt. Der PCF hingegen hatte den Großraum Paris zum Zielobjekt seiner Aufstandsambitionen gemacht. Seit 1943 hatte die Partei die Forces françaises de l'intérieur (FFI), die nun alle bewaffneten Kämpfer der Résistance um sich zu gruppieren suchte, unter ihre Kontrolle zu bringen versucht, und war verbal sogar zu dem Zugeständnis bereit, die ihr eigenen Kämpfer der FTP darin aufgehen zu lassen. Tatsächlich hielt der PCF an dieser eigenständigen Struktur fest, durchdrang aber die FFI personell. Zum wichtigsten militärischen Schachzug gehörte so die Platzierung des Kommunisten Henri Tanguy an der Spitze der FFI Île-de-France. Henri Tanguy, genannt Rol, überging explizit seine Vorgesetzten, um selbst den Aufstand in Paris koordinieren zu können. Wie viele Parteianhänger seiner Generation war RolTanguy noch stark von der Revolution in Russland geprägt, hatte die theoretischen Schriften Lenins studiert und nutzte diese für die Vorbereitung und Durchführung der »insurrection« in Paris ${ }^{308}$. Während er mit den allerdings spärlichst bewaffneten Kämpfern der $\mathrm{FFI}^{309}$ die militärische Seite abdeckte, wurde die politische Arbeit durch die starke kommunistische Präsenz im Comité parisien de libération (CPL) mit dem Gewerkschafter André Tollet an der Spitze und dem Politiker Georges Marrane als Vizepräsident gewährleistet.

Der PCF konnte sich trotz der erheblichen menschlichen Verluste, die das Parteiverbot und die Besatzungszeit mit sich gebracht hatten, im Sommer 1944 auf seinen verbliebenen Einfluss in der banlieue verlassen. Überall dort, wo die Partei vor 1939 und über einen längeren Zeitraum an der Macht gewesen war, funktionierten die eingeübten Wirkungsmechanismen der politischen Mobilisierung trotz Machtverlust, Kollaboration und attentistischer Haltung bei der Bevölkerungsmehrheit weiterhin. In der besonderen historischen Situation nach der Landung der Alliierten im Juni 1944 in der Normandie wurden diese Mobilisierungsmechanismen unter dem Vorzeichen nationaler Befreiung reaktiviert und über die geflickten, aber fortbestehenden Netzwerke der Partei wieder in das Arbeitermilieu hineingetragen. So setzte die Partei alles daran, schon den 14. Juli 1944 als einen Tag des nationalen Widerstandes zu gestalten, an dem sich die Massen nun nicht zu einem Sturm auf die Bas-

308 Henri Rol-Tanguy, Roger Bourderon, Libération de Paris, Les cent documents, Paris 1994.

309 Michel, La libération, S. 32. 
tille, wohl aber zu antideutschen Demonstrationen zusammenfinden sollten. Schauplatz dieser Demonstrationen war teilweise Paris, vor allem aber die ehemals kommunistische banlieue, namentlich die Kommunen Puteaux, Nanterre, Clichy und Aubervilliers, der Norden und Nordwesten von Paris, sowie Ivry und Villeneuve-Saint-Georges im Südosten ${ }^{310}$. Darüber hinaus berichten andere Quellen von der Beflaggung vieler Häuser und auch öffentlicher Gebäude sowie der Kriegerdenkmäler von 1914-18 auf den Friedhöfen in der östlichen banlieue ${ }^{311}$, die von den deutschen und französischen Behörden nicht unterbunden werden konnten. In Ivry begingen die Menschen den 14. Juli mit Feiern in den verschiedenen Stadtvierteln und Tänzen auf der Straße.

Das öffentliche Begehen des Nationalfeiertages stellte den offiziellen, nach außen sichtbaren Ausgangspunkt für weiteres Auflehnen der Bevölkerung in der banlieue unter Anleitung des PCF dar. So sammelten sich immer mehr junge Männer in den FFI. Schwerpunkte entstanden auch hier wieder in den Kommunen und Unternehmen, in denen der PCF traditionell gut vertreten war. Das 1. FFI-Bataillon - geographisch mit dem Canton d'Ivry übereinstimmend - bestand am 15. August aus 1831 Personen. Allein 705 Kämpfer stellte Ivry, gefolgt von seiner Nachbarstadt Vitry mit 500 Personen. Mit weitem Abstand dahinter kamen Kremlin-Bicêtre, Villejuif, Gentilly und Choisy mit immerhin 275 FFI-Kämpfern ${ }^{312}$. Die beiden übrigen Bataillone, die von der südlichen und südwestlichen banlieue gestellt wurden, bestanden aus wesentlich weniger Kämpfern, nämlich 983 respektive $462^{313}$. Ein ähnliches Bild bot sich bei den lokal und betrieblich organisierten milices patriotiques, deren Bildung der PCF seit einem Jahr vorantrieb. Sie waren den entstehenden comités locaux de libération (CLL) unterstellt und nahmen in dieser Übergangsphase polizeiliche Aufgaben wahr ${ }^{314}$. Hierzu hatten sich in einer von Ivrys wichtigsten Fabriken, der Schwedischen Kugellagerfabrik, zweihundert Freiwillige zusammengefunden. Lediglich Voisin in Issy-les-Moulineaux stellte die gleiche Anzahl, während in allen anderen Betrieben in der banlieue mit Ausnahme von Alstom mit 1000 Freiwilligen stets nur ein paar Dutzend Männer mobilisiert werden konnten ${ }^{315}$.

Die Anstrengungen des PCF erstreckten sich über den militärischen Teil hinaus auf die logistische Planung des Aufstandes, etwa den Schutz der Gasund Wasserversorgung für die Bevölkerung, welche ja zum großen Teil aus dem Umland erfolgte. Zu diesem Zweck wurden bewaffnete Einheiten ab-

310 Ibid., S. 42.

311 Compte rendu d'opérations au 15 juillet, FFI subdivision Paris-Est, in: ibid., S.134.

312 Situation des effectifs au 15 août 1944, FFI, in: ibid., S.149.

313 Ibid.

314 Ibid., S. 72.

315 Liste des entreprises avec chiffres approximatifs des effectifs contrôlés par l'AO et organisés en milices patriotiques, Laurent à Rivière, 7. Juli 1944, in: RoL-TANGUY, Bourderon, Libération, S. 147. 
gestellt, die die versorgungstechnisch wichtigen Bereiche abdecken sollten ${ }^{316}$. Grundsätzlich stellte sich aber das Problem der Bewaffnung der Freiwilligen, wenn sie sich der materiell weit überlegenen Wehrmacht entgegenstellen sollten. Die permanente Unterversorgung der französischen Milizen, deren Munition bei weitem nicht ausreichte und deren Bewaffnung sich auf wenige Gewehre und Maschinenpistolen beschränkte, konnte im Grunde bis zur Kapitulation von Choltitz' nicht gelöst werden. Die Résistance konzentrierte sich daher im Sommer 1944 weiterhin auf die Sabotage der gegnerischen Armee und der zuarbeitenden Fabriken. Neben der systematischen Zugentgleisung und dem Kappen von Telefonleitungen wurde versucht, in den Metall verarbeitenden Fabriken crève-pneus - umgebogene Nägel - herzustellen, die für die Reifen der Wehrmachtsfahrzeuge gedacht waren und auf allen wichtigen Straßen im Großraum Paris zum Einsatz kamen. Ende Juni 1944 wurden in Ivrys Lampenfabrik 300000 Lampen, die für den Abtransport nach Deutschland bestimmt waren, zerstört ${ }^{317}$.

Von diesen Aktionen erhoffte sich der PCF nicht nur die militärische und moralische Destabilisierung der deutschen Soldaten, wie sie im Übrigen zu diesem Zeitpunkt auch weiterhin vom kommunistisch gelenkten Travail allemand betrieben wurde ${ }^{318}$, sondern betrachtete dies als erste Etappe auf dem Weg zur politischen Machtübernahme in Paris und Frankreich. Hierzu hatte die Partei lokale und departementale Befreiungskomitees erstellt, welche kein politisches Machtvakuum aufkommen lassen, sondern provisorisch die politischen Geschicke in den Rathäusern und Präfekturen übernehmen sollten. Sie waren zwar offiziell mit Vertretern verschiedener gesellschaftlicher Gruppen und Résistancebewegungen besetzt, standen aber de facto unter kommunistischer Kontrolle ${ }^{319}$. Im Ivryer Fall schloss sich das lokale Befreiungskomitee nahtlos an den kommunistischen Vorgängerstadtrat an und gewährleistete mit Georges Marrane und Venise Gosnat an der Spitze personelle Kontinuität. In der zugespitzten militärischen Situation des August 1944 konnten große Teile der banlieue relativ schnell wieder in die Hände dieser Befreiungskomitees gelangen.

In Paris gestaltete sich der Fall aus verschiedenen Gründen wesentlich schwieriger. Zum einen verfügte die Stadt, an deren Spitze seit 1943 der vichyorientierte Pierre Taittinger stand, über keine kommunistische Tradition wie die banlieue, so dass sich die Bevölkerung gegenüber den politischen Ambitionen des PCF wesentlich mehr zurückhielt. Zum anderen standen in Paris die Entsandten de Gaulles im Wege, die auf einem geordneten Verfahren in

316 Ibid., S.141-147.

317 Communiqué régional pour le mois de juillet 1944, FFI-Région P1, in: ibid., S.128130.

318 Ibid., S.125, vgl. auch Dokumentationszentrum des Musée de la Résistance, fonds André Ouzoulias, carton 2, Résistance allemande, attestation de Jean Chaumeil pour Catherine Dahlem, 12.5.1972.

319 Michel, La libération, S. 72. 
Erwartung der Ankunft des Generals beharrten. Versuche von Rol-Tanguy als Chef der FFI und von Kriegel-Valrimont als Vertreter des Comité d'action (COMAC), sich durch ihre Anwesenheit bei der militärischen Übergabe von Paris von von Choltitz an General Leclerc im Pariser Bahnhof Montparnasse als legitime Machtinhaber zu profilieren, wurden von de Gaulle als solche erkannt und durch eigene Machtdemonstrationen, insbesondere durch den Triumphmarsch am nächsten Tag über die Champs-Élysées, vereitelt ${ }^{320}$. Später warf de Gaulle Leclerc vor, dass er die Anwesenheit der Kommunisten bei diesem hoheitlichen Akt zugelassen hatte, und weigerte sich noch am gleichen Tag, die Vertreter der Résistance im von ihm mitinitiierten Conseil national de la Résistance (CNR) zu empfangen. Das Gleiche galt für das Pariser Befreiungskomitee. Mit diesem ignorierenden Verhalten unterstrich de Gaulle, dass er die legale Staatsmacht anstrebte ${ }^{321}$.

Nachdem der PCF aufgrund der Schwäche der FFI und des konsequent und politisch geschickt agierenden de Gaulle in doppelter Hinsicht daran gescheitert war, die militärische und politische Macht in Paris zu erringen, erfolgte eine letzte große personelle Niederlage. Denn es gelang der Parteiführung im Zuge der Augustereignisse nicht, Georges Marrane als Präfekten des Département de la Seine einzusetzen. Zudem muss dahingestellt bleiben, ob Amerikaner und Briten eine kommunistische Machtübernahme überhaupt geduldet hätten. Trotz seiner administrativen Kompetenz in den regionalen Angelegenheiten, die Marrane nicht nur als Bürgermeister Ivrys, sondern 1936 auch als Vorsitzender des politisch übergeordneten Conseil général de la Seine erworben hatte, konnte er sich als kommunistischer Kandidat nicht gegen Marcel Flouret behaupten. Von dem gaullistischen Delegierten Alexandre Parodi ernannt, konnte sich auch in diesem Fall die etatistische Sichtweise de Gaulles durchsetzen, der die Einsetzung eines »neutralen« Staatsdieners der Vorstellung eines »revolutionären« Präfekten vorzog ${ }^{322}$. Die Kommunisten hatten wiederum im Vorfeld versucht, den gaullistischen Kandidaten zu diskreditieren, indem sie Zweifel an seiner Résistancebiographie aufkommen ließen. Die schnell angestellten Nachforschungen durch Léo Hamon entkräfteten jedoch diese Vorwürfe umgehend ${ }^{323}$.

Diese machtpolitischen Probleme, welche den Status der Kommunisten in Paris intra muros prägten und das Hereintragen ihrer Herrschaft über Stadt und Staat vereitelten, hatte der PCF in der banlieue rouge nicht. Obwohl die kommunistische oder progaullistische Haltung der banlieusards zu diesem Zeitpunkt spekulativ bleiben muss, und sicherlich bei vielen die Freude über das Ende der Besatzungszeit überwog, so lässt sich doch feststellen, dass während der Befreiung Tausende von Menschen Ivrys Rathaus stürmten und

\footnotetext{
320 Ibid., S. 86.

321 Ibid., S. 87-90.

322 Ibid., S. 149.

323 Ibid., S. 44.
} 
darin feierten. Davon zeugen Bildquellen vom 26. August 1944, als der eingesetzte Stadtrat von dort vertrieben wurde. Im Vorfeld war es in verschiedenen Teilen Ivrys wie im gesamten Pariser Großraum ${ }^{324} \mathrm{zu}$ einzelnen Gefechten mit abrückenden Soldaten gekommen, so etwa vor Ivrys Bahnhof, in den sich Angehörige der Wehrmacht zurückgezogen hatten. Im Hafenviertel an der Seine gab es ebenfalls eine Auseinandersetzung mit Waffen, bei der ein FFISchütze starb. Wie in Paris und anderen Vorstädten beteiligten sich die Bürger am Bau von Barrikaden als Panzersperren. Hierzu waren Bäume gefällt und auf die Straße gelegt worden. Diese Technik hatte Georges Marrane aus der Corrèze mitgebracht, wo er sich bis wenige Tage vor der Pariser Befreiung aufgehalten hatte. Dort hatte es dramatische Rückzugsgefechte und Racheakte gegeben - man denke an das Massaker von Tulle. Die Bevölkerung war in die Kämpfe stark involviert gewesen und hatte gefällte Bäume zum Einsatz gebracht.

Da Georges Marrane selbst in die Ereignisse in Paris eingebunden war, übernahm sein ehemaliger Stellvertreter Venise Gosnat die Aufgabe, den Aufstand in Ivry und die symbolisch wichtige Rückeroberung des Rathauses zu koordinieren. Gosnat, welcher im Sommer 1944 unter direkter Order des PCF-Chefs Jacques Duclos stand, hatte sich in den Monaten zuvor gemeinsam mit Jean Chaumeil in einer Wohnung am Boulevard Masséna im 13. Arrondissement von Paris versteckt gehalten. Hierdurch war ein direkter Austausch mit dem angrenzenden Ivry jederzeit möglich ${ }^{325}$. Einige Tage vor der »insurrection« setzte sich Gosnat nach Ivry ab. Es ist zu vermuten, dass er sich im Gebäudekomplex an der Place Philibert-Pompée versteckt hielt, da von hier aus die Initiative für den Zug auf das Rathaus ausging. Als ehemaliger Bewohner und Verwalter dieser cité hatte Gosnat hier nicht nur Ansehen und Autorität, sondern kannte vor allem die meisten Bewohner und konnte so ihre Teilnahme an der Aufstandsbewegung einfordern. Die Bürger Ivrys hatten sich schon bei den ersten Streiks, zu denen der Regionalverband der CGT am 10. August aufgerufen hatte, solidarisch erwiesen. Obwohl dieser »revolutionäre« Generalstreik nur wenig Widerhall gefunden hatte und die meisten Arbeiter bereits am nächsten und in den folgenden Tagen ihre Tätigkeit wieder aufnahmen, hatten sich die Ivryer, Vitryer und Montrouger Bürger hinter die Bewegung gestellt - sie hatten dafür vom CPL allerdings 1 Million Francs in ihrer Solidaritätskasse erhalten ${ }^{326}$ - so dass insgesamt von einer allgemeinen Bereitschaft ausgegangen werden kann, der Bewegung zu folgen.

${ }^{324}$ Die in vielen Bildquellen und Filmmaterial überlieferten großen Gefechte um die Pariser Polizeipräfektur auf der Île de la Cité im Zentrum von Paris stellen ein verzerrtes Bild dar. Tatsächlich war diese unmittelbare Konfrontation eine Ausnahme, die mit dem Streik der Polizeibeamten und der Besetzung ihres Arbeitsplatzes zusammenhing. Die meisten Zusammenstöße zwischen deutschen Soldaten und französischen Widerstandskämpfern in dieser Phase fanden in kleinerem Rahmen statt.

325 Chaumeil, Gosnat, S. 146.

326 Michel, La libération, S. 46. 
Für die Rückeroberung des Rathauses hatte ein Aufruf in der Gemeinde den Treffpunkt für den 20. August um zehn Uhr auf dem Rathausplatz ausgemacht, dem mehrere hundert Menschen gefolgt waren. Mit dem FFI als Vorhut konnte das Rathaus unter Führung Gosnats wieder in kommunistische Hände übergehen. Bei den Auseinandersetzungen starb Ivrys Bürger Édouard Clerville direkt auf dem Platz vor dem Rathaus. Ivry erlebte jedoch nicht das gleiche Schicksal wie das benachbarte Villejuif, das die deutschen Soldaten am 23. August zurückeroberten ${ }^{327}$. Zugleich fanden wilde »Säuberungen« im Hafenviertel statt, wo einige Einzelhändler den aufgebrachten Menschenmassen zum Opfer fielen ${ }^{328}$. Auch für das Rathauspersonal wurde ein Säuberungskomitee eingesetzt.

Auf einem anderen Schauplatz blieb Ivry nicht von der deutschen Vergeltung verschont und erfuhr in der Nacht zum 27. August 1944 die schlimmste Bombardierung seiner Geschichte. In Ivry waren 3382 Haushalte davon betroffen; 173 waren total zerstört worden, 1844 teilweise und 1365 waren von den Folgen des Bombenangriffs beeinträchtigt ${ }^{329}$. Insgesamt war, auf den Gesamtzeitraum der Besatzung gerechnet, rund ein Zehntel des Wohnraumbestandes in seiner Funktion ganz oder teilweise beeinträchtigt $\mathrm{t}^{330}$, so dass die Wiederbeschaffung und der Bau von Wohnungen für rund 8000 betroffene Personen in der Nachkriegszeit wieder zu einem zentralen Aufgabenbereich der kommunistischen Stadtverwaltung avancierten.

Politisch hatten die lokalen Vertreter des PCF die Machtrückeroberung Ivrys und in weitergehender Symbolik seines Rathauses dahingehend vorbereitet, dass in einer Sitzung des Ivryer Befreiungskomitees vom 19. August bereits ein Stadtrat neu gewählt wurde, der ausschließlich aus den überlebenden Mitgliedern der 1935 gewählten und 1939 abgesetzten Stadtversammlung bestand. Die Beständigkeit des politischen Personals zeigte sich auch in der Zusammensetzung ${ }^{331}$ des Komitees, welches nicht nur aus dem ehemaligen Bürgermeister und Beigeordneten, sondern auch aus den Ehefrauen (Mmes Vidal und Guilloux) oder Kindern führender Ivryer Kommunisten (Vital Marquès) bestand, selbst wenn diese offiziell nicht als Abgesandte des PCF,

\footnotetext{
327 Ibid., S. 76.

328 Auskunft von Michèle Rault, Archivleiterin. Hierüber gibt es keine schriftliche Überlieferung. Die Akten des lokalen comité d'épuration sind nicht konsultierbar. Zum Gesamtkomplex der französischen »Säuberungen« nach Ende der deutschen Besatzung vgl. Peter Novick, L'épuration française 1944-1949, Paris 1985.

329 Stadtarchiv Ivry, 5 H 4/4.

330 Ibid.

331 Es ist eine weitere Liste des Ivryer Befreiungskomitees vom 8.1.1945 überliefert, die zusätzliche kommunistische Mitglieder aufweist, darunter der ehemalige Stadtrat Édouard Quincey, die lokale Widerstandskämpferin Lucienne Robin und die Witwe des in Châteaubriant hingerichteten Henri Pourchasse, Louise Pourchasse (Stadtarchiv Ivry, 1 K5/6). Da die lokalen Befreiungskomitees auch für die sogenannten Säuberungen zuständig waren, ist in Erwägung zu ziehen, dass auch Rachegedanken bei der Auswahl dieser Komissionsmitglieder eine Rolle gespielt haben (CHAUmeIL, Gosnat, S.148).
} 
sondern für seine assoziierten Organisationen, wie die Union des femmes françaises oder die Forces unies des jeunesses patriotiques, auftraten ${ }^{332}$.

Während der PCF in Paris trotz der begünstigenden Stellung André Tollets und Georges Marranes im Pariser Befreiungskomitee und der militärischen Unterstützung der FFI die Machtübernahme nicht erreicht hatte, konnte er in der roten banlieue auf Strukturen zurückgreifen, die ihre kommunistische Wiederbesetzung favorisierten. In den Vorstädten stand kein General de Gaulle mit nationalen und internationalen Ambitionen bereit, um einen nahtlosen Übergang von Vichy zur Republik zu gewährleisten und die Nation auf dem Weg in die nationale Befreiung zu begleiten. In den ehemals kommunistischen Hochburgen der banlieue trat der PCF mit den bekannten Akteuren in dieser Rolle auf und gewann verlorenes Prestige zurück und neues hinzu. In Ivry zeichnete sich die Interimsherrschaft des Befreiungskomitees durch die traditionelle Fürsorge des PCF für seine Bürger aus. Die finanzielle Unterstützung der Streikenden des 10. August in Vitry, Ivry und Montrouge durch das CPL hatte dies bereits vorweggenommen. Ivrys Befreiungskomitee kümmerte sich um die Lebensmittelversorgung der Bevölkerung und entsandte mit Hilfe der örtlichen Unternehmer Lastwagen in die nordfranzösischen Kohleregionen, um an Energienachschub zu kommen ${ }^{333}$. Die Rekonstituierung des Milieus geschah über die materielle Seite hinaus durch die psychische Unterstützung der Familien der Gewaltopfer. Sie wurden regelmäßig von städtischen Sozialarbeiterinnen und PCF-Mitgliedern besucht ${ }^{334}$.

Auch für die Opfer der Bombardierung wurde gesorgt. Ivrys municipalité lud gleich für den 29. August zu einer gemeinsamen Trauerfeier aller Betroffenen auf dem Rathausplatz ein. Die Familien der Toten erhielten eine kostenlose zehnjährige Konzession für den örtlichen Friedhof ${ }^{335}$. Nach außen hin grenzte sich das Milieu durch die épuration neu ab, definierte also über diesen »Säuberungsprozess«, welche seiner Angehörigen »dazugehörten«, »treu geblieben« waren und wer auf die feindliche Seite übergegangen war.

Als Maurice Thorez im November 1944 nach fünf Jahren Abwesenheit aus dem Exil in Moskau zurückkehrte, erhielt Ivry zudem seinen politischen Führer wieder. Obwohl Charles de Gaulle einen Monat später am 10. Dezember 1944 einen französisch-sowjetischen Beistandspakt abschloss und Thorez von Stalin vor seiner Rückkehr auf einen politisch moderateren Kurs gebracht worden war, machten sich Thorez und Marrane daran, Ivry zu einer kommunistischen Festung auszubauen, in der Herrschaft und Gedächtnis eine enge und feste Allianz eingingen. Fortan wurde allein die kommunistische Erinnerung und parteinahe Wahrnehmung von Widerstand und Besatzungszeit geduldet und in die kulturelle Repräsentanz eingeschrieben.

332 Stadtarchiv Ivry, 5 H 4/4.

333 Chaumeil, Gosnat, S. $148 \mathrm{f}$.

334 Ibid.

335 Stadtarchiv Ivry, 5 H 4/4. 